NEAG ANNAMÁRIA

\title{
MEDIA LITERACY IN THE HUNGARIAN \\ EDUCATIONAL POLICY ARENA \\ (1995-2012)
}




\section{Institute \\ of Behavioural Sciences and Communication Theory}

Supervisor: Dr. Katalin Lustyik, Ph.D.

(C) Neag Annamária, 2016 


\section{Corvinus University of Budapest \\ Doctoral School of Social Communication}

Media Literacy in the Hungarian Educational Policy Arena (1995-2012)

PhD Thesis

Neag Annamária

Budapest, 2016. 



\section{TABLE OF CONTENTS}

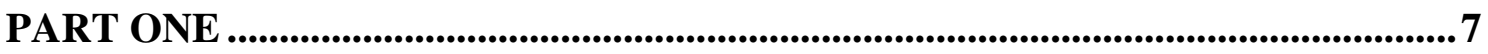

Introduction: "A béka feneke alatt" or "down in the dumps"? ................................... 7

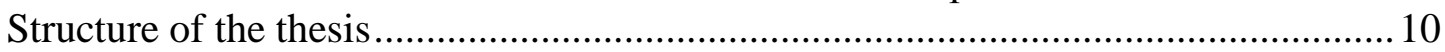

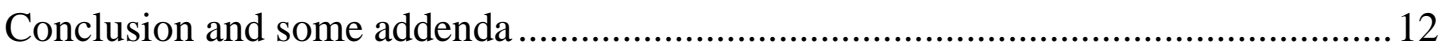

Chapter 1: Media literacy - definitions and historical paths in Hungary .................14

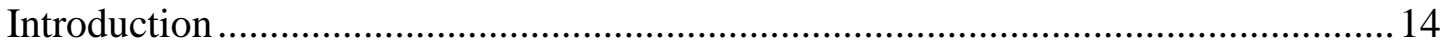

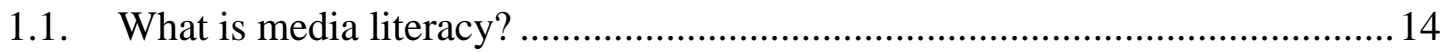

1.2. Historical overview of media literacy education in Hungary ............................ 23

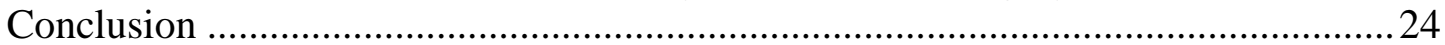

Chapter 2: Media literacy - a new academic field of study .....................................26

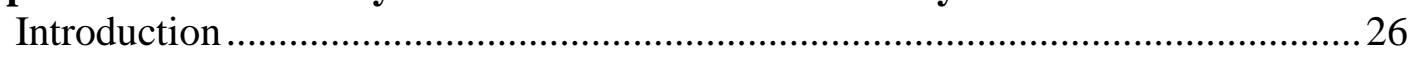

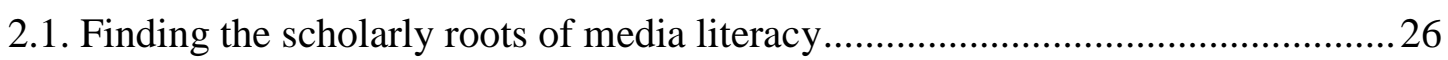

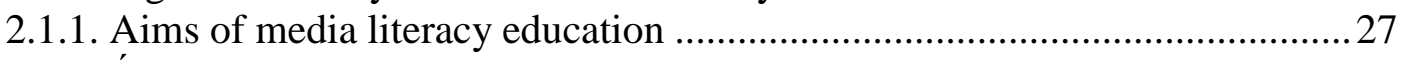

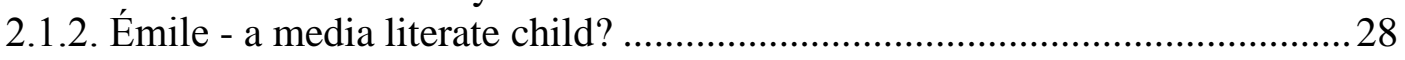

2.1.3. A satisfied fool or a media literate Socrates? ............................................. 32

2.2. Contemporary scholarly perspectives on media literacy .................................... 34

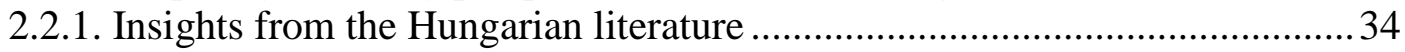

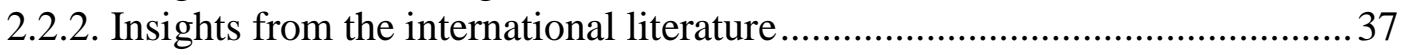

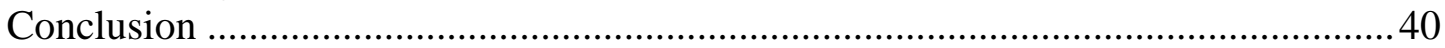

Chapter 3: Methodology ............................................................................................................... 42

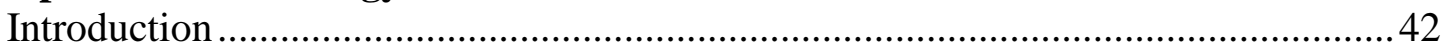

3.1. Critical Discourse Analysis and Policy: The Research Framework .................... 44

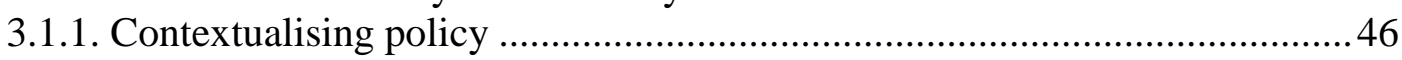

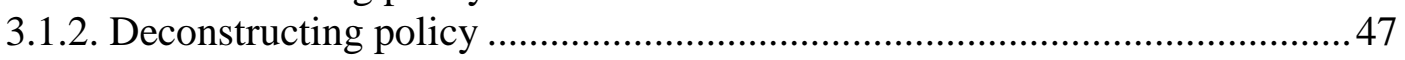

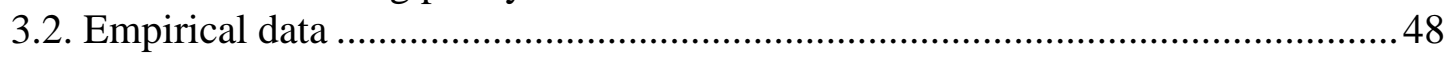

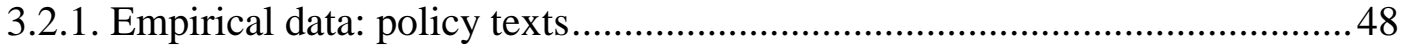

3.2.2. Empirical data: expert interviews.............................................................5 50

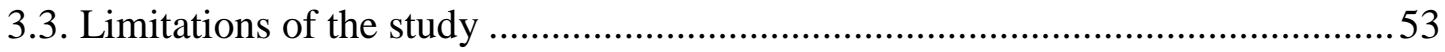

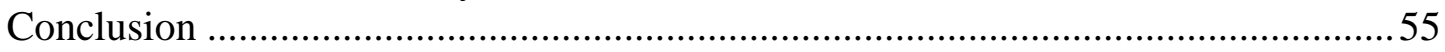

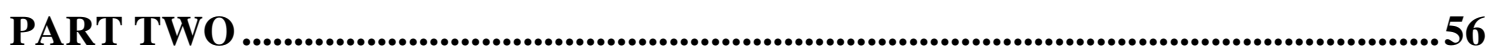

Chapter 4: 1995 - the breakthrough year for media literacy education ...................57

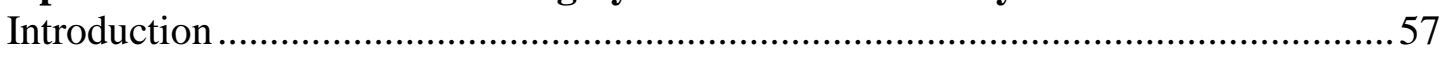

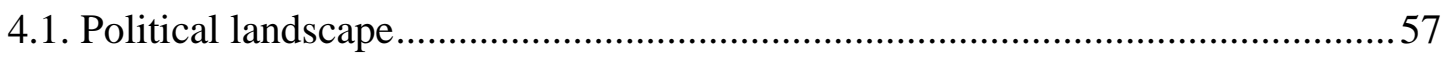

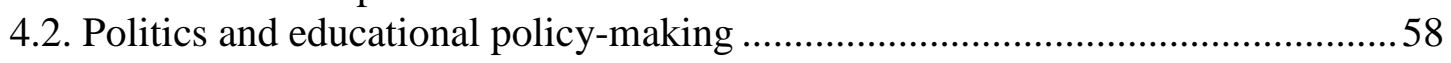

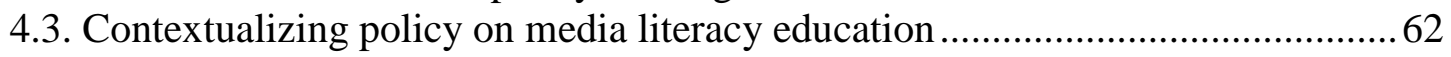

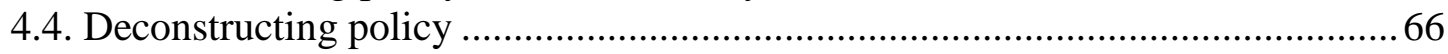

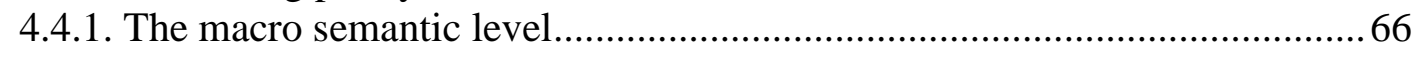

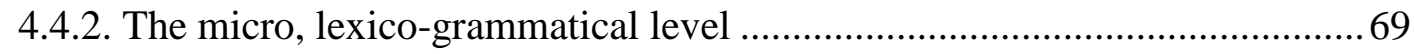

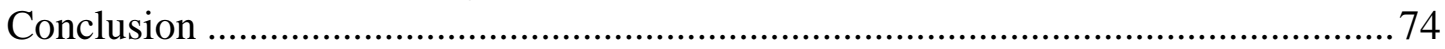

Chapter 5: 2000 - the year of the framework curricula.......................................... 77

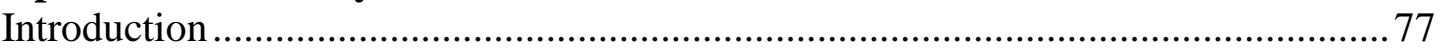

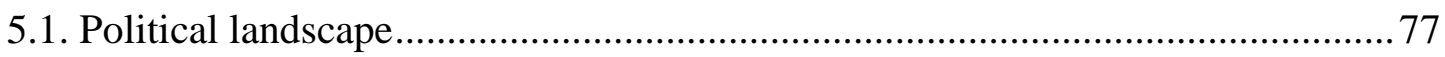

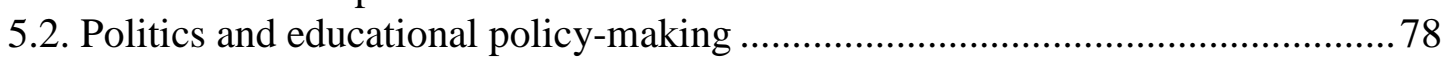

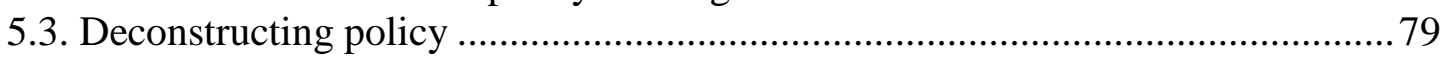

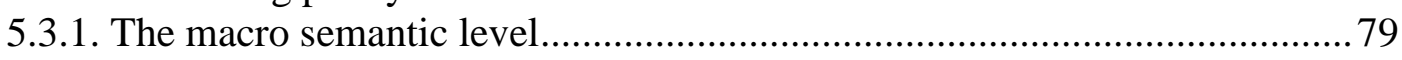

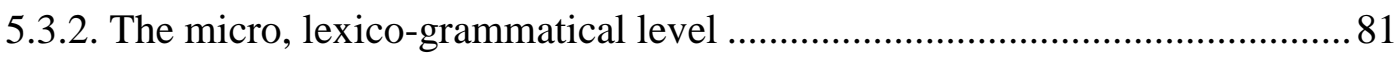

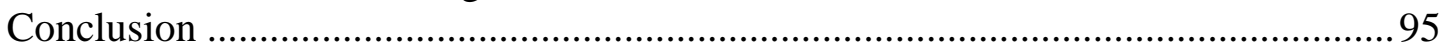


Chapter 6: 2003 and 2007 - international influences in education ..........................98

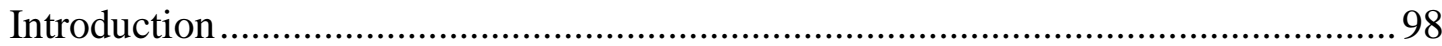

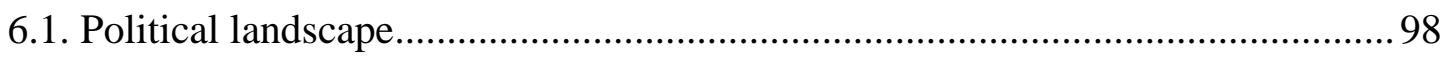

6.2. International developments and Hungarian educational policy-making............ 100

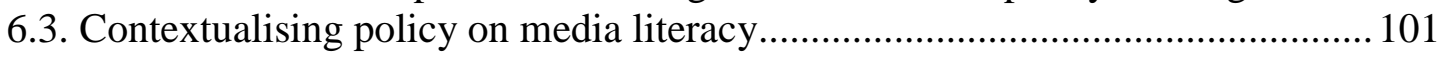

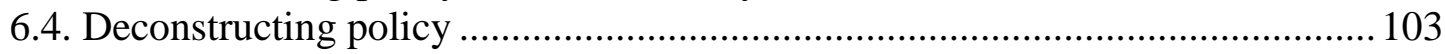

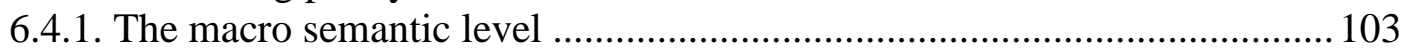

6.4.2. The micro, lexico-grammatical level .................................................... 105

Chapter 7: 2012 - the year of major educational changes...................................119

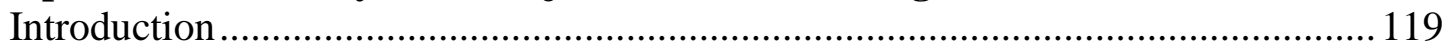

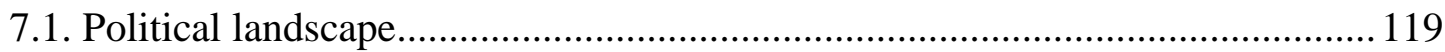

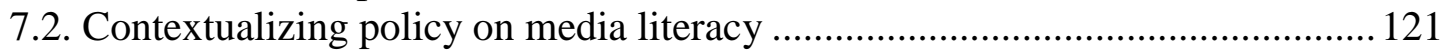

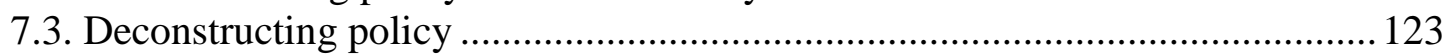

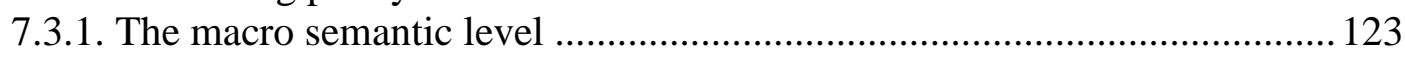

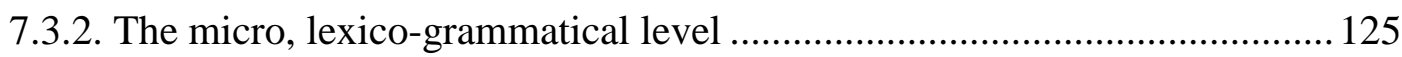

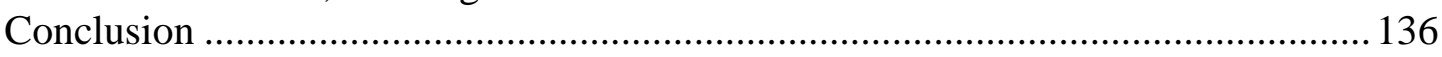

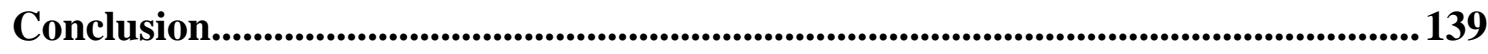

APPENDIX A: CORPUS OF MATERIAL FOR ANALYSIS ...............................150

APPENDIX B: SAMPLE INTERVIEW QUESTIONS ..................................... 151

APPENDIX C: LIST OF INTERVIEWEES .......................................................... 152

LIST OF REFERENCES ................................................................................. 153

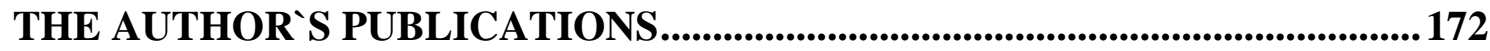




\section{Table of figures}

Figure 1. Media and information literacy, UNESCO

Figure 2: A model representation of Hyatt's analytical framework for critical educational policy analysis

Figure 3. Subject areas of the National Core Curriculum. 63

Figure 4: Synthesized results of CDA-analysis NCC 1995 75

Figure 5: Synthesized results of CDA-analysis framework curricula 2000...................95 Figure 6: Synthesized results of CDA-analysis NCC and framework curricula, 2003 and 2007 117

Figure 7. Synthesized results of CDA-analysis NCC and framework curricula. 136 


\section{Köszönetnyilvánítás}

Bár a doktori disszertációt angolul írtam, úgy gondolom, hogy a köszönetnyilvánítás személyesebb, ha magyarul szól azokhoz, akiknek hálás vagyok. Köszönöm az interjúalanyoknak, a médiamủveltség elkötelezett híveinek a kutatásomra szánt időt. Ők voltak azok, akik az elmúlt húsz évben rengeteget tettek azért, hogy a média a közoktatásban megjelenhessen.

Kati, köszönöm a sok-sok e-mailt, visszajelzést, javítást, ötletet, amit tőled kaptam. Köszönöm, hogy folyamatosan felhívtad a figyelmemet konferenciákra és publikációs lehetőségekre. Bár mindenkinek ennyire jó témavezetője lenne...A stresszoldó Yogi teát külön köszönöm!

Horányi professzor úrnak köszönöm a támogatást, a sok jótanácsot és a kellemes beszélgetéseket.

És végül, nagy-nagy köszönet családomnak. Édesanyámnak köszönöm, hogy a legelső perctől mindenben támogatott. Hálás vagyok a szép üzenetekért, a finom süteményekért és az elmúlt 29 évért. Tamás, köszönöm a megértést, és hogy mellettem álltál e nem túl könnyü periódus alatt: "S még mindig nem tudom elmondani neked,/ mit is jelent az nékem, hogy ha dolgozom,/óvó tekinteted érzem kezem felett./Hasonlat mit sem ér. Felötlik s eldobom./És holnap az egészet ujra kezdem,/mert annyit érek én, amennyit ér a szó/versemben s mert ez addig izgat engem,/míg csont marad belőlem s néhány hajcsomó.” (Radnóti Miklós, Tétova óda) 


\section{PART ONE}

\section{Introduction: "A béka feneke alatt" or "down in the dumps"?}

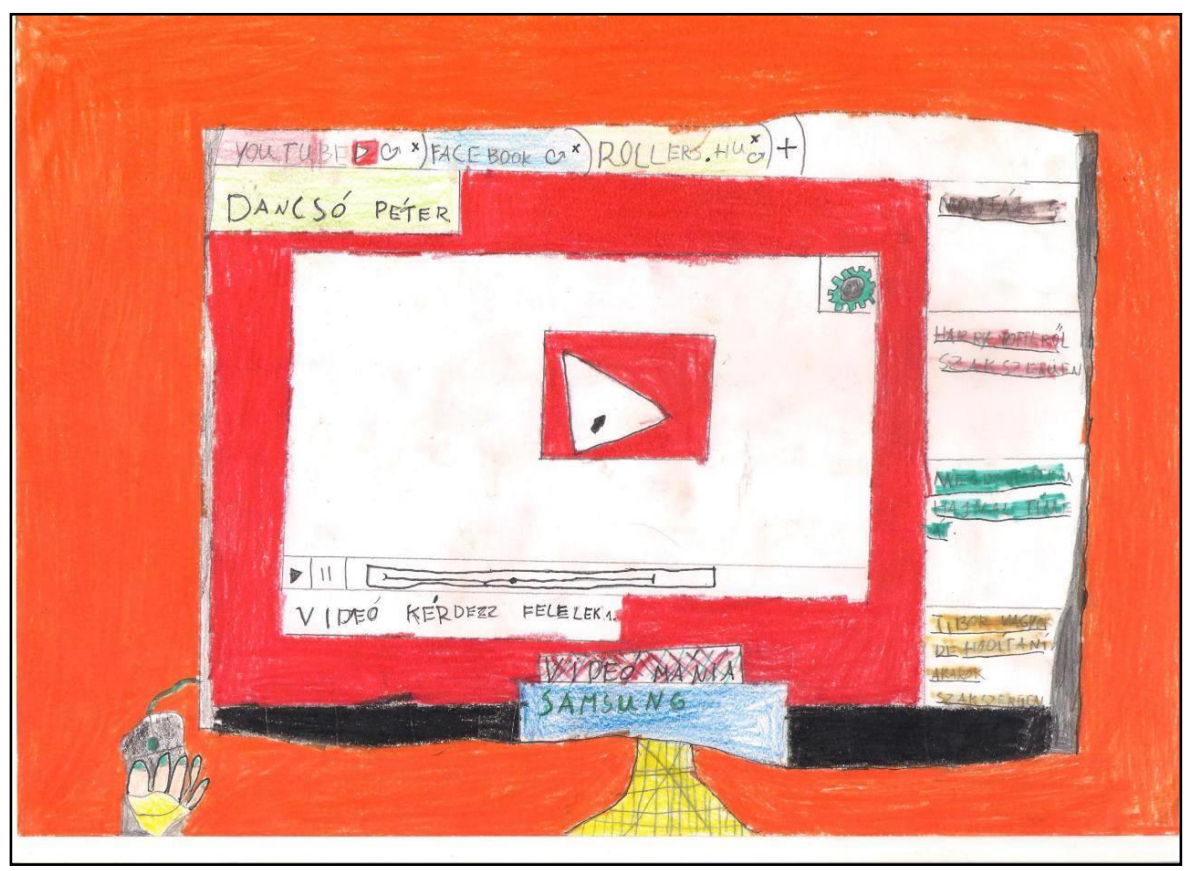

The above drawing appeared among more than 200 artworks made by children aged 9 to 16 for a competition called "Me and the Media", organized in spring 2015 by Magic Valley Media Literacy Education Centre. The drawing, called simply "YouTube", did not win the competition. Nevertheless, when scrolling through the work of arts, I found it remarkable: it symbolized singularly the media world of today's children. The young artist captured the most important aspects of his daily life when it comes to media: YouTube, Facebook and a webstore where scooters and related accessories can be purchased. What is even more spectacular is that the boy wanted to emphasize one specific YouTube channel, most probably his favourite: VideoMánia. VideoMánia is the channel of Péter Dancsó, and it has almost 460,000 subscribers and more than 112,000,000 views as of mid-January 2016 (VideóMánia, 2016). Péter Dancsó is a 29-year-old Hungarian video blogger celebrity, who calls himself a "god emperor" of teenagers and at the recent Online Video Stars Festival Hungary (OVS) was the most sought after star (Dubrovszki, 2015). 
The fact that a child sent in a drawing about a YouTube channel created by a young media professional is telling. It is not a novelty that media, and moreover new media, offer a vast array of content and new opportunities for entertainment, learning, and even production. Along the same lines, researches highlight that there is a gradually earlier appearance of "child culture" (Lange, 2015), in which the link between socialization, everyday life and interaction with the media is unmistakable. In these conditions, it is imperative to know what resources are available for children to critically understand and actively produce mediated content. Media literacy, as a skill to understand the media, was first implied in a 1962 BBC Handbook (Wallis, 2014). Today media literacy is generally understood as a set of abilities to access, understand, critically engage and produce media (more on the different definitions in Chapter 1). In recent years, there have been European Union funded research projects, nongovernmental organizations and academic journals dealing with different topics in connection with media literacy. However, there are still many unanswered questions regarding, for instance, the role of public education in the process of acquiring media literacy.

My determination to understand the position of media literacy in education policy, the interesting historical path of media literacy education in Hungary, and the roles of various actors in the development of media literacy education, led me to the three major research questions: How and why did media literacy education in Hungary make its way into the public education system during the 1990s? In what ways did this area of study evolve over time? What is the position of media literacy education in the contemporary education system in Hungary? Subsequently, some other questions have also arisen: Who were the key actors involved in the development of media literacy education, what were their motivations, and how did they come to define and influence media literacy education in Hungary? For finding the answers to these questions, the dissertation is set out to provide a historical account of the origins of media literacy education in Hungary, the discourses that have shaped educational policy, and the roles of the various actors involved in this process. The relevance of this quest, however, goes beyond the policy history of media literacy education, since as Parry observes, "[...] disputes over the content of curriculum have repeatedly reflected broader political and social concerns, even when portrayed as purely educational issues" (1999, p. 23). The more overarching aim of this dissertation is thus to also present contemporary concerns in connection with mass media and education. 
While this project focuses on media literacy education in public education, children or teachers were not involved in this project. It is equally important to stress that this thesis deals with education policies in connection with teaching about the media, rather than the use of media as teaching material (teaching with media, or educational media). In addition, the thesis does not aim to engage in the debate about the possible effects of the mass media on children. The goal is to examine how media literacy education was introduced, and how this subject evolved in the Hungarian educational policy arena. There are important questions that are not discussed in this dissertation, but should be addressed by future research. Among these, is how media literacy education actually takes place in the classroom, and how pupils become media literate.

This dissertation is unique for several reasons. First, it is one of the first projects within the field of media literacy in Hungary. According to the online database of the National Library of Hungary there are less than ten works that specifically focus on media literacy education in Hungary (Országos Széchényi Könyvtár, 2016). While there are several works that deal with children and the media, to this day, there have been only two Ph.D. dissertations written in the field of media literacy, according to the repository of the Hungarian Doctoral Council (Országos Doktori Tanács, 2016). Second, there is very little academic research available in English devoted to the indepth study of media literacy in Central and Eastern Europe (CEE). Even though there were some European Union-funded international projects that had a CEE component, these could not present the fine detail of the current situation of media literacy education in Hungary. Third, this research is also distinct in the sense that it aims to be a multidisciplinary work developed at the crossroads of media and communication studies, policy studies and pedagogical studies. In addition to this, it uses a novel methodology (interpretive policy analysis) in order to shed light over the path of media literacy education in education policy.

Undertaking this research has involved the collection and analysis of mainly two types of data: official education policy documents and semi-structured expert interviewing. The data are employed in a qualitative sense, and are gathered from the following official educational policy documents: the 1993 Public Education Law (and its further modifications), the 1995 National Core Curricula (and its further modifications) and framework curricula of 1998 (and its further modifications). The interviews were conducted between 2013 and 2015 with policy-makers, media literacy 
experts and politicians who were directly connected to the development of media education in Hungary. The aim of these interviews was to gather valuable information on the process of policy-making in the field of public education. The expert interviews were also intended to further contextualise the data coming from the textual policy analysis.

\section{Structure of the thesis}

The thesis has two main parts: Part One (Chapters 1-3) introduces the definition of media literacy and the most important interconnected terms. This first part also provides the theoretical background of the thesis and it presents the Hungarian and international literature review in the field of media literacy education. Part Two (Chapters 4-8) provides the empirical work carried out for this research project, where each chapter presents a new episode in the development of media literacy education in Hungary from 1995 to 2012 . The thesis ends with the conclusions of this project. I also offer policy recommendations based on these conclusions and I draft possible future research trajectories in the field of media literacy education in Hungary and in neighbouring countries.

In Chapter 1 I set out to find an answer to the question of what media literacy and media literacy education mean. By introducing the sometimes competing, but mostly interrelated terms of visual literacy, digital literacy, information literacy, transliteracy or even multiple literacies, my aim is to present the contemporary (educational) interest in new types of literacies. This chapter also introduces the history of media literacy education in Hungary, beginning from the 1960s with the introduction of aesthetics classes up until 2012, and the latest National Core Curriculum (NCC). The aim is to present a historical context of media literacy as a subject in the Hungarian educational landscape, by focusing on the main dates and key actors, and give a condensed overview of the last 50 years.

It is often said that media literacy is a fairly new field of scholarly study, and it is not easy to identify the canon that influenced its development. In the first part of Chapter 2, I situate media literacy in a broader theoretical context with the help of Jean-Jacques Rousseau and John Stuart Mill. Although the two philosophers represent two different intelectual traditions, their work will be utilized to present different aspects of media literacy. I use Rousseau's famous educational work, Émile, or On 
Education (1762) to understand current concerns and aims of media literacy. John Stuart Mill's (1861) concept of utility is then used for analyzing the relevance of media literacy education in both formal and informal settings. In the next part of this chapter, I turn to contemporary academic literature on media literacy. I first present the Hungarian scholarly literature on media literacy, and then review the international literature. As it is expected, the media literacy research area is not very developed in Hungary, compared to the United Kingdom or other Western countries. In the international review, I organize the research projects into three groups in order to present a more systematical outlook of this field: research carried out on practice of media education; media literacy from a policy-making perspective and measuring media literacy.

Chapter 3 deals with the methodological aspects of the thesis. I first focus on the merits of employing qualitative research for this type of research. The methodology of the research project can be considered interpretivist, an approach that stresses that reality is not given, but it is rather constructed intersubjectively (Cohen and Crabtree, 2006). For examining the development of media literacy in Hungarian educational policy, I used critical discourse analysis and semi-structured elite interviews. Critical discourse analysis is a new approach to policy analysis. I based my work on the analytical framework proposed by David Hyatt (2013), which relies heavily on Norman Fairclough's oeuvre (1993, 2001, 2003). For analyzing the development of media literacy education in Hungary, the empirical data came from educational policy texts that are publicly available. These were then corroborated with information gathered through the semi-structured interviews I conducted with various elite (politicians and policy-makers). The chapter also addresses the distinct limitations of this study, in respect with the difficulties of translation and the chosen research methods.

Chapter 4 presents the empirical research. 1995 proved to be an important year for the development of media literacy education in Hungary: it was then that the subject (called Culture of the Moving Image and Media Education) "gained access" into the National Core Curriculum. In this chapter, I present first the political landscape, starting with the end of the 1980 s and the last decade of the $20^{\text {th }}$ century Hungary. After discussing the relationship between politics and educational policy-making, I turn to analyze the media literacy content in the first National Core Curriculum adopted after the regime change in Hungary in 1995.

In Chapter 5 I further explore the development of media literacy education in Hungary. This chapter introduces some major changes that occurred in the field of 
education after a new government came to power in 1998: the introduction of the framework curricula as an intermediate educational tool between the NCC and local curricula. The chapter will address these changes, and it will examine the role of framework curricula in the development of media literacy education.

Chapter 6 focuses on two important dates of Hungarian educational policy development: 2003 and 2007, when the National Core Curriculum was revised. The chapter presents the new elements that were added to the NCC. With respect to the framework curricula on media literacy education, these were not modified to a large extent, the wording is almost the same with the curricula of 2000.

In Chapter 7 I investigate how media literacy appears in the most recent, 2012, National Core Curriculum. The NCC brought along a major change for this field: media literacy appears both as a separate subject and as a cross-curricular theme in the Hungarian educational system. In the chapter I present the content found in the NCC and in the framework curricula of various subjects in which media literacy appears as a cross-curricular theme (such as Visual Culture, Hungarian Language and Literature or History).

The concluding chapter provides a brief recapitulation of the development of literacy education in the Hungarian educational system. Furthermore, I will also present how critical discourse analysis can reveal subtle information on policy, and how that helped the understanding of this specific policy trajectory. The thesis ends with a discussion on where media literacy education is situated now, and I indicate some possible directions for future research in this field.

\section{Conclusion and some addenda*}

This project provides a multidisciplinary exploration and analysis of the development of media literacy education in Hungary. As a work in policy history, I was interested in how a topic such as media literacy could gain educational relevance, and how it changes over time. The research was carried out in the qualitative social science tradition, and it aimed to present the complex nature of policy developments. By using a framework based on critical discourse analysis, I could identify the sometimes

\footnotetext{
A smaller section of Chapter 2 appeared in an article for the Central European Journal of Communication, as well as a fragment of Chapter 7 in an article for the Journal of Media Literacy Education. These articles were adapted from the previously written drafts of this dissertation. The articles did not contain the level of information that appears in this thesis.
} 
contradicting positions of this subject in the Hungarian educational system. The semistructured interviews revealed passions, intrigues and combating arguments between those involved in this process. While the personal polemics were not revealed in the thesis, the information gathered through interviewing were important in understanding the development of this field of education.

In terms of style and presentation: throughout the thesis, I tried to avoid as much as possible the use of the first person pronoun. This does not mean that I completely dismissed the use of "I", but I tried to use a more distanced narrative voice, in line with a tradition within social sciences. As a researcher in critical discourse analysis, I also know that use of passive voice can be problematic, since this can be a tool for hiding the agency. However, in terms of academic honesty, I referenced all the authors that influenced this work. Those statements that are not marked as references, all belong to me; the question of agency is thus answered. The introduction is an exception in this case since I intended to offer a more personal account of how this research work has developed over time, and what the major landmarks throughout that period were.

One of the milestones in this project was an interview with András Lányi, a university docent who served as a cultural policy advisor for Fidesz - Hungarian Civic Alliance (1990-1992) and an important policy expert in the field of media education. The interview takes us back to the title of this chapter. When asked where media literacy education development is in Hungary now, Lányi replied, "a béka feneke alatt" (interview with András Lányi, 16 January 2015). This roughly translates as "down in the dumps" (literally: "under the frog's bottom"). However, the English version does not convey the very negative connotation this phrase has in Hungarian. This answer was intriguing. Can this be really possible in a world where media has an intricate role in the different spheres of life, from work to sports or entertainment for children and adults alike? The drawing presented in the introductory part of this text is a genuine example of children's contemporary media experiences. Today, the socialization of teenagers has changed drastically, with mass-media becoming one of the key agents of socialization (Kelly and Donohew, 1999; Prot et al, 2015). Moreover, the "foundation of identity within the use of certain media brands" (Lange, 2015) is no novelty either. Hence, the resources available for pupils in formal education should help them become media literate. At least, that is what one would expect. This work aims thus to unravel the 20year-long development of media literacy education in Hungary, and to provide a critical insight to how current media literacy education policies are tackling these challenges. 


\section{Chapter 1: Media literacy - definitions and historical paths in Hungary}

\section{Introduction}

This first chapter is meant to offer a comprehensive overview of how media literacy is defined by various experts and scholars. The chapter will also present other concepts such as digital literacy or transliteracy, which are closely connected to media literacy. The last part of this chapter will provide an overview of the history of media literacy education in Hungary. The roots of this education field lay in the aesthetics classes introduced in the 1960s. The extra-curricular film clubs and alternative education models have also influenced the development of media literacy education in Hungary. The chapter will end with a description of the last 20 years of media literacy education.

\subsection{What is media literacy?}

Interest in media literacy education has been steadily growing in the last 40 years across the globe (Kubey, 2003). From after-school programs to summer camps, from elective to mandatory classes, media education appears in many forms in many countries. When analyzing closely the media literacy movement though, one cannot overlook the fact that media literacy is a somewhat contested phenomenon. One of the starting points of the debate is the very concept of media literacy. The term and its definition have changed over time and the different approaches incorporate a variety of perspectives. As Brown (1998) observes:

Media literacy means many things to many people. Traditionally, it has involved the ability to analyze and appreciate respected works of literature and, by extension, to communicate effectively by writing well. In the past half-century it has come to include the ability to analyze competently and to utilize skillfully print journalism, cinematic productions, radio and television programming, and even computer-mediated information and exchange (including real-time interactive exploration through the global internet). (Brown, 1998, p. 44) 
Several scholars use the term digital literacy or multiple literacies (Kellner, 1998; Livingstone, 2004; Olson \& Pollard, 2004; Kalmus et al., 2009; Plester \& Wood, 2009), while others talk about information literacy (Zurkowsky, 1974; Bundy, 2004). And there are those academics that put emphasis on visual literacy (Chauvin, 2003; Duffelmeyer, 2004). UNESCO, on the other hand, promotes media and information literacy (UNESCO, 2013). In the following a number of interconnected concepts will be discussed, and then the different definitions will be highlighted in order to clarify why there are so many approaches in defining this core term.

With a simple search on Google for media literacy, one can find an array of web pages offering definitions and explanations on what media literacy means. From Wikipedia to the Center for Media Literacy or Girls Inc. Media Literacy; from definitions outlining critical thinking and evaluation to child protection one can be lost in the haze of this fairly new enthusiasm over media literacy. However, one of the widely adopted definitions of media literacy comes from Ofcom, an independent regulator and competition authority for the UK communications industries. Ofcom sees media literacy as "the ability to access, understand and create communications in a variety of contexts" (Ofcom, n.d.) The Ofcom definition is based on an earlier US definition, from the Aspen Institute Report of the National Leadership Conference on Media Literacy:

A media literate person- and everyone should have the opportunity to become onecan access, analyze, evaluate, and produce both print and electronic media. The fundamental objective of media literacy is critical autonomy relationship to all media. Emphases in media literacy training range widely, including informed citizenship, aesthetic appreciation and expression, social advocacy, self-esteem, and consumer competence. (Aufderheide, 1992)

A large number of authors gave definitions to media literacy and debated its traits (see for instance Alvarado, Gutch \& Wollen, 1987; Brown, 1991; Buckingham, 1993; Hobbs, 1994a; Piette, 1997; Kellner, 1998; Kress, 2003; Livingstone, 2004). The common line in these seems to be that media literacy involves specific skills and competencies that enable people to understand mass media and to be critical towards media content. 
An important actor in the media literacy movement is the European Commission. Media literacy as a term first appeared in EU documents in 2007, in the famous European Audiovisual Services Directive. Then there was an official communication on media literacy at the end of 2007. In 2008, a study was published presenting the trends in the field and a recommendation appeared in 2009. But as David Buckingham (2009) correctly observes in these documents "one can find a vast range of ideas about what media literacy is. Among other things, media literacy seems to involve developing skills in handling technology, encouraging appreciation of the European audio-visual heritage, protecting children against harmful content [...], promoting independent public service media, encouraging active citizenship and participation in civil society, enabling people to resist commercial persuasion [...]”' (Buckingham, 2009, p. 14) Although David Buckingham is one of the key figures of media literacy, he admits that the term is sometimes aligned with contemporary buzzwords in educational and social policy for the sake of marketing (Buckingham, 2009). And indeed those who question the aims of this field of education, see media literacy as just another buzzword for financing research projects (interview with Péter Bajomi-Lázár, March 29, 2014 ${ }^{1}$ ). Other critics claim that the children are somehow naturally media literate, since "[...] younger generation is learning to read from the screen as easily as our generation has learned to write from it." (Warschauer, 2001, p. 51) In a similar vein Gauntlett (2007, p.3) comments that "media audiences in general are already extremely capable interpreters of media content, with a critical eye an understanding of contemporary media techniques." While David Buckingham (2010, p. 10) believes that audiences can indeed be active and critical, he also highlights the fact that "there are things that [audiences] generally do not know about the media - and indeed they need to learn [...] about how the media work, about the media industries, about the history of media, about the uses and effects of media within society."

Digital literacy is often used alternately as a term to discuss network literacy (McClure, 1994), social media literacy, or Internet literacy (Martin, 1997). The concept gained popularity in the mid-90s with Paul Gilster's book of the same title. Gilster (1998) defines digital literacy as 'literacy in the Digital Age'. Although his book is very much focused on the Internet, Gilster (1998) emphasizes that digital literacy is much

\footnotetext{
${ }^{1}$ A full list of interviewees can be found in Appendix A.
} 
more than IT/computer literacy, and it involves a 'knowledge assembly', which in his terms means an ability to back-up traditional forms of content with information from various e-sources. Because of the significance of the Internet and its prevalence in everyone's life, Gilster (1998) sees digital literacy as a life skill. Other authors use the term to explain the difference between print and online sources, and the importance of evaluation of the latter one (see Wilson, 1998). Yet other scholars emphasize that digital literacy is the form of literacy, which is essential for dealing with multimedia information (Gritsenko and Dovgiallo, 1997, Koltay, 2011)

Visual literacy is another debated term since the $20^{\text {th }}$ century became dominated by film and television, and the print press started to lose ground. It is no novelty that today we are living in a visual culture. Advocates of visual literacy believe that notions of literacy based solely on verbal text cannot survive, and that visual literacy constitutes a different form of literacy to which educational institutions have to respond in some way (Bolter, 1998). However, the roots of the visual literacy movement go back to the end of the 1960s and the 1970s, when authors started debating the role of visual materials in pedagogy (Cameron and Platter, 1972; Alder et. al, 1974; Branden and Hortin, 1982) ${ }^{2}$. A first definition of the concept was given by John Debes, who outlined that "visual literacy refers to a group of vision-competencies a human being can develop by seeing and at the same time having and integrating other sensory experiences." (Avgerinou and Ericson, 1997, p. 281). Nevertheless, in a review of the concept, Avgerinou and Ericson (1997, p. 280) highlighted the problems that appear in the case of the other terms as well:

\footnotetext{
Many people from very diverse disciplines have attempted to define the concept of Visual Literacy (VL), but with little general consensus so far. This is probably due to the fact that those representing the different disciplines and paradigms are each wanting to interpret Visual Literacy in a way that reflects and flatters their contribution or way of thinking.
}

Another term that is frequently mentioned in discussions about new type of literacies is information literacy. Information literacy is strongly connected to Library Studies and it is defined by the American Library Association as "[ [...] a set of skills

\footnotetext{
${ }^{2}$ More bibliography on visual literacy can be found in Rebecca Clemente's and Roy M. Bohlin's book, Visual literacy: A Selected Bibliography (1990).
} 
needed to find, retrieve, analyze and use information." (American Library Association, n.d.) The origins of the term go back to the $19^{\text {th }}$ century when the assistance given to readers in the library became known as reference service and it gained recognition as a basic function of the library (American Library Association, n.d). In the age of information, Library Studies stress the importance of knowing how to find your way in the maze of information available on- and off-line. The American Library Association issued a report in March 1998 in which the authors emphasized:

$[\ldots]$ the need for all people to become information literate, which means that they are not only able to recognize when information is needed, but they are also able to identify, locate, evaluate, and use effectively information needed for the particular decision or issue at hand. The information literate person, therefore, is empowered for effective decision making, freedom of choice, and full participation in a democratic society. (Breivik, Hancock, \& Senn, 1998)

The supporters of this term talk about the commitment of librarians to inclusion of all social groups through knowledge equity. By building on the centuries old history and experience of libraries, advocates believe that

Combined, information and literacy are appropriate to describe the understandings and capacities essential in a world where information, however provided and accessed, is the pervasive commodity, and where the requirements of 21 st century living give impetus to the concept. (Bundy, 2004, p. 9)

The definition of an information literate person is thus somewhat similar to a media literate person's definition. One difference might be the emphasis of critical thinking. In media literacy, this feature seems to occupy a more central position than in information literacy. However those authors that analyzed the inter-relations of these concepts " [...] prefer to see media literacy as a component of information literacy." (Bawden, 2001, p. 6). Some authors contest the term. Foster (1993) for instance suggests that information literacy is in quest for meaning. He outlines that the parent term - literacy - is clearly defined and it can be quantitatively measured. Literacy - in contrast with information literacy - has also a clear opposite, illiteracy. Foster (1993) thinks that talking about 
information literacy is nothing more that an exercise in public relations. He even goes further and states that the promotion of the information literacy concept is "an effort to deny the ancillary status of librarianship by inventing a social malady with which librarians as 'information professionals' are uniquely qualified to deal” (Foster, 1993, p. 346)

Media and information literacy (MIL) - According to the United Nations Educational, Scientific and Cultural Organization (UNESCO) and the United Nations Alliance of Civilizations (UNAOC) websites media and information literacy is a "[...] recently-developed pedagogical approach that takes into consideration the new cultures emerging from the Information Society" (UNESCO, n.d.). On the website, there are a number of reasons why the UNESCO finds media education important, and how it supports children and youth in becoming media literate. However, the main webpage does not give a straightforward explanation of the term itself and it does not provide a reason why "information" was added to "media literacy". The authors even mention the fact that "some prefer the terms Media Literacy, Media Education, News Literacy, Digital Literacy, Information Literacy, etc." (UNESCO, n.d.). Elsewhere though UNESCO is presenting media and information literacy as an overarching term that incorporates digital, ICT, information and media literacy (UNESCO, 2013). In this document, UNESCO emphasizes that the organization developed a schema for assessing media and information literacy with the aim to "[...] equip policy makers with a strategic framework, supported by evidence-based information, for taking concrete actions to ensure that all citizens acquire media and information competencies." (UNESCO, 2013, p. 9) In the definition of this term, the authors emphasize that the various types of literacies overlap in a number of characteristics such as their object of interest or their interdisciplinary approach. Other common features, according to the authors of the framework, is that that all these literacies have a rights-based approach, and that critical and reflective thinking and cultivation of competencies is important in all of them. Lastly, UNESCO highlights that these different literacies have an impact on people's personal, social and professional life (UNESCO, 2013). Therefore, UNESCO suggests using the terms information literacy, media literacy, news literacy, ICT and digital literacy under the umbrella term named: media and information literacy (See Figure 1 below, reproduced from the UNESCO website). 


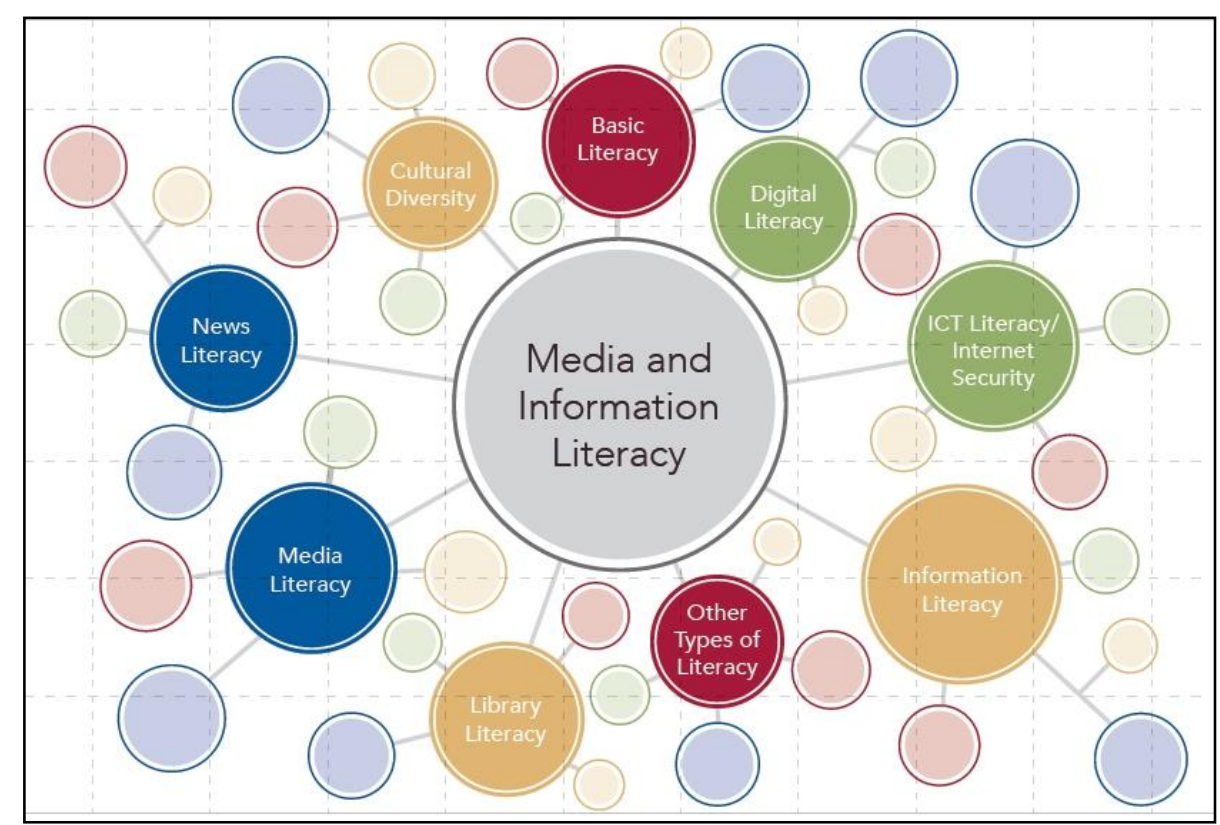

Figure 1. Media and information literacy, UNESCO

In a recent interview Divina Frau-Meigs, UNESCO expert, explains that:

[...] MIL needs to create the Internet of subjects to make sense of the Internet of things. The international trend risks to marginalize MIL, as computer literacy and IT literacy are in competition for their place in the curriculum, with heavy pressure and lobbying from the pure players that need to recruit the workers they need to develop their applications and services. [...] In this context, MIL is more than ever necessary, with critical thinking and creativity at the core of the competences it promotes. (Gabinete Comuncacion Y Educacion, 2014)

It seems that MIL has been created to counteract the campaign of ICT companies that promote IT and digital literacies. It is still unclear though whether the media and information literacy term will be accepted and used by all players in the field of media education. One step towards that goal was achieved by adopting the Paris Declaration on Media and Information Literacy. The authors of the Declaration outline that:

It is important to make clear to stakeholders that it is neither useful nor efficient to promote a single literacy or single skill set without embedding it in the wider context of MIL. Instead of a risk of marginalization or displacement or dilution of MIL in new skills and competences, the relevance of MIL needs to be underlined as essential. (UNESCO, 2014) 
Transliteracy is a term that was coined by the Transliteracies Research Project at University of California in $2005 .{ }^{3}$ Transliteracy " [...] offers a wider analysis of reading, writing and interacting across a range of platforms, tools, media and cultures, transliteracy does not replace, but rather contains, «media literacy» and also «digital literacy.»" (Thomas et al., 2007) In a similar tone, Frau-Meigs (2014) explains transliteracy as a form of augmented media and information literacy:

[...] it aims at incorporating pre-digital MIL competences, values and attitudes into the new context of the internet of things. This new context implies to look at information as the core material of the knowledge societies we are trying to foster. Transliteracy therefore considers Information as Dispositif, Information as Data and Information as Document. (Gabinete Comuncacion Y Educacion, 2014)

The question arises: if transliteracy is a somewhat overarching term for media and information literacy plus digital literacy, why are both (or the three) needed to express roughly the same issue.

We can reach the same conclusion if we take into consideration what Kellner (1998, p. 118) introduces as multiple literacies: "In addition to critical media literacy, print literacy, computer literacy, and multimedia literacy $[\ldots]$, multiple literacies involve cultural literacy, social literacy, and ecoliteracy." Going further Kellner (1998) stresses that multiple literacies are important for students' and citizens' empowerment, for creating a better culture and society and for a fuller democratic participation. In a later article, Kellner (2007) uses critical media literacy to define a broad term that "[...] expands literacy to include information literacy, technical literacy, multimodal literacy, and other attempts to broaden print literacy concepts to include different tools and modes of communicating." (Kellner and Share, 2007, p. 61)

The often overlapping and competing terms and their definitions make it difficult to see the forest for the trees. The load of information available for people seems to concern academics from different disciplines. No doubt about it, the novelty of the digital world and even more the changes brought by social media ask for new skills

\footnotetext{
${ }^{3}$ More on the Transliteracies Research Project can be found here: http://transliteracies.english.ucsb.edu/category/about
} 
and competencies. Moreover, as Livingstone (2014) observes, telecommunications, IT and electronic media converge into network information and communication technologies. A possible reason, thus, for the existence of all these interconnected concepts is that this technological convergence draws the different types of literacies closer together. However, it seems that each of the advocates of the above presented terms will probably lobby for a wide acceptance of their own concepts. Nonetheless, it is essential to note that without consensus, the work done in these fields is fragmented and it will not have a significant impact.

Although, as shown above, some of the terms overlap, for the purpose of this academic work, a clear understanding and definition of media literacy had to be selected. Throughout the thesis, media literacy will be understood in the same manner as proposed by Aufderheide (1992), and the broader definition offered by the National Association for Media Literacy Education (NAMLE, n.d.):

[...] media literacy is seen to consist of a series of communication competencies, including the ability to access, analyze, evaluate, and communicate information in a variety of forms, including print and non-print messages. Media literacy empowers people to be both critical thinkers and creative producers of an increasingly wide range of messages using image, language, and sound. It is the skillful application of literacy skills to media and technology messages.

Media literacy education in this academic work is used to denominate the pedagogic field that aims to teach the skills needed to become media literate. Although media literacy education can be done in both informal and formal settings, this work deals with the latter one, specifically within public schools. A further specification is that media literacy as a term did not appear in educational policy until the early 2000s. However, when analyzing these documents I focused on the contents that described what is considered today media literacy (e.g. educational contents that advocate for understanding the moving image, or the role of the media in society). After analyzing the many interrelated concept, in order to understand current developments, the next step is to have an overview on the historical path of media literacy education in Hungary. 


\subsection{Historical overview of media literacy education in Hungary}

There is no thorough written account on the recent developments of media literacy education in Hungary. This text is built primarily upon the oral accounts and personal notes of one of the leading advocates of media literacy education in the country, László Hartai ${ }^{4}$. Imre Szíjjártó's (2007) work on Hungarian media literacy education was also used to offer a secondary view to this retrospection. Media literacy education in Hungary can be traced back to the end of the 1950s (when the first film clubs were organized) and the 1960s when film aesthetics was first introduced in the curriculum of literature classes in the Hungarian education system ${ }^{5}$. Literature teachers across the country were assigned by the Ministry of Education to teach four hours of film aesthetics per year in secondary schools' educational program. Besides these classes, pupils were required to attend compulsory movie screenings at cinemas. This regulation was included in the National Core Curriculum of 1978 and stayed in force until 1995. It is important to note however, that the majority of these literature teachers were not trained and thus they did not have the necessary knowledge to teach this subject and according to Hartai (interview with László Hartai, March 13, 2014) this eventually led to the "disappearance" of the film aesthetics topics in the teachers" everyday practice. Some secondary-level schools across the country continued to offer programs about film-making and film culture as an extra-curricular activities. These activities were organized mostly by passionate teachers who were not in contact with each other, but in the 1990s they would become important participants in the development of media literacy education. Some of these educators met for the first time in 1992 to form a working group that would later lobby for the introduction of film education in the forthcoming new National Core Curriculum. The early activists had several major concerns, namely the lack of a curriculum for the subject, the lack of textbooks and the most serious, the lack of prepared teaching staff. Hartai (2002, p. 5) states:

\footnotetext{
${ }^{4}$ László Hartai is the director of a non-governmental organization that advocates media literacy called Magyar Mozgókép és Médiaoktatási Egyesület (Hungarian Association of Film and Media Education). $\mathrm{He}$ is the author of a number of pedagogical books on media literacy and he organizes adult education courses for teachers on methodology, media theory and creative workshops.

${ }^{5}$ It is important to mention the role of István Szőts in the history of media literacy education. István Szőts was a Transylvanian movie director, who in 1945 wrote an important pamphlet on the contemporary situation of filmmaking in Hungary. In this pamphlet he also highlights the role of schools in film education (Szőts, 1945). His pamphlet was not considered relevant at that time though by the authorities, and after the 1956 Hungarian revolution, he chose to emigrate to Austria.
} 
It was quite obvious that we can have the most sensational textbook, but we cannot talk about anything without educators. [...] It was not until 2000 when this specialization appeared in the film theory-film history department at Eötvös Lóránd University in Budapest. We came to acknowledge that at least for the next 20 years everything depended on the continuous professional development of in-service teachers.

Finally, in 1996 the Hungarian Government accepted the "Moving Image Program" to aid the implementation of the new subject, titled Culture of the Moving Image and Media Education, into the new National Core Curriculum. The new subject was introduced in the Curriculum in the 1998/1999 academic year. In the 2003/2004 academic year media literacy became a compulsory subject for 3rd and 4th graders at secondary schools. From 2005, pupils could further choose the Culture of the Moving Image and Media Education as an exam subject for their secondary school final examination. Grades from this examination may count towards matriculation to higher education. The new National Core Curriculum of 2012 introduced several changes: media literacy became both a stand-alone and a cross-curricular subject in the Hungarian educational system. These changes will be analyzed in detail in the second part of this thesis.

\section{Conclusion}

The aim of this chapter was to show how a new field of study struggles with finding common ground - and a common definition to its core concept among the different stakeholders (e.g. academics, governmental officials, media specialists). The often-overlapping terms are used in many instances to explain similar interests. It is thus debatable why it is thus so difficult to reach an agreement over what media literacy (education) means. Wallis found seven competing discourses in recent UK media literacy policy, and "within these discourses, media literacy as a term is, to varying degrees embraced and rejected in turn, depending upon the perceived expedience of its use" (2014, p. 230). Similarly, the historical development of media literacy education in Hungary shows common patterns: from aesthetics to film literacy and media literacy, a 
number of terms have been used in defining this area of education. In an effort to strengthen the presence of this field in academia, and to understand current developments, the next chapter will try to connect the goals of media literacy education with the work of two of the founders of modern social thought, JeanJacque Rousseau and John Stuart Mill. 


\section{Chapter 2: Media literacy - a new academic field of study}

\section{Introduction}

This chapter serves as an introduction to the theoretical debates in the field of media literacy. As a new area of study, media literacy has an interdisciplinary nature, and combines theories and approaches from communication and media studies, pedagogy studies, sociology, and even civic studies. The aim of this chapter is then to present the main scholars influencing this academic field of study, and to make a connection with thinkers representing the reconstructive education approach, JeanJacques Rousseau and John Stuart Mill. The chapter will end with a description of the latest developments in media literacy research both in Hungary and around the world.

\subsection{Finding the scholarly roots of media literacy}

Media literacy has emerged as a new field of scientific inquiry at the crossroad of media studies and education. Because of the interdisciplinary nature of the field, it is not easy to pinpoint the theories that are to be considered the theoretical basis of media literacy.

Capello, Fellini and Hobbs (2011) mention authors such as Dewey, Freinet, Laporta, Gerbner, Eco, McLuhan, Horkheimer and Adorno, Althusser, Freire, or Postman, whose work was significant in the development of media literacy. Hobbs and Jensen (2013) also remark that we can trace a multitude of theoretical roots and perspectives at the origins of media literacy: Marxian and neo-Marxian sociology of culture, activism in education, history of communication and culture, critical pedagogy, educational theory, empiricism, etc. In addition to the above-mentioned scholars Kellner and Share argue that "an important arena of theoretical work for critical media literacy comes from the multidisciplinary field of cultural studies" (2007, p. 11). Thus, Kellner and Share (2007) outline the work of the Frankfurt and Birmingham School in shaping the future of media literacy education. From this condensed introduction, it becomes clear that media literacy as a field it is somewhat still in its childhodd. As presented earlier, scholars are still debating what should its name be, how it should be defined and 
which authors should be in the canons of the field. Another problem faced by advocates of media literacy education is that globally, as Jolls and Wilson (2014, p. 68) points out, "media literacy is rarely institutionalized in education systems and not taught consistently."

In this present part, the aim is to situate media literacy in a broader theoretical context and analyze the aims of media literacy education while relying on two of the main scholars of modern social thought: Jean-Jacques Rousseau and John Stuart Mill. Media literacy will be thus explored as a field at the crossroad of education and media. The two authors were selected because they are both advocates of the so-called reconstructive education, "which tries to effect a transformation of the mind-set and produce new persons" (Parry, 1999, p. 23). Parry (1999) distinguishes between constructive and reconstructive education, based on Dennis Thompson's (1970) classic differentiation between ideals of citizenship. Rousseau and Mill belong to the second group, and they both advocate for the "reinvigoration of the social and political world by the newly-educated children" (Parry, 1999, p. 29). Media literacy education can be understood as a very similar endeavor - to educate children for becoming 'new' persons who are able to transform their own understanding of the world, and the existing social practices.

The departing point for this analysis will be Jean-Jacques Rousseau's “Émile", published in 1762, in which a new, perhaps utopian, education method is sketched. Rousseau's treatise is as timely as ever when it comes to understanding the educational aims of media literacy. The second author who will help in understanding the overall role of media literacy education is the famous methodological individualist, John Stuart Mill. His approach will shed a different light on this topic compared to the collectivist Rousseau, but it will help in understanding the importance of this specific subject not only in school curricula, but also in many other aspects of social life.

\subsubsection{Aims of media literacy education}

For setting the stage of this present quest, an outline of the major aims of media literacy education, as defined by a number of relevant actors in this field, will be presented. In the Core Principles of Media Literacy Education in the United States (2007), listed on their website the authors state: "The purpose of media literacy 
education is to help individuals of all ages develop the habits of inquiry and skills of expression that they need to be critical thinkers, effective communicators and active citizens in today's world." The European Commission defines media literacy on its website as "the ability of people to access, understand, create and critically evaluate different types of media. [...] Media literacy is vital for economic growth and job creation. Digital technologies are a key driver of competitiveness and innovation in the media, information, and communication technology sectors." (European Commission, 2016). In Hungary the National Core Curriculum (2012, p. 10644) defines the aim of media literacy education as a means through which children can become

competent participants of the global mediated public: to understand the language of new and old media. Media literacy education prepares [students] for the culture of participatory democracy and value-based everyday life that is being influenced by the media. It does so through developing a critical attitude and through its actionoriented attitude. [...]

Although one can obviously spot some differences among these goals, there are some clear commonalities as well: critical usage and analysis of media messages, creating media content in a variety of forms, reflecting or making sense of media texts, but also an active participation in the mediated public. In the following, these aims will be analyzed in the light of Rousseau's Émile (1762/1993). From there it will be argued that the aims of media literacy education may support the overall development of citizens. John Stuart Mill's concept of utility (1861/1993) will offer the theoretical framework in this argument.

\subsection{2. Émile - a media literate child?}

Rousseau, a political and social thinker, became an influential education theorist by writing the book Émile, or On Education. Émile was (and still is today in some aspects) a work of educational reform. The book was considered quite provocative at that time, and one of the many criticisms it received was that this type of education is in fact impracticable. One of the main themes of Rousseau $(1762 / 1993$, p. 37) is that people in nature are good, it is society that corrupts:

Everything is good as it leaves the hands of the Author of things [God]; everything degenerates in the hands of man....He turns everything upside down... He wants 
nothing as nature made it, not even man; for him man must be trained like a school horse; man must be fashioned in keeping with his fancy like a tree in his garden.

This is the first point where we can connect media literacy education to Rousseau's argument. In many instances, one can read about the necessity of training students to become relevant actors in the economy, to get good jobs and to start a company. However, Rousseau in fact talks about education, not training, which is completely different. He highlights the importance of developing a child's own thinking: "my Émile, who has been carefully guarded for eighteen years with the sole object of preserving aright judgment and a healthy heart." (Rousseau, 1762/1993, p. 244). Thinking and judgment have been the heart of media literacy education. For having a critical approach towards mass-media texts, the first and foremost principle of media literacy is exactly active inquiry. Or, as Rousseau puts it, Émile has to think for himself and thus be preserved from error and prejudice, he is not in danger of being corrupted by society. Thinking people would be called in media literacy terms active audience: those who can judge media content and decide on its own - one of the major aims of media education.

P.D. Jimack (1993, xxxiii) observes that Rousseau is critical on the very foundations of educational practice and "proposes a new way of looking at children and their education; the pedagogical doctrine of Émile is a structured whole, in which each age is important both in its own right - children are at last seen as children - and as a preparation for future development." Today this seems commonsense. Yet for media literacy practitioners it is the basis of their pedagogy. If one is interested in media literacy curricula, she can find a wealth of teaching material that support the argument of a child-centered education. These programs have specific curricula, programs and activities taking into consideration the age, the development, the previous knowledge, and most importantly, the societal conditions in which children are living in. For instance there are large differences in media literacy programs in the EU countries (where they focus on online bullying, for instance), and Brazil (where the focus is more on equitable access to information).

Rousseau believes that good education means protecting the child from the corrupting influence of society. This is why he teaches Émile in the countryside, for instance. In this aspect media literacy seems to be in trouble though: while initially the 
aim of media literacy was to protect children from the harmful media content, by today most scholars agree that children should not be kept away from the media, but taught to understand it critically. So would Rousseau despise media usage? It is a difficult question, since he considers books "the curse of childhood". Yet Rousseau places much emphasis on the development of senses for the whole of education. He says: "His sense experiences are the raw material of thought; they should, therefore, be presented to him in fitting order..." (Rousseau, 1762/1993, p. 31). Rousseau obviously thought about having the child out of doors, running about in the meadow, and so on. But in today's world I believe that media is so pervasive, built into our everyday lives, that it is quite difficult to ignore it. While this might seem a provocative idea, I would argue that today children's ability to use touch screen tablets, phones and so on is also part of children's development of senses. Rousseau also says "Give your child no verbal lessons; he should be taught by experience alone..." This advice does support the overall argument. Douglas Rushkoff (1996), for instance, asserts that today's young generations experience the world mostly not through physical boundaries, but through screens. Rousseau values learning through experience, and similarly media literacy experts also recognize the importance of media experiences. While, of course, one could argue that media cannot be compared to natural experiences, I would highlight once again that in today's world it becomes almost impossible to separate our offline and virtual culture.

Going further, Rousseau (1762/1993, p. 170) argues: "do not forget that it is rarely your business to suggest what he ought to learn; it is for him to want to learn, to seek and to find it." This is a provocative idea even now: can we or should we let a child decide on what he wants to learn? As presented before media literacy is rarely institutionalized and in many countries it is an elective class or an after-school activity. Therefore, it is still somewhat free of institutional constraints in its practice. Many of the curricula made for this subject highlights the utilitarian aspect Rousseau is talking about. For instance, Scheibe and Rogow (2008) advise teachers to be flexible in assignments, stimulate interest in a new topic or facilitate use of a range of media formats to express students' opinions and illustrate their understanding of the world. Similarly Renee Hobbs says that there are a multitude of reasons why educators introduce media literacy as part of the curriculum: from seeing it as a tool make contemporary education relevant for students (by building links between the classroom and the culture) to seeing media literacy as a "way to give children the opportunity to 
tell their own stories and better understand the power of those who shape the stories of our culture and our times" (Hobbs, 1996, p. 104).

There are two more aspects that connect media literacy education to Rousseau: one is the importance of manual trade and the other is the development of the aesthetic faculties in adolescence. Rousseau sees as an important part of education the learning of manual trade, which is carpentry in case of Émile. He sees this as a fulfillment of a civic responsibility and securing Émile's future and his independence. But what is the connection between media literacy and manual trade? I would argue that one of the aims of media education is exactly the creation of media text. The question of production is actually very important for media literacy education since media literacy is not only about analyzing and evaluating media, but about creating media in a variety of forms, to express our opinions and feelings through writing, speaking, filming, etc. While this is not exactly carpentry, we can draw a parallel with today's high-tech world. I strongly believe that this idea is not very different to Rousseau's: media production today can be regarded as a civic responsibility and it can also be a first step towards becoming a media professional, and thus securing one's future and independence.

Finally, in Book IV Rousseau (1762/1993, p. 215) talks about finishing Émile's education: "We made him a worker and a thinker; we have now to make him loving a tender-hearted, to perfect reason through feeling." Rousseau believes that Émile in puberty has to focus on the moral, emotional and aesthetic aspects of education in order to complete his education. The importance given to aesthetics can be another meeting point with media literacy education. Martens (2010, p. 8) observes that "historically, media literacy education has often been synonym for learning to appreciate the aesthetic qualities of mass media, especially the cinematic arts." Moreover, another scholar, Lev Manovich (2007, p. 1), believes that the latest technological changes brought about an "aesthetisation of information tools". He notes that because of the large amount of time we spend with our digital devices, the user interface became anesthetized in order to appeal to our senses (Manovich, 2007, p. 4). Rousseau's aims with cultivating Émile's aesthetic taste are thus very much in line with media education goals: he intends to cultivate Émile's reliance on his own inner resources and prepare him for selfsufficiency (Jimack, 1993, p. xxxi). 
The purpose of this first part was to see how Rousseau's treatise can be used for understanding and advocating for the educational aims of media literacy. It was argued that although a couple of centuries old, Rousseau's Émile is as timely as ever, and as a backbone of modern education it can be successfully used in situating media literacy in a deeper theoretical context. In the following, the focus will be on John Stuart Mill's concept of utility in analyzing the importance of this specific subject for people's overall education.

\subsubsection{A satisfied fool or a media literate Socrates?}

In a 2005 article Kellner and Share advocate for critical media literacy. In their understanding critical media literacy cannot be separated from radical democracy since this type of education will develop skills for enhancing democracy and participation:

It takes a comprehensive approach that would teach critical skills and how to use media as instruments of social communication and change. The technologies of communication are becoming more and more accessible to young people and ordinary citizens, and can be used to promote education, democratic self- expression, and social progress. (Kellner and Share, 2005, p. 373)

However, why should one want that? Is it not enough to have a decent job that pays well enough? Why should one bother about things such as democracy, change or selfexpression? Bentham would argue that in this sense there is no need for media literacy education. It makes no sense in Benthamite utilitarian terms to receive an education that makes one more dissatisfied with the current state of democracy or with the media landscape. And indeed there is a growing pressure from the market and some politicians to formulate the role of education in terms of employment. However, there is another famous utilitarian who argues otherwise. J.S. Mill believed that: "It is better to be a human being dissatisfied than a pig satisfied; better to be Socrates dissatisfied than a fool satisfied" (Mill, 1861/1993, p. 14).

Mill's thoughts from Utilitarianism and On Liberty can be used to argue for a media literacy education that equips children and young people with the capacity of not only digesting, but also critically viewing media, among other advantages.It is important 
to note though that, in contrast with Rousseau, Mill has no extended work on formal education. Yet Alan Ryan (2011) observes that actually education is omnipresent in Mill's work, and that Mill made a differentiation between a 'narrow' and a 'wider' meaning of education. The 'narrow' education was the formal one, while the 'wider' embraced "all the influences that make us who and what we are" (Ryan, 2011, p. 653). In Mill's writing whatever has an effect on our emotional, intellectual development can be considered educational in this broad sense (Ryan, 2011). If I would have to categorize media literacy with these two concepts ('narrow' vs. 'wide'), I would be in quite a trouble. On one hand when formalized in school settings media education would fit into the 'narrow' group, but on the other media is omnipresent in our society and it does have an effect on our development, thus it would also fit into the broader category. Either way this shows that media literacy education can be analyzed in Millian terms.

Iona and James Tarrant argue against the usual characterization of Mill's utilitarianism as a hierarchy of 'pleasures'. The authors believe that Mill's utilitarianism can be better understood as a hierarchy of preferences "because the former emphasizes the dependence of utility on the individual" (Tarrant and Tarrant, 2004, p. 109). The authors quote Mill in support of their interpretation: "human beings have faculties more elevated than the animal appetites, and when once made conscious of them, do not regard anything as happiness which does not include their gratification (Mill, 1861/1993, p. 8)" Mill goes even further with saying that "And if the fool, or the pig, are of a different opinion, it is because they only know their side of the question." (Mill, 1861/1993, p. 10). This quote prompts the scholars to highlight that Mill has a very special understanding of utility which "relies on the idea of a hierarchy of preferences, an individual whose faculties are 'more elevated' has better preferences." (Tarrant and Tarrant, 2004, p. 110) In this sense Mill tells us that the individual after this development would consider herself to be better off: 'no intelligent being would consent to be a fool, no instructed person an ignoramus ... . even though they should be persuaded that the fool is better satisfied with their lot than they are with theirs." (Mill, 1861/1993, p. 9)

This framework is important in understanding the role of media literacy education in our everyday life. Within utilitarianism, it is better to be a critical media literate person than one who is ignorant, even though this critical existence does not 
bring satisfaction. A media literacy education challenges accepted values and beliefs, and it does not offer contentment. Yet, if we use Mill's utility concept, we can argue that the person who became media literate will prefer her post-education situation. This person will prefer to understand how media conglomerates work, why Disney princesses look the way they do, and why certain media outlets present news in certain modes. This person will prefer to being critical than to being a fool resting in blissful ignorance.

Iona and James Tarrant (2004, p. 113) argue that "an education whose primary goal is "serving the daily uses of life' might not increase utility in this broad sense." What they are referring to is that education should be much more than satisfying market needs. In this sense media literacy offers a type of knowledge that goes well beyond economic interests. Media literacy education aims to empower citizens in understanding the societies in which they are living in, but it also aims to strengthen their participation in the democratic dialogue. In Mill's terms media literacy will educate individuals in order to transform their preferences to better ones. Thus, the importance of media literacy education cannot be underestimated. According to Mill's understanding of utility it would serve countries to educate people to the level of Socrates, and media literacy education could be one step towards that level.

In this previous part, the goals of media literacy education were analyzed through the works of Rousseau and Mill, as an effort to see how this new education field can be connected to modern social thought. In the next part I will turn to contemporary approaches to media literacy research.

\subsection{Contemporary scholarly perspectives on media literacy}

\subsubsection{Insights from the Hungarian literature}

Media literacy education as a formal school subject has been in the National Core Curriculum only since 1995, and thus Hungarian scholarly interest on the topic was fairly low. However, Hungarian researchers participated in a number of international comparative research projects that analyzed educational policies and teacher training in this field. 
One of the firsts to discuss media education was Imre Szíjártó (2007) who identified five periods of Hungarian media education from 1957 until 1996. He writes that media first appeared in schools in 1957 with the foundation of the first film clubs. The next period was defined by the national curriculum of 1965 in which film aesthetics was included in Hungarian language and literature curriculum. According to Szíjártó (2007) the third period lasted from 1978 to 1980 during which time the curriculum became less and less important, and aesthetics disappeared from the classroom. The forth section lasted from 1980 to 1995, a period of experiments and alternative teaching. The last period identified by Szíjártó started in 1996 with the introduction of the elective media class (Culture of the Moving Image and Media Education) into the national curriculum.

Imre Szíjártó also participated in the Euromedia comparative project that presented an international perspective of teaching media to 14-16 year-olds in Europe (Hart and Süss, 2002). The project revealed - through teacher interviews and classroom observation- that in Hungary there was a gradual shift from an aesthetic approach to a social science approach in media education. The report emphasized a number of difficulties such as the problem of teacher training. However, the report ended on a positive note:

[...] regulations (in process) directing the continued education of teachers and the monetary funds set aside in the national budget for this goal might very well paint an optimistic picture of the future of Motion picture and media education. (Szíjártó, 2002, p. 76)

Research on media education was taken up ten years later, when Csilla Herczog and Réka Racskó (2012) investigated Hungarian teenagers' media literacy skills. The researchers focused on teenagers aged 14 to 18 and they measured media literacy knowledge through quantitative methods on a sample of 2954 pupils. The quantitative results were then corroborated with qualitative findings gathered from classroom observation, interviews, focus groups and narrative analysis. The researchers found that there is limited interaction during media literacy classes between students and teachers. Moreover the results showed some alarming results: the initial hypothesis (students who had media literacy classes would perform better at the media literacy test), could not be 
proven entirely (Herczog and Racskó, 2012, p. 11). The researchers also recommended a

[...] change in attitudes and the practice in and beyond the community of media teachers, in which it is accepted that media education is based on the 'existing media experiences' of students, thus giving chance to differentiated teaching methods, in addition, to recognize that there is a need for media exercises to help self-expression, as these can lead students to a higher level of theorizing. (Herczog and Racskó, 2012, p. 15)

Since the 2007 European Commission act on media literacy, there is a growing interest in comparing and assessing similarities and differences between the various approaches to media education in the countries of the European Union. Hungary participated in a number of these. One of the latest reports is the European Media Literacy Education Study (2014). The main objectives of the study were to develop policy recommendations and to contribute to the harmonization of tools used to measure media literacy skills (Gabinete de Comunicación y Educación, 2014). The country report on Hungary emphasizes the main issues the country faces when it comes to media literacy: the lack of teachers' media training, a stronger focus on ICT education in schools, and the changes in educational policies on media literacy (Gabinete de Comunicación y Educación, 2014).

Another international comparative report, the ANR Translit and COST (European Cooperation in Science and Technology) "Transforming Audiences/Transforming Societies" published in 2014, analyzes media education through a number of dimensions, such as the historical background of the subject, the legal/policy framework, the level of teacher training, materials used in classrooms, and funding. The researchers who evaluated media education in Hungary, were on the opinion that:

[...] there are visible intentions to centralize, homogenize media education as well as the whole education system and content which narrows down the possibilities and colorfulness in education. In our opinion, there is another problem with the content of media education, as it focuses again on high culture media products, European and Hungarian cinema creations and critical consumption of other media contents. It does not take into account the real tendencies of popular culture which is in the focus of students' interests. (Schleicher and Rétfalvi, 2014, p. 6) 


\subsubsection{Insights from the international literature}

There is a wealth of studies on the different aspects of the intricate relationship between media and children. Earlier research focused on films and television, while the latter ones, on new media and digital environments. From psychology to sociology or media studies, variate aspects have been analyzed on the topic of children and media. Media literacy scholars form a relatively new and narrow group who are interested in specific aspects of the relationship between children and media. For a more articulate overview of previous works, the research projects were organized into three major groups. As with all categorizations, it might be possible that some projects might fit in more than one group, while others may not fit strictly in any of these groups.

In the first group were placed those projects that examined the actual practice of media education. In these works, authors use a number of methods - from classroom observation to interviews or surveys - to describe and analyze how media education happens in different formal and informal settings. In the following, a number of researches that were carried out in recent years around the globe will be highlighted.

The OnAir project was aimed at collecting, documenting and developing media education practices in Belgium, Bulgaria, Italy, Lithuania, Poland, and Romania (Parola and Ranieri, 2011.) The researchers assessed the role of documentation in improving teachers' practical knowledge. The results of the project showed that the documentation of media education practices was inadequate: there was not enough information on instructional practices, and teachers were not reflecting on their educational methods. Media education can also mean empowerment for underprivileged groups. This aspect is highlighted in another project that focuses on the practice of media education. Elizaveta Friesem (2014) analyzed the connection between media literacy, video production and disadvantaged youth. The researcher offered "[...] an account of a media literacy intervention that involved making videos with a class of foster youth" (Friesem, 2014 , p. 44). The article presents the process of acquiring media and digital literacy through media production. Paulette Stewart and Olivia Bravo (2013) reported about the development of information literacy courses at the University of the West Indies, Mona, and Jamaica. The article also presented a multi-year media literacy project for Jamaican primary and junior high school students. The researchers discussed the aims, the teaching methodology and the assessment forms carried out in the ongoing initiatives 
within the Caribbean. The article presents thus an overview of the current status of media and information literacy within the Carribean.

The second major category in media literacy research examines the advancement of the field from a policy-making perspective. Several large-scale studies have been carried out in recent years into the topic of media literacy in Europe. The European Commission, for instance, funded a number of research projects that aimed to pinpoint the state of media education across the European Union. As we have mentioned earlier Hungary participated in most of these studies (European Media Literacy Education Study, the ANR Translit and COST "Transforming Audiences/Transforming Societies"). MEDEAnet (2012-2014) was another project supported by the European Commission. In this case, the focus was not just on the status of media literacy, but also on how the media are being used to support teaching and learning in four European countries (Estonia, Greece, Bulgaria and Romania) and three regions (BadenWürttemberg, Flanders, Upper Austria). During this period three reports were issued that had different focuses. The first one analyzed policies, trends and developments related to media literacy and media education. The second annual report (published in 2013) "concentrated on the extent to which media literacy is incorporated into curriculum design for compulsory level education" (MedeaNet, 2013). The report showed that there was discrepancy between the curriculum and the effective daily classroom practice in most countries. The last research report dealt with the topic of training in the production of educational media. The researchers reflected on the importance of high quality teachers and their training as an important component of media education. Common problems and possible solutions were in focus of another comparative research project that analyzed media literacy in Finland, Sweden, the United Kingdom and the Netherlands (Kennisnet, 2013). The interviews with media literacy specialists and the policy analysis showed a common trend across Europe:

There is a great deal of discussion of media literacy, and many thousands of pages have been filled writing about it. Nevertheless, those thousands of pages seldom have any direct impact as regards the work actually taking place in classrooms. [...] media education is often still seen as "a luxury" - as a kind of supplement to «the really important subjects» (Kennisnet, 2013, p. 38) 
Nevertheless, the report also highlighted many positive features of media education in these countries, such as the training of teachers in Finland or the strong media education heritage in the UK.

The third group consists of works that focus on measuring media literacy levels. Since the Audiovisual Media Services Directive (2007) set out a reporting obligation for the European Commission to measure the level of media literacy in EU states, there has been a number of studies proposing different methods of measurement. Most studies though struggle with defining media literacy competences and a conceptual framework that is agreed upon among the experts in this field (The European Cooperation in Science and Technology, 2013). One of the first papers, Study on Assessment Criteria for Media Literacy Levels (EAVI, 2009) set out to formulate a tool for media literacy measurement through two dimensions: as individual competences and environmental factors. The individual competences "draw on a broad range of capabilities, and embrace increasing levels of awareness, the capacity for critical thought and an ability to produce and communicate a message" (EAVI, 2009, p. 7). Environmental factors are defined as contextual factors that impact the broad span of media literacy, such as information availability, media policy, and education (EAVI, 2009). By using this method, the researchers could find positive correlation between a country's social and educational level and the level of media literacy. The study also showed that "if there is no formal strategy for the fostering of a media literate population, then that population is unlikely to be media literate" (EAVI, 2009, p. 12). The United Kingdom's Office of Communication (Ofcom) has a specific approach to measuring media literacy. Ofcom has two main surveys annually: one for adults (aged 16 and over) and one for children (5-15) and parents. Besides the quantitative survey, Ofcom carries out a qualitative longitudinal study of about 15 participants, who have been interviewed about their media use since $2005^{6}$. One of the most important output of the Ofcom's surveys is the identification of trends over time. In recent years they added social networking and privacy-related questions, for instance, and they also focused on digital participation and citizen interests. Another type of assessment was introduced by a team of researchers from the Catholic University of Louvain, Jerry Jacques, Pierre Fastrez and Thierry De Smedt, who analyzed media literacy competencies. They introduced a matrix definition

\footnotetext{
${ }^{6}$ See more on Ofcom's reports here: http://stakeholders.ofcom.org.uk/market-data-research/medialiteracy-pubs/
} 
of media literacy "that includes the ability to organize media objects from social perspective as a specific set of competences" (Jacques, Fastrez, and De Smedt, 2013, p. 42). They worked on digital media and collected data on Facebook. The method relied on card sorting tasks and it required subjects "[...] to group cards representing features from Facebook pages into piles, based on their similarity, according to criteria of their choice" (Jacques, Fastrez, and De Smedt, 2013, p. 42). Although the researchers found that their method needs simplification and that its practicality is limited, the card sorting technique allowed them to "elicit the subjects' ability to categorise and organise traces of mediated social interactions conceptually with respect to different social criteria, showcasing the relative richness and fineness of their understanding of this domain of experience" (Jacques, Fastrez, and De Smedt, 2013, p. 53). The researchers believe that their assessment could be the first step in trying to yield standardized performance based assessment methods and indicators. The UNESCO also developed a global framework for the assessment of media and information literacy (MIL). The assessment framework adopts two tiers: the first one is entitled Country Readiness, which provides information on a country's level of media and information literacy, and the second tier is called MIL Competencies, and it includes a matrix for assessing competencies at the individual and institutional level (UNESCO, 2013). The overall aim of this UNESCO framework is to provide methodological guidance and tools for the national adaptation processes of media and information literacy assessment (UNESCO, 2013, p. 19).

\section{Conclusion}

The aim of this chapter was to position media literacy in a broader theoretical context through the work of Jean-Jacques Rousseau and John Stuart Mill. Rousseau's views on education, as they were presented in Émile, were juxtaposed to media literacy education aims. The analysis revealed that the work of Rousseau is not as far-off from contemporary interests in media literacy education as one would expect. Mill's concept of utilitarianism was important to understand the value of media literacy education goals. If one would like to position Mill's ideas into current media literacy approaches, the conclusion of the analysis would be the following slogan: „better to be a dissatisfied media literate Socrates than a satisfied fool". The aim of the first part of this chapter was also to embed this thesis in an academic canon belonging to the field of reconstructive education. The work of Rousseau and Mill offered a strong theoretic 
basis for understanding the goals of media literacy education. This basis was also productive for analyzing the contemporary questions of media literacy that surfaced in the empirical part of this study. The second part of the chapter dealt with contemporary research approaches to media literacy education in Hungary and abroad. The international literature review was grouped according to the research directions drafted in those projects. The three groups were the following: research on the practice of media literacy education, media literacy from a policy-research perspective, and measuring media literacy competency. The Hungarian review displayed the relatively low number of research projects done in this field. This present work aims to fill in this gap by using a new research approach: critical discourse analysis. The methodology of the project will be presented in the next chapter. 


\section{Chapter 3: Methodology}

\section{Introduction}

Early on in this research project, when interviewing the first policy experts, it became clear that the traditional, quantitative approach to inquiry would not be appropriate to disentangle the history of media literacy education alone. Similarly, at the initial screening of the policy documents collected for analysis, the importance of the language itself used in these document became obvious. It was understood that the alternating way media literacy appeared in the policies, the concepts, aims and expected knowledge in connection with media literacy education, could best be examined by focusing on language use. Wallis $(2014$, p. 97) observed in his research that the "changing use of language is also an aspect of the reinvention of the way in which governments work." For these reasons, the project's methodology is embedded in the qualitative interpretivist tradition, and more specifically, the methods used belong to a new approach in policy studies: critical policy analysis.

Although quantitative approaches in social sciences are still strong, qualitative research is considered today a well-established and respected research approach. One of the consequences of its rising popularity is that it is more difficult to provide a simple definition for this type of research, since "qualitative research is no longer just simply «not quantitative research», but has developed an identity (or maybe multiple identities) of its own" (Flick, 2007, p. ix). Denzin and Lincoln (2005) provide an "initial, generic definition":

Qualitative research is a situated activity that locates the observer in the world. It consists of a set of interpretative, material practices that make the world visible. These practices transform the world. They turn the world into series of representations, including field notes, interviews, conversations, photographs $[\ldots]$. This means that qualitative researchers study things in their natural settings, attempting to make sense of, or interpret, phenomena in terms of the meanings people bring to them. (Denzin and Lincoln, 2005, p. 3)

The research undertaken for this thesis draws upon this qualitative tradition. Besides the above mentioned reasons, there were a number of other arguments in favor of 
qualitative methodologies. One of these can be best presented by Uwe Flick's argument (2007):

qualitative research often is not restricted to the production of knowledge or insights for scientific purposes. Often, the intention is to change the issue under study or to produce knowledge that is practically relevant - which means relevant for producing or promoting solutions to practical problems. (Flick, 2007, p. 6)

Similarly Denzin and Lincoln (2005, p. xvi) believe that “... qualitative research is an inquiry project, but it is also a moral, allegorical, and therapeutic project." The final aim of this present research is in this sense also practical. The goal of the thesis is not only to trace the development of media literacy education, but also to find answers which will further media literacy in Hungarian educational policy-making. Furthermore, as indicated in the previous chapter, this dissertation aims to strengthen the academic field of media literacy in the Central and Eastern European region.

The methodology adopted in this project can be broadly considered interpretivist. The interpretivist paradigm draws upon the work of Schultz and Garfinkel (phenomenology), the Chicago School of Sociology, and Boad and Malinowski (Cohen and Carbtree, 2006). For a more comprehensive understanding, it is important to highlight that the interpretivist approach was developed as a critique of positivism. Intepretivism is founded on the theoretical belief that reality is not a given fact, but rather a construction: "[...] what we know is always negotiated within cultures, social settings, and relationship with other people" (Cohen and Carbtree, 2006). In the same vein the interest in this project was to understand how policy-makers and experts make sense of their work and experiences, the policy texts they are creating and "how they express this understanding through what they do and -in particular- what they say" (Wallis, 2014, p. 96). For exploring these issues, the examination of the use of language used in policy-texts and the information gathered through expert interviews became the basis of this analysis.

The qualitative and interpretivist approach initially might seem to be in contradiction with classical educational policy studies, which were mostly influenced by positivism and post-positivism (Levinson, Sutton, \& Winstead, 2009; Nagel, 1984). The traditional view presented policy-making as a "deliberate process, undertaken by a known and bounded set of actors, who use research and reason to ensure the best policy outcomes" (Deim et al., 2014, p.1069). However, in the last three decades a growing 
number of policy researchers started using a new approach: they started focusing on critical frameworks. Diem et al. (2014) highlight the work of Ball (1991, 1993, 1994) and Stone (2002) who begin changing the common approach to policy analysis. Nevertheless, other researchers also critiqued the traditional toolkit in policy research, because they considered it limiting, and a too easy solution for all problems under investigation (Deim et al., 2014). One of the biggest divides between traditional research in educational policy-making and critical policy analysis is whether policy change and reform can indeed be planned and manageable. Diem et al. (2014, p. 1076) argue that critical policy analysis enables "a deeper critique of the contextual nuances and complexities of the policy process", and that the role of power and voice in policy processes is inescapable. In their interviews with leading scholars working in the field of critical policy analysis, Deim et al. (2014) found five fundamental group of scholarly investigations. In the first group they positioned those critical policy analysts that evaluate the contrast between policy rhetoric and reality. Another topic of interest to those working with critical methodologies is the roots and development of policies. In connection with this topic, researchers also analyze tools and processes that facilitate the institutionalization of policy. A third group of interest is how power and resources are being distributed. The fourth concern deals with the inequality and privilege in relation with the broad effects of policy. The last concern of critical analysts is how non-dominant groups resist processes of domination (Deim et al., 2014, p. 1072). This $\mathrm{PhD}$ disseration can be positioned in the group that focuses on the roots and development of media literacy in educational policy-making. Similarly to other scholars working with a deconstructivist frame, the research project is based on a framework that draws upon critical discourse analysis.

\subsection{Critical Discourse Analysis and Policy: The Research Framework}

Meutzenfeldt (1992, p. 4) defines discourse as: "the complex of [...] notions, categories, ways of thinking and ways of communicating that constitutes a powerinfused system of knowledge". In policy analysis the concept of discourse is used to examine "how political processes and policy-making shape and are shaped by both social power relations and the power of the state." (Taylor, 1997, p. 25) Another basis for working with critical policy analysis is Norman Fairclough's work. Fairclough discusses the relationship between "discursive practices, events and texts", and "wider 
social and cultural structures, relationships and processes" through which he explores the linkages between discourse, ideology and power (Fairclough, 1993, p. 135). Building on Fairclough's approach, this thesis will focus on the different discourses on media literacy that appear in education policies. Fulcher makes a similar point, when she outlines that policy can be seen as a "struggle between contenders of competing objectives, where language-or more specifically, discourse-is used tactically" (Fulcher, 1989, p. 7). Codd (1988) futher explains that policies are the outcomes of the political struggles over meaning:

Policy documents can be said to constitute the official discourse of the state. [...] Thus policies produced by and for the state are obvious instances in which language serves a political purpose, constructing particular meanings and signs that work to mask social conflict and foster commitment to the notion of universal public interest. In this way, policy documents produce real social effects through the production and maintenance of consent. (Codd, 1988, p. 237)

Thus for "uncovering" the Hungarian education policy-making process, I followed the footsteps of those scholars who recommend a "new set of tools" (Ball, 1990, p. 18) for understanding policy-making. I applied approaches that "have moved away from the notion of policy as a product (merely enshrined in a policy text) to one which focuses on policy as process" (Hyatt, 2013, p. 836). In doing so, David Hyatt's analytical framework was used (see Figure 2 below) that builds upon "a more linguistic element to supplement and elucidate critical educational policy analysis that draws on a discursive perspective." (Hyatt, 2013, p. 836). This framework comprises two elements: one that deals with contextualizing and one with deconstructing the policy.

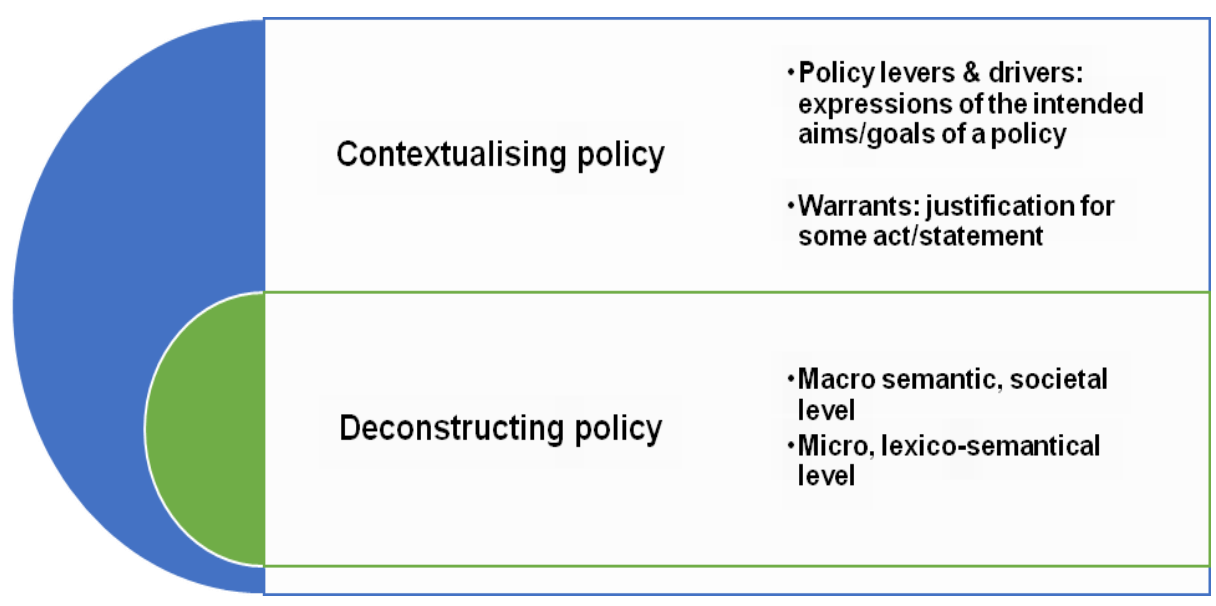

Figure 2: A model representation of Hyatt's analytical framework for critical educational policy analysis 


\subsubsection{Contextualising policy}

The contextualizing element is important in understanding the political and social context in which policy was made. Moreover, it is very important that education policy-making has to be placed within a broader economic, social and historical context. The framework thus follows Codd's (1988, pp. 243-244) argument who highlights that: "Policy documents [...] are ideological texts that have been constructed within a particular context. The task of deconstruction begins with the recognition of that context." The contextualization component is composed of two elements: policy levers and drivers - these refer "to expressions of the intended aims or goals of a policy" (Hyatt, 2013, p. 838) - and warrants, or "the justification, authority or «reasonable grounds» established for some act, course of action, statement or belief' (CochranSmith and Fries, 2001, p. 4) According to Hyatt (2013) levers aid policy-steering, being instruments 'the state has at its disposal to direct, manage and shape change in public services... functional mechanisms through which government and its agencies seek to implement policies' (Steer et al., 2007, p. 177). In educational settings, these levers can be target-setting, funding, inspection etc. (Hyatt, 2013). As another important element of contextualization, warrants provide justification for policies. The construction and the debate of policy happen through language and thus they are discursively meditated (Hyatt, 2013). Cochran-Smith and Fries (2001) identify three types of warrants: evidentiary warrants, accountability warrants and political warrants. The evidentiary warrant is "the establishment of a position based on evidence" (Hyatt, 2013, p. 839). This warrant is based on the commonly accepted view that if a justification is based on evidence, it is undisputable. The CDA-approach can help us in highlighting that facts, research figures, findings are never neutral: they are always constructed (Hyatt, 2013). The accountability warrant on the other hand, emphasizes results and outcomes. In policy-making, this type of warrants focus on what the results will be, if a specific policy will be adopted (e.g. initiatives that aim to improve standards). And finally political warrants "refer to the way in which a policy is justified in terms of the public/national interest, the public good" (Hyatt, 2013, p. 839). 


\subsubsection{Deconstructing policy}

The second component of the analytical framework deals with a fine-grained textual analysis: deconstructing the policy. This component engages with text and discourse using a number of analytical lenses and tools derived from Critical Discourse Analysis, CDA, (Fairclough, 1995) and Critical Literacy Analysis (Hyatt, 2005). For a more thorough understanding of the tools used in this analysis, it is important introduce some aspects of Norman Fairclough's social theory of discourse. By discourse, Fairclough means primarily spoken or written language. When he is referring to language use as discourse, he talks about "a form of social practice" (Fairclough, 1993, p. 131). Fairclough argues that language "is socially shaped, but it is also socially shaping, or constitutive. [...] Language use is always simultaneously constitutive of (i) social identities, (ii) social relations and (iii) systems of knowledge and belief [...]" (Fairclough, 1993, p. 131). The value of using CDA for this thesis is thus the opportunity to analyze social practices and processes, such as policy-making, from a semiotic point of view.

When it comes to the macro semantic level of the deconstruction, Hyatt uses a number of criteria borrowed from critical discursive approaches in analyzing policy texts: modes of legitimation, interdiscursivity and intertextuality. Legitimation in this type of analysis means attaching values and norms to policies so to justify them. Hyatt (2013) uses Fairclough's four main modes through which legitimation is accomplished in discourses: authorization (reference to tradition or authority), rationalization (reference to a social action's usefulness), moral evaluation (reference to what is considered bad or good) and mythopoesis (moral advises on the positive or negative outcomes of certain actions). Interdiscursivity and intertextuality is again borrowed from Fairclough. He uses interdiscursivity to describe "the normal heterogeneity of texts in being constituted by combinations of diverse genres and discourses" (Fairclough, 1993, p. 134). Intertextuality is defined as borrowings from other texts as a means for supporting claims or reinforcing arguments (Hyatt, 2013).

Finally, the last element of the framework deals with the micro lexicosemantical analysis of the texts. In this analysis, one can use criteria such as evaluation, presupposition/implication and lexico-grammatical constructions in deciphering policy texts. Evaluation can be used in when analyzing a "speaker or writer's attitude or stance 
towards, viewpoint on, or feelings about the entities or propositions that he or she is talking about" (Hunston and Thompson, 2000, p. 5). Hyatt (2013, p. 841) explains that evaluation can be carried by words, such as excellent or terrible, but it can be also carried by "superficially neutral choices [...] but which have the potential to evoke judgemental responses" (such as the use of reform, deregulation, innovation in policy texts). And finally, prepsupposition/implication and lexico-grammatical constructions are both tools in textual analysis. For instance, the use of change of state verbs (the government has modified unfair policy) presupposes or implies "the factuality of a previous state" (Hyatt, 2013, p. 842). Similarly, specific lexico-grammatical constructions aid in understanding how reality is constructed. In this instance, the specific use of pronouns ( $u$ s versus them), voice and tense, or figures of speech can be revealing in terms of rhetorical constructions. The above mentioned elements became thus the building blocks in the analysis of Hungarian education policy.

\subsection{Empirical data}

The textual data for this analysis comes from three sources: (1) the National Core Curricula, (2) the frame curricula, and (3) the Act on Public Education ${ }^{7}$. For a more refined understanding of the policy, these findings were then corroborated by information gathered through expert interviews. For broadening the context of these policies, yearly official education reports (Jelentés a magyar közoktatásról) were also examined. These reports proved to be especially valuable since they provided "a comprehensive analysis of the development of education" (Lannert, 2004), and over the last twenty years they "contributed to the predictability, rationality and quality of education policy process" (Lannert, 2004). It is important to note that these reports were not analyzed with the help of the CDA-framework presented earlier; these were used for contextualising the findings.

\subsubsection{Empirical data: policy texts}

The selection of data begun with education documents dated in 1995 (the year when the first National Core Curriculum of the newly democratic country was adopted) and continued up to the latest National Core Curriculum which was ratified in 2012.

\footnotetext{
${ }^{7}$ A full list of the analyzed official documents can be found in Appendix A.
} 
The reason behind this choice was that the Culture of the Moving Image and Media Education subject was introduced in the $1995 \mathrm{NCC}$, and the latest changes in media literacy education were instituted in 2012. Data collection has involved first the quest for the NCCs: some of the documents were easily obtained online, mainly on the website of the Hungarian Institute for Educational Research and Development (Oktatáskutató és Fejlesztő Intézet). Each NCC and framework curricula were closely read and examined to find all references to media literacy education. All those texts that corresponded to what today is considered the discursive territory of media literacy were included. In some cases these policies were not labelled as media literacy (for instance those adopted in 1995). However the education goals (such as for children to become critical TV viewers) outlined in those texts belong today to the discursive territory of media literacy, and thus these policies were also added to the corpus. Besides selecting the specific fragments referring to media literacy education, the general introduction of all documents were also analyzed since they aided understanding the education policies. Moreover, these introductory parts were important for policy contextualisation.

Therefore, the following policy documents construct the corpus of this analysis: the Public Education Act (1993, and its subsequent amendments) governmental decrees regulating the National Core Curriculum (1995, 2003, 2007 and 2012), and the framework curriculum decrees (2000, 2003, 2007, and 2014). For complementing and contextualising these educational documents, parliamentary motions and committee meeting minutes ${ }^{8}$ have also been collected. In addition to these official governmental documents, I also searched for documents written by governmental stakeholders on media literacy. These documents were not easily found, a simple search on the internet did not prove to be enough. In this quest I was helped by those involved in policymaking. The interviewees pointed out specific events or writings of political actors that discussed the topic of media education. Unfortunately, we cannot talk about a great number of such materials. There are only a few articles in which politicians discuss about media literacy, and these are mostly specific speeches delivered, for instance, at conference openings. As with the yearly education reports, these articles were used for

\footnotetext{
${ }^{8}$ These documents have been collected from the website of the Hungarian Parliament by searching for various key words in connection with the topic of this research project (e.g. national core curriculum Nemzeti alaptanterv, public education law - közoktatási törvény, media literacy - médiatudatosság, etc.). The various committee meeting minutes and motions (1994-present) can be found on this website: http://www.parlament.hu/iromanyok-elozo-ciklusbeli-adatai
} 
understanding the context of policy-making, and the framework of analysis presented earlier was not applied on these texts.

\subsubsection{Empirical data: expert interviews}

Apart from the analysis of policy documents, the research involved a series of interviews with experts. These interviews were important in terms of methodology for a deeper understanding of the empirical data. Moreover, these discussions offered a broader appreciation of how the different processes, both governmental and interpersonal, shaped the policies. The term expert is used to represent those actors who in one way or in other could influence the policy process, and more specifically education policy-making. This sample includes academics, teachers, research fellows and pedagogical developers working at the Hungarian Institute for Educational Research and Development. The interviewees were mostly in charge with developing media literacy curriculum in the last twenty years. Two political actors were also interviewed during this research project. These two actors can be considered elites. However, in methodological terms there are no fundamental differences between expert and elite interviewing. Littig (2009) highlights that the central themes, such as the problems of getting access, the specifics of the interactions and the interview process overlap in these two methodological traditions. Therefore, Littig (2009, p. 100) contends that "interviews with the elite aimed at generating explicit, tacit, professional or occupational knowledge should be seen as expert interviews." Thus, for the purpose of this thesis, I considered the two elite political actors as belonging to specific group of experts. I could easily access most of the interviewees, usually through an email or phone call, or by approaching them at conferences. I had no problem in tracing people, the email addresses could be found on websites. Nine prominent actors were finally interviewed (see Appendix B for a full list).

The general literature on interviewing experts highlights the value of this type of interviewing:

[...] documentary evidence cannot simply be understood at face value. The story behind the production of each document needs to be probed and analysed, and the contents need to be triangulated against data from other documents and other forms of evidence. It is also always necessary to remember that there is 
never one objective reality to be discovered, but a range of competing perspectives that interact and intersect with each other. (Walford, 1994, p.

Among the other advantages of expert interviewing, Van Audenhove (2007) outlines the fact that experts have high insight in aggregated and/or specific knowledge on policymaking processes, group behaviors and strategies. He also emphasizes that experts are often networked persons who can help in finding other interviewees. Moreover, experts are usually motivated persons, engaged in the topic, who are often more willing to cooperate and exchange (Van Audenhove, 2007). These features proved to be accurate in this project too: the interviewees were open and involved in the topic. The fact that they were indeed networked people helped me in finding further interviewees. In using a snowball method, I asked them whether they can appoint other actors who could offer different insights, and they readily did.

It was somewhat a surprise to me that the interviewees were ready to discuss more sensitive aspects of policy-making too, such as the different political interests influencing educational policies. And this leads us to one of the critiques of this method: expert knowledge is never neutral. As Van Audenhove (2007) notes experts are part of the societal debate, they have direct or indirect decisional powers. The fields in which they are working are also not neutral, since the educational field is deeply entrenched by power relations (Van Audenhove, 2007). For overcoming these issues, I paid attention to the selection of experts (e.g., I interviewed experts working during periods when different political parties were in office). I also considered and re-considered the interpretation of the interviews.

One of the strengths of this type of interviewing is that the knowledge shared by the experts runs through three dimensions (Van Audenhove): there is a technical knowledge on specific operations, laws; there is a process knowledge on routines and interactions; and lastly there is an explanatory knowledge, a subjective interpretation of policy-making. During the interviews these three dimensions frequently overlapped: for instance when asked about how different groups in the Hungarian Institute for Educational Research and Development work, interviewees could explain in detail not only the specific policies, but also the work processes. The experts then gave insights to how they interpreted these. 
When it comes to the disadvantages of expert interviewing, critiques highlight on one hand the fact that was already discussed, and namely that the knowledge is not neutral. While one cannot argue against it, what I could do is to take into consideration this critique and approach interviewees and interview texts without letting this information out of sight. On the other hand, some also highlight that in expert interviewing the effects of interaction between researcher and interviewees can be rather high. The reason for this are: the procedures used to interview are not rigorously standardized, the dialog is open and the interviewer actively participates, there is a danger of getting only illustrative information, and that these interviews are not intersubjectively repeatable (Van Audenhove, 2007). In a defense against these critiques, I used semi-structured interviews in which the basic questions were the same for each participant, which allowed a certain standardization of the process. The interviews then contained some specific or on the spot, improvised questions as well, depending on the interviewee's position and involvement in the process of policy-making. This way I could also provide useful and relevant information, and not "illustrative" information. For not losing track and obtain all the relevant information, a number of themes were prepared beforehand. One more shortcoming to expert interviewing is quite specific to post-Communist regimes. Rivera et al (2002) observe that there are particular challenges that have methodological consequences for researchers due to the instability of the institutional structures. Similarly, the less formalized role definitions in the political sphere can also pose problems. Neumann (2011, p. 231), in writing about her experiences in interviewing Hungarian policy-making experts, concludes that there is a "[...] paradox of the institutionally constrained role interpretations within an uncertain state bureaucracy facing changing expectations." The institutional context and the ambiguous power relations between the researcher and the interviewees influenced the dynamic interplay in the interviews for this project as well. This was mostly true with those interviewees who were the main actors when Culture of the Moving Image and Media Education was introduced back in 1995. Similarly to Neumann (2011, p. 225) and her team's experience, I also met the "inaccessible politician" (who offered a short 30-minute-long interview), the "reflexive transgressor, social scientists who temporarily crossed the boundary between science and politics", and also the "gate openers", who were happy to talk about their experiences. As it is with most expert interviews, in all of these cases it was utterly important to adapt to the situation and negotiate the power 
relations. In most of these cases, this was successfully done, and the interviews produced relevant information.

When it comes to the practicalities of interviewing, I arranged interviews either in person or by Skype or email. In some instances, I also arranged follow-up interviews in order to clarify or ask for further comments on specific policies. Virtual interviews were both time saving and had an economic side to it. Although live interviews do have clear advantages that no one can deny, virtual interviews had the advantage of being free from formalities, and interviewers were free to choose whenever they wanted to answer my questions. Before the interviews, I sent a short description of the project in which I highlighted reasons for contacting the specific interviewee. All those who agreed to be interviewed were then asked whether they allow to be recorded for transcription. There were no serious inhibitions on part of the interviewees, only one asked to see his quotes if I decided to use them in my writing. The only problems I encountered during interviews what the problem of memory when it came to the events from the mid-1990s. In retrospective interviewing subjectivity, ephemerality and partisanship can be seen as major problems (Turnbull, 2000). Therefore, during these interviews, I tried to pinpoint factual inconsistencies, to challenge some assertions, to re-ask specific questions or to highlight problems of coherence. Adding to this, information gathered through one interview was then cross-checked in other interviews, documents or media reports. However, several scholars argue that there is no "single fixed «truthful» account of policy formation" (Selwyn, 2013; Thompson, Frisch and Hamilton, 1994). What one can do then is to approach data coming from retrospective interviewing with caution, and to use secondary sources as basis for comparison and cross-checking (Selwyn, 2013).

\subsection{Limitations of the study}

All studies and research project have certain limitations. This thesis is not different in this sense, and I find it important to list these in order to critically approach my own work. One of the major challenges was language. All policies and other texts were in Hungarian, as well as almost all interviews were carried out in Hungarian. For the purpose of this project, it was necessary to translate the relevant parts into English. The translation might have possibly brought along some loss in meaning. In trying to 
overcome this, it was relevant to fully explain the context, so it would be comprehensible for those who do not speak Hungarian as well.

The topic of language brings us to the limitations of the analysis: a framework based on critical discourse analysis will most probably find its critics. As Martin and Wodak (2003) righty observe "CDA has never been ... one single or specific theory" and neither "is one specific methodology characteristic of research in CDA" (Martin and Wodak, 2003, p. 5). Among the most frequent criticisms is that critical discourse analysts are highly selective in what they choose to describe, they over-interpret specific aspects and under-represent others (Widdowson, 1998). In this dissertation though it was quite clear the selection of empirical date: I analyzed those fragments and texts from educational policies that specifically dealt with media literacy, either explicitly or by reference. When it comes to interpretation one has to highlight that CDA is a hermeneutical discipline, and thus it will probably deal with one of a number of other alternative readings (Wallis, 2014, p. 110), though I focused on giving as many evidence from the texts as possible to support each of my claims.

Finally one of the most common critiques of those using CDA, and furthermore those using CDA in policy analysis, is that they pursue an agenda of their own. As Carol Bacchi (2000, p. 46)) puts it:

In the main, policy analysts who describe policy-as-discourse have at some level an agenda for change. They tend to be political progressives, loosely positioned on the left of the political spectrum. They define discourse then in ways that identify what they see to be the constraints on change, while attempting to maintain space for a kind of activism. Their primary purpose in invoking discourse is to draw attention to the meaning making which goes on in legal and policy debates.

While I cannot say that I pursued an agenda through this study, I cannot deny that I do hope that this project can bring along some kind of change in Hungarian educational policy-making in terms of media literacy education. Because just as Finch (1984, p. 231) says: "one important implication of policy-oriented qualitative research is that it has the potential for engaging the researched as well as the researcher in evaluating the status quo and bringing about change". The conclusions and recommendations 
presented in the last chapter of this dissertation might be considered as a personal reflection on what could be changed in Hungarian media literacy education.

\section{Conclusion}

This chapter presented the methodological aspects of the study. The chapter started with a brief introduction of qualitative research and then turned to introducing relevant aspects of critical policy analysis. I then expanded on the analytical framework used in analyzing policy texts, its structure and composing elements. The most important feature of this type of critical analysis is that it adds depth to exploring educational policies in a historical context. The particular structure of the framework helped in reflecting how both macro, societal and micro, lexico-grammatical elements influenced discourse on media literacy over the years. In this chapter the two main kind of data was also presented: policy texts and expert interviews. While policy texts have been analyzed with the help of the analytical framework, expert interviews were used as complementary and contextual evidence and as a means for triangulation. The chapter ended with a discussion on the limitations of these methods. After presenting the methodological aspects of the dissertation, the next chapter will introduce the second part, and namely the empirical study. 
PART TWO

The empirical study 


\section{Chapter 4: 1995 - the breakthrough year for media literacy education}

\section{Introduction}

The national core curriculum of 1995 emerged in a tumultuous period of political and social changes. Before analysing the media literacy content, it is thus imperative to describe the political situation, which greatly influenced the first national core curriculum of the newly democratic Hungary. I will briefly introduce the main political events of the 1990s, and then turn to present how they influenced educational policy-making. This initial step is crucial in contextualizing and understanding policy levers, drivers and warrants, as defined by Hyatt's framework (2013). I will then analyse the content dealing with media literacy in the National Core Curriculum. The chapter will end with a discussion on how this initial democratic period was to become crucial in the history of media literacy education in Hungary.

\subsection{Political landscape}

The 1980s meant mostly a pushback of the paternalistic style of government as "the role of ideology in legitimation all but disappeared" (Körösényi and Renwick, 1999, p. 9). The régime introduced a series of reforms, which helped its selflegitimation, but societal and economical control relaxed. The Communist system eventually collapsed in the end of 1989: the regime change in Hungary had a somewhat „élite character”, since in comparison to Romania or Poland, or other Central and Eastern European countries, there was no bloodshed during mass demonstrations. Historians and political analysts highlight that the Hungarian communist regime fell mainly because of an internal decay, the pressure of the emerging political opposition and the influence of internal reformers (Körösényi and Renwick, 1999, p. 23). After the last congress of the Communist Party in October 1989, the series of events led eventually to the total demise of communism.

By the early 1990s there were three important political camps: the liberal (Szabad Demokraták Szövetsége, SZDSZ; Fiatal Demokraták Szövetsége, FDSZ), the socialist (Magyar Szocialista Párt, MSZP), and the national-conservative/Christian camp (Magyar Demokrata Fórum, MDF; Független Kisgazdapárt, FKGP; Kereszténydemokrata Néppárt, KDNP). In the 1990 elections, the MDF won with 
$24.73 \%$ of the votes, and it formed a centre-right coalition (with KDNP and FKGP) and was the leading party for the following four years. The next elections brought a serious defeat for the MDF: the MSZP-SZDSZ coalition won, with MSZP taking 32.99\% of votes (Gábor, Levendel and Stumpf, 1994, p. 474). The last elections of that decade resulted in yet another major change: Fidesz-MPP took over MSZP. (Magyar Közlöny, 1998).

Public education faced major changes due to the political transformation of the country. Among them, the changes in the structure of elected bodies, the importance of newly formed professional bureaucratic institutions, and the new role of municipalities and the civil sector can be considered the most important (Halász, 2001).

Another important element of the political landscape in this period was Hungary's application for a full membership to the European Union (EU) on March 31, 1994. Hungary was the first country of the former Soviet bloc to formally apply for joining the EU (Böröcz and Kovács, 2001). However, it is necessary to add that in the first period, the economic and political spheres were the ones mostly influenced by these developments. A stronger effect on public education and consequently the main policies governing the area of education could be observed later on in the beginning of the 2000s.

In terms of the economy, at the end of the 1980s and throughout the first years of the 1990s, Hungary faced its biggest recession since the Second World War: almost one-third of those employed lost their jobs. The economic recession (and its adjacent processes: low public spending, inflation, etc.) deeply influenced the education sector as well (Halász, 2001). A return to a stable economy was only possible in the later part of the 1990s.

\subsection{Politics and educational policy-making}

When examined in detail, throughout the last 30 years changes in political life were followed closely by changes in educational policy-making. Zoltán Báthory, pedagogue and educational scholar, highlights in his book The Marathon Reform (Maratoni reform) that the reform of the Hungarian educational system can be traced back to the 1972 Party Resolution. According to Báthory, "irrespective of the content of the Resolution, or the proportion of novel versus backward statements, its importance can be measured by its influence on public education" (Báthory, 2001, p. 14). Following 
the Resolution, in 1973 the so-called Main Research Direction Number 6 (Országos Távlati Tudományok Kutatási Terv 6. számú föirány) approach was developed. The Main Research Directions were important themes that were to be closely monitored and researched. In 1972, initially there were only five subjects: Research on solid bodies, Mechanisms of life process regulation, Complex scientific assessment of administrations research, Socialist enterprise and Research on biologically active compounds. After the Resolution, however, research on the development of public education was also added to these themes. Consequently, a major reform was implemented that resulted in the 1978 national curriculum.

In the 1980s, the changes in the political system became visible in public education as well. The three main notions influencing public education during that period were autonomy, decentralisation and alternative teaching (Báthory, 1994). In parallel with a relaxation of the regime's grip, there were more and more pedagogues and educational scholars questioning rules coming from "above", and there were more and more teachers experimenting with alternative pedagogies. The alternative road became "legal" with the passing of the 1985 Law on Education that allowed the existence of kindergartens, schools and pedagogies that followed alternative educational models.

With the political turn, in line with the three main political camps of the early 1990s, three distinct view of educational policy came to the fore: the conservative, the liberal, and the socialist-social democrat (Báthory, 2001, p. 93). While at the very beginning of the 1990s there was a strong sense of cooperation in the field of education, this cooperation disappeared and the main political camps had quite polarised views on how the Hungarian educational system should progress:

The roller-coaster movement of educational policy-making and pedagogy of the 1990s and its discharges can be best exemplified by the story of the national core curriculum. [...] The national core curriculum gave rise to debates, conflicts, conspiracies, radio and TV round tables. Squibs, pamphlets and even poems were written on this topic. (Báthory, 2001, p. 131)

These conflicts resulted in a total of six (!) national core curricula between 1989 and 1995. 
The first NCC was presented to professional circles in May 1990. In contrast with the previous NCC of 1978, this new document was intended to break with centralisation and was aimed at introducing a new concept: the minimum curriculum. The minimum curriculum was proposed as a foundation for the development of schoolbased curricula, taking into consideration the specific needs of each school. The new document was heavily criticised.

As a result a new NCC was drafted by the spring of 1991. However, the second version was not accepted either. Thus a third NCC was presented at the beginning of 1992. This NCC introduced the concept of development areas and the requirements were determined according to specific school periods. A strong conflict was on the way between those arguing for modernisation and those who wanted to continue a more conservative line in education. Zoltán Báthory believed that the controversy surrounding the national core curriculum was, in part, influenced by the radicalisation of the governing conservative party (MDF) and the media wars ${ }^{9}$ (Báthory, 2001, p. 143).

As a consequence, a fourth national core curriculum was developed by the ministry of culture and public education. This new NCC was built on a new system, and it introduced a three level regulation: the core curriculum, the framework curriculum and the local school curriculum. This new NCC was not accepted either, and NCC number five was on its way when in 1994 a new government was installed. The MSZPSZDSZ government asked for a sixth version of the national core curriculum. This version was finally accepted and its implementation started in 1996. NCC 6 did not last long though: with the Fidesz victory of 1998, the Law on Public Education was amended. The two-level regulation (NCC and school curricula) was discarded, and framework curricula were again reintroduced. Zoltán Báthory (2001, p. 163) believes that "the mistakes of the NCC's introduction, the reform tiredness of pedagogues, the bad economic situation of the country, the conflicts between educational researchers [...] led to the new central-right government's easy halt of reforms and to an early retirement of the National Core Curriculum."

\footnotetext{
${ }^{9}$ The regime change was followed by a very turbulent period in Hungarian media history. The media wars (médiaháború) phrase refers to conflicts that arouse between different political actors, governments, and journalists after the political transition. There are many topics in connection with the media wars. Some of the most important: the political influence over the media, the lack of lustration after the 1989 regime change in the media, the independence of journalists and so on. For a more thorough description of the media wars, see Vince Paál (ed.), 2013. A magyarországi médiaháború története. Média és politika 1989-2010.
} 
Similarly, Gábor Halász (2001) considers the NCC implementation the most important event in public education and in the internal operation of schools. According to him, the biggest contradiction was to be found between the very modern curriculum approach of the NCC and the existing school mechanisms (Halász, 2001). As Török (2015) observes, a sort of management naivety led policy-makers and politicians alike, in believing that the Anglo-Saxon education model can be transplanted into the Hungarian public education without major problems. One of the consequences of this belief was that the major actors fervently referred to an implementation deficit, highlighting that the education system is too conservative and it resists change (Török, 2015). Furthermore Halász believes that the developments did not lead to the establishment of complex pedagogical programs (e.g. subject descriptions that also present applicable teaching materials, guide books or other training materials.) For our purpose, it is important to mention one of Halász's comments:

Although there were smaller or bigger initiatives almost everywhere, there were no truly significant, publicly funded programs on such priority areas as foreign language education, early development of communicational and cooperative skills, civil education, preparation for the world of media and consumerism, science education or environmental studies. (Halász, 2001, p. 35)

Besides the political parties, some new actors also shaped developments in this period in the field of education. Among these the two most important actors were the World Bank and the European Community. Their role was more pronounced in higher education and vocational education though (Halász, 2011).

In this short and condensed history of the Hungarian educational landscape of the 1990s, it becomes clear that public education was turned into a political battlefield. This can be understood as one of the consequences of the regime change. During the Communist period, the one existing political center was powerful enough to override all other social arenas. However, the restructuring of the political reality, and the "liberation" of the social subsystems had major consequences for the sphere of education as well. Halász (2001) similarly observes that the first ten years of democracy did influence in many ways public education. Nonetheless, he believes that changes were less radical than the political rhetorics and the fierce professional debates of that time would indicate. The story of Hungarian NCC could be a great example for to what 
Ball and Bowe are referring to when discussing whether a national core curriculum can reflect an unambiguous position of the government:

[...] policy process is a good deal more complex than this and that there is a dialectical process in which the 'moments' of legislation [...], documentation $[\ldots]$ and 'implementation' [...] may be more or less loosely coupled. Policy texts are not closed, their meanings are neither fixed nor clear, and the carryover of meanings from one policy arena and one educational site to another is subject to interpretational slippage and contestation. (Ball and Bowe, 1992, p. 98)

\subsection{Contextualizing policy on media literacy education}

For understanding how media literacy was contextualized in the first NCC after 1989, I will first analyse two aspects: policy levers \& drivers and warrants. The levers and drivers deal with the specific aspect of what are the aims of a certain policy document and how these goals can be reached by specific instruments the state has at its disposal (such as target-setting, inspection or funding).

What was very specific for the 1995 curriculum was the two-level regulation model that was introduced in contrast with the centralised model known during communism. The new model had two building blocks: 1.) the NCC that defined basic requirements in ten subject areas and 2.) the detailed local curricula, which was a "school-level document that directly regulated teachers' classroom level work and which had to be developed by each school" (Halász, 1998, p. 48)

Media literacy, as such, is not mentioned in the NCC. This is not at least surprising since the term "médiatudatosság" (media literacy) or "médiamüveltség" (media culture) has only just recently, in the last five to ten years, gained recognition in Hungary. In the 1995-NCC the term used is "médiaismeret" (media knowledge or media education). Media education appears for the first time in the chapter on the NCC's ten subject areas, and within that in the Arts subject area. 
1. Mother tongue and literature

2. Living foreign language

3. Mathematics

4. Man and society: Societal, civic and economic knowledge, People skills, History

5. Man and nature: Natural science, Physics, Chemistry, Biology and Hygiene

6. Earth and environment

7. Arts: Literature, Music, Dance and Drama, Visual Culture, Culture of the Moving Image and Media Education

8. Informatics: Computer science, Library education

9. Home and practical knowledge: technology, home economics and management, career orientation

10. Physical education and sports

Figure 3. Subject areas of the National Core Curriculum

Although media literacy as a term does not appear in the NCC, we can spot a very important policy lever in connection with it in the common requirements. All subject areas have a number of common cross-curricular requirements. These requirements have to appear in all levels of public education, according to the NCC. There are seven common requirements (certain knowledge areas that should appear in all subjects): 1) Homeland studies (Hon- és népismeret), 2) Connections to Europe and the Wider World (Kapcsolódás Európához és a nagyvilághoz), 3) Environmental Education (Környezeti nevelés), 4) Culture of Communication (Kommunikációs kultúra), 5) Physical and Mental Health (Testi és lelki egészség), 6) Learning to Learn (Tanulás), and 7) Career Orientation (Pályaorientáció). Among these, the specific lever in connection with what we call now media literacy appears in Culture of Communication:

Today, the vast majority of information is not addressed to us personally, but through intermediary artificial systems. The massive, passive consumption of 
information could lead to a distortion of living and thinking. Therefore, the schools must educate the youth to understand and be selective about the new audiovisual environment. (NCC, 1995)

This text signifies a very important milestone in the history of media education in Hungary: only few years after the 1989 events, and the curriculum experts already highlighted that one of the goals of the national core curriculum should be to have media literate pupils.

For understanding this goal thoroughly, it is important to see what levers were at that time accessible to the Hungarian government. According to Hyatt (2013) levers aid policy-steering, being instruments "the state has at its disposal to direct, manage and shape change in public services... functional mechanisms through which government and its agencies seek to implement policies" (Steer et al. 2007, 177). The 1995 NCC presented a very different approach to education, compared to previous educational customs. It was intended to be a minimum curriculum, a basis for framework curricula and other educational programs. The NCC (1995) explicitly highlights that in the framework curricula, in the local programs and in teaching materials:

[...] it is mandatory to validate the key principles, to integrate the subject areas, the sub-areas and the indicated topics. [It is mandatory] to have educational materials and activities that can be the basis for reaching the general and detailed development requirements. These documents [the curricula, programs and materials] have to provide the professional conditions for every student to be able to know the minimal requirements. (NCC, 1995)

The levers accessible for the government are thus the minimal requirements as stipulated in the NCC. Furthermore, the NCC defines broad subject areas, instead of traditional academic subjects and it only presents the proposed distribution of teaching time between them. For the Arts subject area (where the Moving Image Culture and Media Education subject is listed), the percentage is somewhat higher for primary and lower education (12\%-16\%) and a bit lower for grades 7 to $10(9 \%-12 \%)$.

However, the framework curricula and the local programs had to follow the NCC's indications. Furthermore, the 1993 Act on Public Education stipulates that the 
National Core Curriculum can "present compulsory provisions in how public education is being organized, specifically in limiting the weekly and daily workload of pupils." (1993, p. 4) All other information on targets, funding, inspection etc. can be found in the 1993 LXXVI Act on Public Education. The Act and the NCC together were thus strong instruments in directing change in public education.

As another important element of contextualization, warrants provide justification for policies. The construction and the debate of policy happen through language and thus they are discursively meditated (Hyatt, 2013). Cochran-Smith and Fries (2001) identify three types of warrants: evidentiary warrants, accountability warrants, and political warrants. For the first new National Core Curriculum, the political warrant stands out. As presented in the previous section, the NCC became the battlefield for fierce political clashes between the different governments and parties. The long and divisive debates surrounding the NCC introduction led to widespread uncertainty in the sphere of public education. This uncertainty was coupled with a more general feeling of social unrest in many other areas of the public realm after the regime change. However, when there was no further possibility to delay the introduction of the NCC, the ruling political actors were forced to make a decision, and face the lasting opposition of political adversaries (Török, 2015). It is no wonder then that the final, $1995 \mathrm{NCC}$ was being thus justified in terms of education for a 'good society' (a society that is interested in the welfare of everybody, and a commitment towards the best social values):

The NCC requirements are defined by values formulated in the Constitution, the preamble of the Act on Public Education, in certain international conventions on fundamental human rights, freedom of conscience and freedom of religion, and [values of] public education, children's rights, and rights of national and ethnic minorities. These values are complemented by the European development of civic values, scientific-technical progress, and the domestic cultural values and pedagogical traditions. (NCC, 1995) 


\subsection{Deconstructing policy}

In the following I will focus on analyzing the policy concerning media literacy education from a macro semantic and societal level, and then turn to the micro, lexicogrammatical level. Since the "[...] key aim of critical approach to analysis resides in attempts to uncover the process of naturalization in any discourse" (Hyatt, 2013, p. 840). I will present a number of relevant aspects regarding media literacy that can be discovered by using analytical lenses and tools derived from CDA.

\subsubsection{The macro semantic level}

When it comes to policy analysis it is crucial to shed light on how governments justify their actions. Policies are frequently justified by attaching them to dominant norms (Hyatt, 2013). According to Fairclough (2003) there are four modes to accomplish legitimation discursively: authorization, rationalization, moral evaluation and mythopoesis (legitimation through narratives). The legitimation of the National Core Curriculum is positioned in the introductory part of the document. In analysing this fragment, it is telling that the authors of the NCC combine two modes of legitimation: authorization and moral evaluation. The very first sentence is: "The NCC is the fundamental document of Hungarian public education as it was laid down in the -successively modified- 1993 Act no. LXXIX" (NCC, 1995). The authors reference here another law as justification. When it comes to moral evaluation the authors of the NCC make reference to such values as fundamental human rights, freedom of conscience and religion, children's and minority rights, etc. The discourses found in the first NCC after the regime change are linked to discourses about the importance of democracy: "The NCC requirements are permeated by the values of democracy" (NCC, 1995). The value system that is presented in the NCC includes references to national values (national traditions, development of national self-identity, etc.), European values and the future common problems facing humanity. It is very important to note the order of these values: starting with democracy, then national values and lastly issues of humankind. With only six years after the political turn, this sequence is not surprising: policy-makers focus on the new values important to the political system. It is interesting to compare this finding to the order of values that 
appear in the latest, 2012 NCC. In the latter, national and family values come to the fore, while universal values are only mentioned once in the introduction of the core curriculum.

Another important element important in analyzing texts from a macro, societal level is evaluation. According to Hunston and Thompson, evaluation is the "the expression of the speaker or writer's attitude or stance towards, viewpoint on, or feelings about the entities or propositions that he or she is talking about" (2000, p. 5).

Further on evaluation can be inscribed or evoked (Martin, 2000). Inscribed evaluation presents the unconcealed opinion of the authors, while evoked evaluation uses neutral choices. In case of the NCC, one can find both inscribed and evoked evaluation. One example of inscribed evaluation comes up when the authors highlight that the new NCC is a "unitary foundation" (NCC, 1995) for preparing framework curricula, pedagogical programs and local curricula through its "modern combination of basic educational content and competencies to be developed" (NCC, 1995). Evaluation in this case is overtly constructed. Meanwhile there are a number of phrases which fit into the evoked category: "[the NCC] gives an opportunity for the enforcement of school operators', parents', and pupils' values and interests, for the enforcement of pedagogues' professional pursuits, as well as for taking into consideration the existing situation, conditions and opportunities" (NCC, 1995). The message here is clear: the new NCC takes into consideration the needs and interests of those directly impacted by its adoption. The ideological value behind this phrase is then that the NCC is a unitary document that supports differentiation. Similarly we can find evoked evaluation in the following phrase: "The values of the NCC, the unified and basic requirements and the differentiation built in these, serve the purpose of [...] the pupils' personal development" (NCC, 1995). The underlying evaluation here is that the new document is child-centred. This perspective is then further strengthened by inscribed evaluation as well. In terms of evaluation thus, what comes across from this introductive part of the NCC is that the new curriculum is indeed new because it "breaks away" (NCC, 1995) from older regulations, it is "modern", it takes into consideration the schools' and pupils' existing conditions and it has as a main task to serve personal development.

A further aspect of analysis is the use of presuppositions or implications, when the authors apply different devices to represent constructions as true propositions. Negative questions and tags, factive verbs and adjectives or change of state verbs all 
presuppose the truth of their complement sentence. Besides these, Lauri Kartunnen (1971) introduced the so-called implicative verbs, such as 'manage' that also involve presuppositions ${ }^{10}$. In the case of the NCC, one of the most interesting presuppositions is that schools and teachers would like differentiation. There is a whole fragment in the introductory part of the document entitled: Differentiation built on uniform bases ('egységes alapokra épülő differenciálás'). In this fragment the authors use the following verbs: 'serve' (alapul szolgál), 'help/offer' (an opportunity) (elősegíti, lehetőséget ad), and 'realise' (valósítják meg). The following fragment is revealing:

Content regulation is built on the diversified activities of schools, teachers and students and on an unified common basis. It gives an opportunity to school owners, parents and pupils to validate their values, interests and professional aspirations, and to take into account the existing circumstances, conditions and opportunities. (NCC, 1995)

In the above fragment the presupposition of the authors is that school owners, teachers and parents want to have their interests, values and aspirations to be taken into account by a core curriculum that offers a basis on which to build local curricula. The NCC was offering thus this opportunity for them. This is once again, a proof of the Anglo-Saxon influence mentioned earlier. Educational experts agree now that this presupposition was only wishful thinking (Ütőné, 2004). „The schools and the teachers were not prepared for such freedom. They were accustomed to have everything clearly stipulated, with centralised teaching requirements. This is why, probably, this NCC was met with strong resistance and was later taken into a more centralised direction." - as Jakab explained (interview with György Jakab, November 4, 2015).

\footnotetext{
${ }^{10}$ While it is difficult to draw parallels between English and Hungarian, some verbs can be considered factive and implicative in both languages. Of course, the inventory of these types of verbs is not the same in both languages. For more on implicative verbs, see Karttunen (1971).
} 


\subsubsection{The micro, lexico-grammatical level}

The following analysis draws largely on Fairclough $(1989,1995)$ and his framework. Fairclough's model $(1989,1995)$ for critical discourse analysis consists of threeinterrelated dimensions of discourse. The first dimension deals with the object of the analysis (in this case, the educational policies). The second dimension analyses the processes by which the object is produced and recieved. Finally, the third dimension discusses the socio-historical conditions in which that object was produced. While much of Hyatt's framework (2013) draws on Fairclough's work (1989, 1995), it does not follow entirely Fairclough's model, but selects some of Fairclough's concepts and adds analytical tools derived from Critical Literacy Analysis (Hyatt, 2005). Therefore, in the micro analysis of the texts, the following elements will be taken into consideration:

Vocabulary:

- The relational, experimental and expressive values of words used (such as euphemisms, ideologically contested words, formal and informal words, etc.)

- Use of stylistic devices (metaphors, repetition, etc.)

\section{Grammar}

- Passive/active sentences \& agency

- Use of specific terms

- Use of verbs (tenses and modality) and pronouns

- The expressive values of grammatical features

As previously mentioned, the term media literacy does not appear as such in the National Core Curriculum of 1995. Therefore, this analysis took into account all relevant textual content that referred to what today we would call media literacy education. References to media literacy can be found on the one hand in the common cross-curricular requirements, referred to as Communication Culture. On the other hand, media literacy education appears in specific subjects: mainly in Culture of the Moving Image and Media Education and partly in Information Technology. In the microanalysis I will first focus on the cross-curricular requirements, and then I will examine media literacy elements in the above mentioned two subjects. 


\section{Cross-curricular requirements}

Media literacy first appears in the so-called cross-curricular requirements. These requirements "are to pervade every element of education in schools" (NCC, 1995). Out of the seven cross-curricular requirements, Communication Culture occupies the fourth place, proceeded by Homeland studies (Hon- és népismeret), Connections to Europe and the Wider World (Kapcsolódás Európához és a nagyvilághoz), and Environmental Education (Környezeti nevelés). When it comes to the microanalysis of the specific content we can spot some interesting features. The cross-curricular requirement starts with a definition: Communication Culture is the "understanding, selection, analysis, evaluation, use, transmission and creation of information that serves cognition, learning, knowledge, human relationships, collaboration and social interaction" (NCC, 1995). The definition uses general terms and offers broad applications of the major element here, and namely 'information'. When observed closely, all other requirements are also phrased in loose terms. Since these cross-curricular requirements have to appear in some form in all subjects, the authors use enumerations in order to offer over-arching examples and explanations that can aid the introduction of these elements in everyday teaching. For our purposes the last three phrases are of particular interest:

Today, the vast majority of information is not gathered through "messages" addressed to us personally, but through intermediary artificial systems. The massive, passive consumption of information can lead to a distortion of living and thinking. Therefore, the schools must educate youth to understand and be selective about the new audio-visual environment. (NCC, 1995)

It is important to note the usage of quotation marks for messages. Quotation marks are generally used for specific purposes, such as an interface between spoken and written modes, in narrative as aids to imagine specific characters (Schiffrin, Tannen \& Hamilton, 2001), to quote someone or to highlight expression borrowed from others or other styles (Keszler, 2009). In this case though none of the above seems to explain the quotation marks. I reckon that this might be understood in light of the second part of the phrase. Before 1989 there were only a few media outlets, and people were more accustomed to learn about novelties through their community. Messages then included mostly face-to-face communication. But after the regime change ("today"), there was a 
change of paradigm, and people receive information through "artificial systems". The second phrase offers a further description, and has a darker tone: high mass-media usage can lead to a "distortion" of people's lifestyles and thinking. There is no additional explanation of what "massive" usage or "distortion" actually is. "Distortion" (torzulás) is emphatically used here, aimed to strengthen the intention of the authors. The last sentence offers education as the solution, as shown by the adverb ("therefore"/"ezért"). Throughout the last 20 years of media literacy education, TV and cinematic arts were the focus point. The same point can be made when closely analysing this last phrase. Although the second phrase talks about "information consumption" in general, this consumption refers only to the "audio-visual environment".

Going further, the analysis of modality shows an interesting process: the selected fragment starts with the indicative mood and then with the use of the modal verbs ("can lead to" and "must educate") it turns to the subjunctive mood. The indicative mood allows the authors to express strong affirmations, while the subjunctive mood allows expression of hypotheses (in this case, the possible distortion of living) and commands (of schools to educate youth).

While in this text there is no mention of the term media literacy, these three phrases reflect quite well the early understanding of media literacy: a strong emphasis on protection from harmful media effects. In this text, it is also important to highlight the fact that the responsibility of educating media literate children rests solely on the schools.

\section{Culture of the Moving Image and Media Education}

The Culture of the Moving Image and Media Education subject is part of the Arts subject area, together with Literature, Music, Dance and Drama, and Visual Culture. In the Arts subject area description Culture of the Moving Image and Media Education is the last in line to be presented. Incidentally (or rather not) the first subject is Literature, while Visual Culture is the one proceeding this subject. The description of the Arts area introduces briefly all these subjects. The Culture of the Moving Image and Media Education subject is presented in the following way: 
A substantial proportion of information and experience received by children is acquired through images and visual impressions. Culture of the Moving Image and Media Education prepares pupils for the reception, expedient utilization and ordering of a wide variety of visual experience. (NCC, 1995)

This short and condensed definition of the subject shows the very strong moving image focus of early media education activists. It is interesting to note that although the subject preceding this definition is called Visual Culture, there is no connection made between the two. Yet when examined carefully there is an overwhelming reference to visuality: "images", "visual impressions", "visual experience". There is no word on any other topic that might be important in terms of media education such as print or radio media, for instance. This is quite striking since the second part of the subject's title is "media education".

The aims of the subject are presented through an enumeration of verbs: "to receive", "to use" and "to arrange" visual experiences. The verbs show an interest of the authors to have children to engage with this type of media. Media production is actually one of the major scopes of media literacy education. However it is intriguing to see the adjective here: "expedient utilization" ("célszerü hasznosítás"). In discourse analysis, adjectives are particularly important because they express " [...] speakers' and writers' perceptions, evaluations, and judgements about people, things, experiences and events" (Strauss, Feiz, 2014, p. 29). This specific adjective implies that there is an utilization that is appropriate, in comparison with other utilizations that are - by comparison - not. This type of phrasing can be connected and understood in light of the above discussed child protection discourse which appeared in the cross-curricular requirements too.

The detailed requirements of the subject are divided into requirements expected by the $8^{\text {th }}$ and the $10^{\text {th }}$ grade. Visually the requirements appear in clearly structured tables that have three main units: Teaching materials (Tananyag), Developmental requirements (Fejlesztési követelmények), and Minimal achievements (Minimális teljesitmény). Those familiar with curricula studies, can notice that these requirements are an interesting combination of input and output-type of education model. According to György Jakab, this combination is the result of long debates between those advocating for a more traditional approach to education (focus on 
input) and the "reformists" (focus on output). The critical discourse analysis combined with information gathered through the interviews strengthens once more Ball and Bowe's (2006, p.113) comment: "[...] as policy, the National Curriculum remains both the object and subject of struggles over meaning."

When it comes to the linguistic aspect, the authors use a succinct description of what has to be taught and what is required from pupils. Most of the sentence lacks verbs, which makes the communication impersonal. Where there are verbs (mostly when it comes to expected achievements), the third person singular is being used: e.g. "He/She has the ability to consciously use the mass media" (NCC, 1995). However, there is no definition of what "conscious use" means. The requirements are sentenced in similarly broad and generalizing terms. This can be explained by the role envisaged for the National Core Curriculum: that is should be only a basis, a guidance on which local curricula can be built. Unfortunately, this educational model (and choice of wording) lead to many conflicts and misunderstandings. As one author observes for another subject: "Geography teachers were expecting a National Core Curriculum that, as usually, would specify when and what should be taught during Geography classes. But in fact Geography cannot be taught with by using the NCC (an no other subject either, for that matter)" (Ütőné, 2004, p. 98).

Going further, it is interesting to observe how the first unit (Teaching materials) builds on four parts: Motion picture literacy (Mozgóképírás, -olvasás), Art studies (Müvészeti ismeretek), Cultural history (Müvelödéstörténet), and Communication systems (Kommunikációs rendszerek). As I mentioned earlier, here, once more, the overwhelming content revolves around the moving image, and more so on film aesthetics. The description of teaching materials uses specific terms borrowed from aesthetics, such as "composition", "space and time", "montage".

A more social sciences approach can only be found in the last part of the Teaching materials, in Communication systems. The fact that this is the last one in the table, shows that the authors' did not emphasis this aspect. And the last important and intriguing aspect is, that the print press and the radio are mentioned only once in these tables. 


\section{Information technology}

Media literacy activists frequently debate the relationship between information technology (IT) and media literacy. The discussion is even more complex since there is a wealth of terms that are being used by IT specialists and educators, such as digital literacy, coding, information literacy. These all share some common ground with media literacy. Moreover, UNESCO is promoting the term media and information literacy, instead of just media literacy.

In this aspect, it is revealing to see that the discussion of which field should promote critical media usage appears as early as 1995 in Hungary as well. In the description of the Information technology subject, the main areas of teaching are as follows: computer skills, information literacy, the technical aspects of information management, and mass media. The relationship between the two subjects is lexically strengthened, since in parenthesis it is indicated that further information can be found in the chapter on Moving Image Culture and Media Studies. Unfortunately, however, there are no other details on how the two subject should be "combined", or what is expected from IT teachers to cover on the topic of mass media.

\section{Conclusion}

In this chapter, the aim was to analyze the 1995 National Core Curriculum from the perspective of media literacy education. This was the first Core Curriculum ratified in the new democratic Hungary. The adoption of this document was proceeded by fierce debates among the different political camps, a mass media frenzy and political battles. By presenting the political landscape and the relationship between politics and policy-making, my goal was to highlight how the NCC became a document in which different ideologies and discourses collided. The 1995 NCC presented a new approach to education, since it was intended to be only an aid for preparing school-based curricula. In Figure $\mathbf{4}$ below the synthesized results of the analysis have been outlined. 


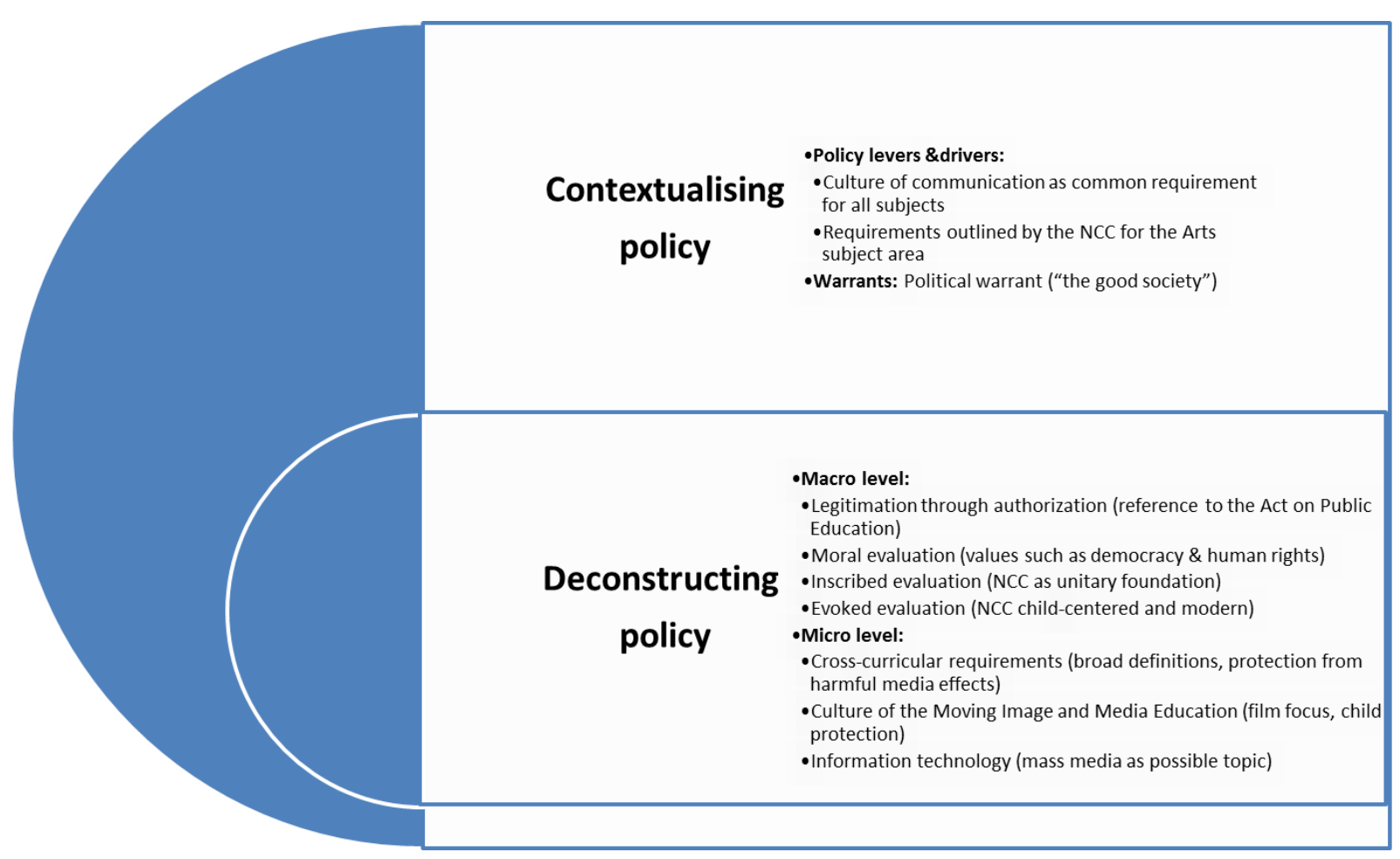

Figure 4: Synthesized results of CDA-analysis NCC 1995

In terms of media literacy education in Hungary, 1995 was a very important milestone: activists successfully lobbied for the introduction of the Culture of the Moving Image and Media Education subject. The micro-level analysis revealed that what we call today media literacy not only is addressed in the Culture of the Moving Image subject, but also in a specific cross-curricular requirement (Culture of Communication). The emphasis in the cross-curricular requirement is mainly on protection from harmful media effects. The micro-analysis also helped in revealing the mass amount of content on film and aesthetics in the stand alone subject. Early advocates of media literacy had a strong moving image background, and this is obvious from the description of the subject as well. While film culture is widely addressed in the Culture of the Moving Image and Media Education subject, print media and radio are mentioned only once. With an emphasis on film aesthetics, the critical and social studies aspect of media literacy (e.g. the role of media in society, civic participation through media) remained mostly undiscussed in the NCC. And lastly, an interesting aspect that was found was the appearance of mass media in Information Technology. This shows an early sign of what has now become a major 
debate between proponents of media literacy, digital literacy or media and information literacy.

The next chapter will deal with a very important year for media literacy education in Hungary, year 2000 when frame curricula were introduced, and this has shaped to a large extent the further development of media literacy education. 


\section{Chapter 5: 2000 - the year of the framework curricula}

\section{Introduction}

As presented in the previous chapter, the NCC was finally passed in 1995, and it became mandatory for schools to implement and follow the guidelines of the NCC and prepare local curricula by school year 1998/1999. However, there were serious issues with the introduction of these guidelines. A large majority of schools had problems in understanding and transposing the requirements of the (what they considered) undetailed NCC into local curricula. Therefore the new government elected in 1998, introduced in the school year 2000/2001 the framework curricula to complement the 1995 NCC. In terms of media literacy education, the introduction of frame curricula meant a new chapter: Culture of the Moving Image and Media Education became a module subject. I will address these changes in detail when analysing the framework curricula for this subject. The chapter will conclude with a discussion on how societal (and political) changes influenced the development of media literacy education at the turn of the millenium.

\subsection{Political landscape}

If at the beginning of the 1990s Fidesz was known for its radical liberalism, by the mid-1999s it slowly turned to occupy the centre-right political space. As a result the 1998 political campaign became a bipolar fight between the socialist and the centreright forces (Izsák, 2010). May 1998 brought a major victory for Fidesz: the party won 148 seats in Parliament overtaking the Hungarian Socialist Party (MSZP), who managed to win only 134 seats. By forging an alliance with what remained of the Hungarian Democratic Forum and the Independent Smallholders' Party, Fidesz controlled 55\% of the parliamentary seats (Kovács, 2011).

In terms of the economy, a so-called stabilization policy was introduced in 1995. This was the renowned Bokros package, that meant severe austerity measures. But as a result, from 1997 onwards the GDP had an annual growth of more than 4\% (Forgács, 2001). However, throughout the 1990s income inequality became stronger. In order to understand the adverse reaction of teachers to the $1995 \mathrm{NCC}$, and consequently, the 
introduction of framework curricula, it is important to mention that Hungarian teachers were among those who had permanently low income: in 1998, the gross incomes in education were $12 \%$ lower than the national average (Forgács, 2001).

\subsection{Politics and educational policy-making}

A national survey was carried out in the fall of 1998 at the request of the Ministry of Education to assess the process of introducing the new local curricula (based on the guidelines presented in the 1995 National Core Curriculum). The survey results indicated serious concerns and problems. There were misunderstandings on the responsibilities of schools and teachers. The survey results also highlighted that teachers and school administrators were worried about the extended strain put on educational staff. They also feared that the NCC would further enlarge the existing gap among schools (Szocioreflex, 1999): those schools that had more resources (both material and human) benefited more from decentralised curricula. And finally, the survey drew attention to a lack of flexibility and responsiveness on the part of teachers' and head masters. The educational professionals were not prepared for this wide range of drastic changes (Halász and Lannert, 2004).

One of the major elements of the Fidesz educational program was the urgent review and correction of the National Core Curriculum, according to László Környei, deputy state secretary of education (Schüttler, 1998). After the elections, the government's solution for these problems was the introduction of framework curricula. The framework curricula were intermediary curricula between the NCC and the local curricula. However:

the framework curriculum was not a theoretically designed item of content regulation, but a quick answer to the paradoxical situation of 1998 (when local curricula had to be introduced, and it turned out that there were many unsolved problems). (Kerber, 2000, p. 24)

Similarly, György Jakab (2002) observes, there was no political intention to reach a broad social consensus regarding the reform of the educational system. For the new government it sufficed to have the support of those who were against the 1995 NCC.

The major aim of the introduction of the framework curricula was the restoration of the Hungarian school system's unity. As a result, public education management 
became more regulated, a stricter framework for curricular freedom of schools was introduced and the traditional subject structure was reinstated (Jakab, 2002). The new regulatory tool specified the compulsory lessons in each subject and it enhanced the integration of the system, making horizontal and vertical mobility easier (Halász and Lannert, 2004). These changes had a very serious impact on the Culture of the Moving Image and Media Education subject. This aspect will be discussed in the following fragment.

\subsection{Deconstructing policy}

In terms of Hyatt's framework, a separate fragment would deal with the specifics of policy contextualization. However, the NCC was thoroughly analyzed in the previous chapter, and the policy levers and drivers and warrants did not change. The following part will focus on the analysis of the framework curricula on media literacy education from both a macro semantic and a micro lexico-grammatical level. By borrowing tools and lenses from critical discourse analysis, this next part will present the changes in policy with regards of media literacy through the introduction of the framework curricula.

\subsubsection{The macro semantic level}

For understanding the role of media literacy education in this new regulatory framework I will analyse the framework curriculum of this subject from a macro semantic and societal level and then from a micro lexico-grammatical level. The new curriculum is very important because with the revision of the National Core Curriculum of 2003 and 2007, its text has been only modified slightly.

The analysis of the macro semantic level can help us understand how governments legitimize their actions. In this case, it is important to see how the Hungarian government justified the introduction of a new level of regulation, namely the framework curricula. The 1999 Amendment to the Public Education Act specified that " $[I] n$ the period when general culture is grounded, the framework curricula, that are built on the educational areas of the National Core Curriculum, guarantee the content integrity of school education and interschool mobility" (Amendment..., 1999). In this short, but very condense sentence several modes of legitimation can be found. Policies 
are very often justified by attaching them to norms and values that are deemed important. As outlined previously, Fairclough (2003) discusses four modes of legitimation: authorisation, rationalisation, moral evaluation and legitimation through narratives (mythopoesis). The Hungarian policy-makers are using here at least two modes of legitimation that involve implicit assumptions. One of the modes used is authorisation, a reference to authority or law as justification. When introducing the framework curricula, policy-makers highlight that it is built on the educational areas of the NCC. By referencing the already adopted NCC, the justification of framework curricula rests on solid ground. Since the NCC has been accepted, and the framework curricula builds on its educational areas, this new regulation should also be accepted. This is quite surprising because the NCC and the framework curricula had diverging aims (centralisation versus decentralisation), and "in many ways, its [the framework curricula's] logic contradicted the philosophy of the NCC" (Halász and Lannert, 2004). This contradiction was also discovered in the parliamentary debates at the time. In a written interpellation, for instance, an MSZP Member of Parliament commented: "The introduction to compulsory framework curricula represents a return to an earlier rigid regulation. Time and the development of the Hungarian education system now makes this anachronistic" (Módosító javaslat, 1999).

The other mode of legitimation used in this sentence is rationalisation. Rationalisation implies a reference to the benefit of a particular action. In this text, the usefulness of the framework curricula is stressed by emphasizing that the new regulation will guarantee content integrity and interschool mobility. A very subtle mode of legitimation is also implied in the sentence: mythopoesis. Mythopoesis usually implies "moral and cautionary tales advising us as to the positive/negative outcomes of particular courses of action" (Hyatt, 2013, p. 840). In this sentence there is no "moral tale", however, there is a cautionary part: "in the period when general culture is grounded". The policymakers try to emphasise that in a period when there is important knowledge taught to children (general culture), it is important to have a framework that guarantees that every child can have access to this education. 


\subsubsection{The micro, lexico-grammatical level}

In an assessment of the Culture of the Moving image subject, György Jakab (2001) writes that globally there were three important paradigms in media education. The first paradigm (vaccine paradigm) highlighted the importance of culture as an antidote against the manipulation of the media followed by the mass culture paradigm in the 1960s. Educators brought into schools popular movies and TV shows in order to decipher those. From the eighties onwards, the third paradigm (representation paradigm) emphasized a semiotic approach to media texts. Jakab reckons that in Hungary both the mass culture paradigm and the representation paradigm are prevalent. In the lexico-grammatical level analysis, I will focus on the framework curricula of Culture of the Moving Image and Media Education subject, to see whether Jakab's statements can be confirmed.

In 2000, there were two versions of framework curricula written for this subject for grades 8 and 11-12. In the following analysis, I will present both versions in order to have a complete overview of how this subject was positioned at the beginning of the new century. The analysis, as presented in the previous chapter, relies on Fairclough's (1989, 1995) and Hyatt's work on critical textual analysis. For revealing the most important features of these texts, I paid particular attention to the relational and expressive values of words used, the modes and agencies, and the use of specific terms and stylistic devices (such as metaphors, repetition, etc.). First, the framework curricula for grade 8 and then the curricula for grades 11-12 will be presented.

The text of the framework curricula is organized in several, clearly demarcated parts. Both version A and B start with a description of Aims and tasks (Célok és feladatok). The next parts present the Development requirements (Fejlesztési követelmények), the Starting activities (Belépö tevékenységformák), and then the main Topics (Témakörök). The framework curricula end with the Conditions for advancement (A továbbhaladás feltételei).

Framework curriculum for grade 8 - version $A$. On a more macro level, the first part of the curricula, the Aims and tasks, provides an interesting terrain of analysing the legitimation and evaluation features of this policy discourse. So how is this subject justified to its audience, namely the schools and teachers? In trying to understand the 
legitimation of this subject, it is important to mention its historical development. In the previous chapter I presented that through a successful lobby campaign, media education activists were able to introduce this new subject into the NCC. However, with the framework curricula and the reintroduction of subject structures, the place and role of newly introduced subjects became insecure. With the new framework curricula, traditional subjects (such as Mathematics, History, etc.) had a fixed number of hours per week, as well as a fixed curriculum and requirements. In order to have both the traditional subjects and the new modernizing elements (Culture of the Moving Image..., Dance and Drama, Social Sciences, etc.), policy-makers introduced a somewhat inbetween subject, the so-called module subject. These module subjects had a smaller number of stipulated hours per academic year (less than 1 hour per week). Therefore, schools had a number of options on how to use these subjects. One of the options was to add these classes to some other traditional subject (e.g. to combine Culture of the Moving Image with Literature), or to organize intensive teaching periods (such as thematic weeks or special school projects) (Jakab, 2003). In this context, it was most probably imperative to position the Culture of the Moving Image and Media Education as a relevant subject for children's education.

The mode of legitimation used in this case is rationalization: the authors of the framework curriculum stress the value and the usefulness of this subject for society. The relevance of this subject is juxtaposed in the framework curriculum for grade 8 with the “extraordinary impact of media on people's perception and personality" (Mozgókép és médiaismeret, 2000, p. 385). On a micro level, very specific features stress the "extraordinary impact" of media. The authors use the stylistic device of enumeration to highlight the influence of the media. Televison "makes a daily program for the crowds" (“tömegek napirendjét osztja be”) (Mozgókép és médiaismeret, 2000, p. 385), “it proposes ways of thinking about the world's issues" (Mozgókép és médiaismeret, 2000, p. 385) ("sugalmazza hogyan gondolkodjunk a világ dolgairól”), “it starts dietary, shopping trends" (Mozgókép és médiaismeret, 2000, p. 385) ("étkezési, vásárlási divatokat indít"). Furthermore, this impact is stressed once more in the next phrase. Now, besides television, the authors of the framework curriculum (Mozgókép és médiaismeret, 2000, p. 385) add film and the internet to the tools that can "change the language, the values, the sense of rhythm, tastes, desires, heroes, taboos, art, pleasure, creativity and understanding." Rationalization, as a mode of legitimation, in this case rests on the powerful stylistic device of enumeration. 
As a further mode of legitimizing the importance of media literacy education, the authors turn to a form of mythopoesis, or legitimation through narratives. However, this is not a narrative in the strict sense, but it does have the characteristics of "moral and cautionary tales" (Fairclough, 2003, p. 99). Since media is such a powerful agent and it can influence so many aspects of our life - the argument goes - "media education is an essential tool of personality development", according to the framework curriculum (2000, p. 385). The latent implication is that with the introduction of this subject, good things will follow (students will have an opportunity for development), while if not, certain bad things will happen given the over-arching power of media.

The "powerful media" paradigm has been around since the beginning of the 1940s with the introduction of the hypodermic needle theory or the magic bullet theory. This model regards mass media as an all-powerful entity, while the audience is regarded as being passive. Moreover, the magic bullet theory stressed that media can have a powerful influence on behaviour (Theorieënoverzicht TCW, 2010). Since that time though, more sophisticated models of mass communication have been set up, which try to explain the impact of media on society. There is no agreement between scholars on the strength of the effect of mass media on people, but the hypodermic needle model has been refuted as too simplistic. Hence, it is quite striking that when presenting the aims and tasks of the subject, the authors make use of the powerful media paradigm. One of the possible explanations comes from a media literacy expert, who is trying to lobby for the introduction of this subject into her own country's (Romania) curricula. Nicoleta Fotiade (Interview with Nicoleta Fotiade, November 4, 2013) explained that media literacy experts had to use whatever tools they ccould in order to convince politicians of the importance of this subject. While they believe that media effects have to be analysed with caution, sometimes they have to use the popular view of an all-powerful media to get politicians, schools and teachers to consider the introduction of media literacy education. This supposition is strengthened lexically when analysing the next fragment of the framework curriculum (2000, p. 385):

This subject aims, thus, to help students acquire the necessary know-how to approach various media texts with an independent and critical attitude and to use traditional and new media with an open mind. 
The introductory part would have us believe that because of the power of media, children should be kept away from it, as many educationalists and psychologists suggest. However, if we take into consideration the above phrase, we can see that it supports an active relationship with the media. The contradiction can be easily explained: as a first step, the authors had to legitimize the subject, and then, they offer media literacy education as a solution. From a micro level, it is interesting to see the evaluative statements in this phrase. Evaluative statements are used to show desirability and undesirability, what is good and what is bad (Fairclough, 2010). Usually evaluative statements are constructed with the help of adjectives (such as "beautiful"), or a noun phrases ("a beautiful apartment"). In this case, what is desirable is to have "an independent" and a "critical" attitude (evaluative adjectives) and an "open mind" (evaluative noun phrase). These are all transparent cases, in which one can easily spot the implicit values of the statements. For media literacy advocates, the "ideal" pupil will be one who uses the media in a self-reliant and analytical way. At the time when this framework curricula appeared (more than 15 years ago), this idea was certainly novel. It was not until recently (in 2014) that responsible media use was advertised through a national media campaign ${ }^{11}$.

The next section of the framework curriculum introduced the so-called Development requirements. These requirements were one of the major novelties introduced by the 1995 National Core Curriculum. The section starts with outlining the benefits of the Culture of the Moving Image and Media Education subject, then continues with describing the requirements.

The benefits are expressed in terms of skills and competences gained through studying this subject. It is important to observe here its interdiscursivity aspects. Interdiscursivity or constitutive intertextuality, as Fairclough explaines "draws attention to the potential heterogeneity of texts in terms of the diverse discourse conventions, types of discourse, which can be drawn upon in their production" (1992, p. 284). The relevance of Culture of the Moving Image... subject is presented through the skills that pupils can gain by attending these classes. While the Development requirements were one of the new features introduced by the NCC and the framework curricula, these are in line with the

\footnotetext{
11 Médiaunió Foundation chooses each year a topic considered socially relevant. By involving communications professionals and experts of the selected field, it runs a year-long national campaign to draw the attention to the chosen social issue. The Neked8 campaign ran both in 2014 and 2015, and it aimed to raise awareness on the importance of responsible media use.
} 
new trend of mixing discourses of consumerism and education. The Culture of the Moving Image subject's relevance is presented through the measurable outcomes that can be acquired (such as grades or qualifications), rather than highlighting an engagement with the process of learning" (Hyatt, 2013. p. 841). These outcomes range from "communications and collaboration skills" to "creative inclinations" and "problem-solving skills".

Going further, the authors of the framework curricula enumerate the requirements. The sentences are formulated in imperative mood with the use of impersonal verbs: "should be made aware of" ("tudatosítani kell"), "should be sought" ("törekedni kell"), "the possibility [of creative exercises] must be ensured" ("lehetőséget kell biztosítani”). As mentioned in the previous chapter, impersonal verbs contribute to the vagueness of the text. While we might think that teachers are the ones towards whom these requirements are directed to, there is no further explanation of how these requirements can be met. Of particular interest is one of the phrases of the framework curriculum for grade 8 (2000, p. 386):

It should be made clear how and through which means mediated communication (e.g. the entertainment industry) threatens high culture and personal autonomy (e.g. information addiction, urge consumption), but the possibility of preserving cultural heritage and the development of selection ability (e.g. digital archives, public sphere) by technical picture reproduction and network communication should also be made clear.

From a micro lexical perspective, one can see that the phrase is built upon two blocks: the first one presents the supposed threats, while the other the opportunities of mediated communication. Between these two sentences there is a constrastive/concessive semantic relation marked by a conjunction ("but"). However, when observed closely the attitude towards mass media is not so much different in the two supposedly constrastive sentences. The verbs used in these sentences ("to threaten", "to preserve") show the antagonism between high culture and the popular culture represented by the media. The contrastive conjunction ("but") does not really introduce a distinct idea, it strengthens the view that media in some instances can help propagate high culture ideals as well. Once more, I can only presume that these arguments can be linked to the professional background of the early media education activists (film directors, philosophers, etc.). 
In connection with the Development requirements, the framework curricula offered Starting activities, which formulated "activity-based development requirements for schools" (Jakab, 2002, p. 11). The framework curricula proposed in-class activities such as group viewing of audiovisual shows, short presentations or project work. This section was a novelty in terms of curriculum development, because it offered practical suggestions for media education teachers. Thus the framework curriculum was not meant only to be a theoretical aid, but a practical tool as well that could be used in class.

The next section of the framework curriculum for grade 8 presents the main Topics, divided into four areas: Language of the moving image (Mozgóképnyelv), Systemisation of the moving image (Mozgóképi szövegek rendszerezése), Social role of media (A media társadalmi szerepe), and Typical media texts and program types (Jellegzetes médiaszövegek, müsortípusok). For each topic, there is a list of possible themes that can be introduced in class, such as the discovery of the film and the cinema for the first area. The order of introducing these areas is revealing: the first two deal with film and cinema, the third with the social role of mass media and the last one presents a typology of media texts. On a micro level, there is an abundance of terms directly connected to the moving image (such as light and shadow, close-up, celluloid, etc.). Even in the third area (Social role of media), a majority of themes are directly or indirectly connected to audiovisual media (the role of program schedules, airtime, public and commercial media, etc.). The print press, photography and ads are only mentioned in the last topic (Typical media texts and program types).

The last section of the framework curriculum for grade 8 deals with the conditions needed for further progress. The conditions are presented using verbs in imperative mood, while the subject for whom these conditions are necessary is presented through the generic term "the pupils" ("a tanulók"). There is no further specification on different types of learners, from which we can deduce that these are the minimal requirements for all pupils. Out of the seven sentences in this part, four present conditions strictly connected to the moving image. The last three requirements are also connected to the moving image, but indirectly, such as "[The pupil] will apply his/her knowledge on moving image and functions of mass media when choosing a program" (2000, p. 388). While in the previous part, there were some topics connected to the 
internet and printed media, intriguingly these are not mentioned in the conditions needed for pupils' progress.

Framework curriculum for grade 8 - version $\boldsymbol{B}$ The framework curricula (2000) introduces succinctly the second version for grade 8: "For the Culture of the moving image and media education subject two framework curricula had been written with standalone objectives and tasks, and with different content. For the local curriculum either version A or version B can be taken into account." (2000, p. 389) It is, the least to say, odd that there is no further clarification offered on why two types of curricula was created. When asked about this aspect, policy expert György Jakab (interview with György Jakab, December 9, 2015) explained in short: ,it was a solution of compromise between several professional directions." It is very important to note though that Jakab also added, that the majority of teachers were using the textbooks written by the authors of the version A curriculum. Here is a straightforward example of Stephen J. Ball's policy cycle approach. Ball (1992) wrote extensively on how policy-making is not a linear, „rational” process, as it is frequently argued. He suggested that there is a „multidirectional reality of policy as both text and process” (Lingard, Sellar, 2013, p. 268). In this case competing professional groups offered two different curricula, but this is not apparent just by a microanalysis of the text. While it is not clear how this compromise was reached, it is interesting to note how policy can be understood in Foucaldian terms: what kind of discursive frameworks are used in a policy, who has the opportunity to speak, and what can be said in respect of policy.

What can be observed instantly when looking at the text, it is its length, or to put it more plainly: its very short length compared to version A (several pages shorter). While this is not in itself a result, it is important to mention it, since it can add to the overall understanding of this text.

Similarly with version A, this second version follows the same pattern of structure: first it introduces the Aims and tasks, which is followed by Development requirements, Starting activities, Topics and Conditions for advancement. The first block, Aims and tasks - one would expect- should present the main goals of this subject. In version A, the main goal is introduced in the first sentence, by the verb "serves" (the subject serves the goal of...). However, there is no straightforward aim introduced in the same section of version B. The Aims and tasks section starts with a so-called statement of fact: “The basic knowledge of audiovisual media's language, functioning, 
diverse application area and its cultural importance belongs now to general knowledge." (2000, p. 389). Statement of facts or 'realis' statements, according to Fairclough (2003), are utterances about what is or was the case. ${ }^{12}$ Statements of fact are implicitly evaluative because they choose to present certain facts and not others. Fairclough (2003) adds that "facts are selected for the values they convey, within the particular value system that is implicit." (p. 111) In this case the aim of the authors might be to highlight the importance of audiovisual media in contemporary society. The implied goal is then, to position this subject as one highly relevant for the general knowledge of pupils. Another interesting element of this section is the third sentence. While in the whole text (four phrases in total) the verbs appear in the third person singular, in this sentence the verb is in the first person plural: "For studying complex cultural and social phenomena we need to find tools suitable for adolescents." (2000, p. 389) By using the first person plural the authors situate themselves and the readers in the 'same team'. The choice of this form can also indicate that solutions are also expected from teachers (to find "tools suitable for adolescents").

The second block deals with Development goals. The microanalysis of this part reveals a very interesting mixture: the goals have roots in aesthetics, film culture, and to a certain degree, social studies. The basic goal is "deepening of sensitivity" (2000, p. 389), as well as learning about audiovisual culture and the development of a sovereign and differentiated behaviour towards the media. The phrasing of the basic goal is quite unusual, and this is the only curriculum in which I could find a reference to (aesthetic) sensitivity. However, when analysing the curriculum, there is no explanation or activities specifically proposed to "deepen" pupils' sensitivity. This reference to (aesthetic) sensitivity can be likened to a reference made to high culture in version A of this curriculum (mass media's threatening effect on high culture). In both instances, the authors seem to draw upon the differences between high culture and low culture (with mass media clearly belonging to the latter). Nevertheless, this is not surprising. In 1998 Herbert Zell argued for a new media literacy model, based on contextual media aesthetics in order to understand "how the basic aesthetic building blocks are used to create and shape our cognitive and affective mental maps" (Zell, 1998, p. 81).

\footnotetext{
12 The other type of statements are: 'irrealist statements' or predictions and evaluations.
} 
The Starting activities are less developed compared to version A. Similarly to the first version, the focus is on the audiovisual media. The activities range from discussing shows and films to photo animation, going to the cinema, or getting to know the CDROM. Interestingly there is no other device mentioned here, except for the CD-ROM.

The next unit deals with the Topics that need to be addressed by the teachers. The topics are divided into six areas: Media ("Médiumok"), Discovering the moving image ("A mozgókép felfedezése"), The visible man ("A látható ember"), What is the moving image for? (“Mire való a mozógkép?"), Look closer (“Láss, ne csak nézz!”), How is television functioning? (“Hogyan müködik a televízió?”). It is suprising to see the title of these thematic areas in a framework curriculum. The authors use a number of stylistic devices: metaphor ("The visible man"), exclamation and questions. This a typical case of genre mixing (Fairclough, 2003). The genre in this case is a mixture of a literary writing and educational policy text. This makes the text somewhat difficult to decipher. For instance, in the case of "The visible man" here are the possible topics to discuss in class: image and imagination; technical image and reality; film truth - film lies; the milestones of moving image development. It is unclear how the metaphor in the title is connected to the possible topics. Similarly for the Look closer unit ${ }^{13}$ one of the possible topics is How can an image be interpreted, but the exact Hungarian phrasing is a figure of speech ("Hogyan lehet a képet «ragozni»?) It is unclear why the authors decided to introduce literary devices into this policy text. The last topic area deals with the functioning and role of television, taking into consideration issues as technique, business, politics, and art. Just as in version A, the print press, the radio and the internet is only marginally discussed.

The last unit of the curriculum presents the Conditions for advancement. Once again the knowledge needed from pupils evolves around audiovisual content. Just as with version A of the curriculum these conditions are presented using verbs in imperative mood ("the pupil should know" - "a tanuló ismerje meg”). The imperative mood is a clear signifier of the authors' intentions: in this case, the enumerated conditions have to be fulfilled in order to advance. The unit is made of four sentences, out of which three deal with content strictly connected to audiovisual media. Media literacy appears in the last

\footnotetext{
${ }^{13}$ The exact Hungarian translation would be: Watch, not just look! This does not make much sense in English. However, in Hungarian it is a wordgame because „láss” and „nézz” are very close in meaning. The phrase signifies to pay attention, or look closer.
} 
sentence, although it is not named as such: "[The pupil] should consciously choose between shows, experience and knowledge resources." (2000, p. 390) It is noteworthy that critical choice appears here as a condition for advancement, but there is no clarification of what "conscious" means in this context.

Framework curriculum for grade 11 and 12 -version $A$. As was the case with the framework curricula for eight graders, there were two separate versions of curricula for grade 11 and 12. In version A the yearly class time is 18 hours for grade 11 and 16 hours for grade 12. As presented earlier, Culture of the Moving Image and Media Education became a module subject and it had a smaller number of stipulated hours per academic year (less than 1 hour per week).

Version A of this curriculum builds on the presumption that pupils had already studies this subject in grade 8 . This presumption can be spotted when looking closer at the lexical elements of the text. Throughout the curriculum, there are references to themes connected to the curriculum for grade 8, such as "The basic moving image and cultural history awareness acquired in grade 8 [...]" $(2000$, p. 770$)$ or " $[\ldots]$ the activities used at the end of general school can be adapted to a high school setting as well." (2000, p. 770). While on one hand this continuity is a quite obvious and natural choice, on the other it is important to add that not all pupils have attended these classes in grade 8 . Therefore, it is important to ask whether a child who had never studied Culture of the moving image and media education in general school can benefit from this curriculum.

As was the case with the previous curricula, this one is also built upon specific units. The first one is Aims and tasks, the second is Starting activities, the third presents possible Topics, and the last one is Conditions for advancement. In version A the Conditions for advancement are joint for grades 11 and 12. However, there are no Development requirements in version A. There is no explanation in the curriculum on why this unit is missing from the text. The micro, lexico-grammatical analysis of the Aims and tasks presents a strong moving image focus. The very first sentence of this unit is clearly revealing in this sense:

In high school education Culture of the moving image and media education serves firstly the development of moving image (film, TV, video, computer game, web) literacy, the development of an independent and critical thinking, and the 
clarification of the social role and operating mode of audiovisual media. At the same time it is the basic tool for personality development.

It is interesting to note the order in which these aims are being presented, with moving image literacy being the first one. While computer games and the web are mentioned here, there is no other reference to these throughout the framework curricula. This is unfortunate, if we take into consideration that at the beginning of the millennium, IT was a stand-alone subject in Hungary, and educators worldwide emphasized the importance of computers (and video games) in media education (Alverman and Hagood, 2000; Buckingham and Sefton-Green, 1994).

If we go further, we can see that the first phrase presents the aims of this subject, and then comes the last sentence. It is unusual that this sentence is not formulated as the ones proceeding it; it is a statement of facts ('realis statement'). 'Realis' statements are important because the way they are being formulated: they present assertion about 'reality'. In this case the first phrase presents goals, and the last sentence states that this subject is a "basic tool for personality development". Statement of facts are also important because they can be evaluative in an implicit way (Fairclough, 2003). The implicit evaluation here is that this subject is essential for the development of pupils.

The next paragraph focuses on specific goals that have to be reached. The moving image and aesthetics come to the fore, once more, since the aims are the development of film literacy, the knowledge of history of styles (stílustörténet), artworks and development of analysis skills. In terms of media studies, the authors highlight the importance of studying the economic, political and legal factors affecting media institutions, and factors influencing media reception. The order in which these aims are introduced is not trivial. Syntax has an important ideological implication. Teun Van Dijk (1998) explains that "word order as well as transactional structures of sentences may code for underlying semantic (or indeed, cognitive) agency" (p. 24). This same pattern can be observed throughout the curriculum. When it comes to the Topics that have to be addressed in class, the thematic areas are the following: Moving image language, Organization of moving image texts, The social role of media and Typical media texts and program types. For $12^{\text {th }}$ graders Moving image language does not appear in the thematic areas, only the other three areas are present. In these areas the predominance of film culture and film aesthetics is clear. Out of the four thematic areas 
two deal almost exclusively with the moving image, and one discusses related topics, such as advertisements and music videos (Typical media texts and program types). The concepts that appear in these descriptions belong to the language of film culture: "camera", "subjective image", "montage", "role play", "European New Wave" and so on. This is, once more, a clear example of what van Dijk (1998) defines as "semantic macropropositions of discourse" (p. 27). Semantic macropropositions "subjectively define the information in a discourse that speakers find the most relevant or important. This means that topicalization may also be subject to ideological management. Ingroup speakers may be expected to de-topicalize information that is inconsistent with their interests [...]" (van Dijk, 1998, p. 27). Since the authors of the curriculum had a background and an interest in film-making, they topicalized film culture in these texts.

A different approach can be discovered in only one of the thematic areas, the one discussing the social role of media. The difference can be spotted by the new concepts that appear in this area. These belong to the language of social sciences: "media representation", "principle of cultivation", or "public sphere". An interesting element in the curriculum for $11^{\text {th }}$ graders is the following: "The role of media in formulating topics relevant for citizens: the principle of cultivation." (2000, p. 772) What is unique in this sentence is the concept of "citizens", one that is adopted from civic studies. This is an early example of what Mihailidis (2009) calls "finding connections in media literacy education" (p. 61). Mihailidis (2009) argues for a purposive media literacy, which highlights "the connections between media analysis and a nuanced understanding of media's role in community, civic life, and democratic society" (p. 53). It is quite important to note that this civic aspect is taken up in a curriculum written in 2000 , even if this is addressed only marginally. From a Representational point of view (Fairclough, 2003), thus, elements connected to film culture are given prominence, while elements in connection with social studies are included, but only to some extent. We can look at this text in terms of what is excluded, as well. For instance, the relationship between mass media and health issues does not appear in this curriculum. This is not intended to be a critique of the text, but an example of how what is " "said" in a text is always said against the background of what is «unsaid»- what is made explicit is always grounded in what is left implicit" (Fairclough, 2003, p. 17). 
Framework curriculum for grade 11 and 12 - version B. As was the case with the framework curricula for grade 8 , there is no explanation why there are two separate curricula, and how these can be differentiated in terms of school specialization or educational background of the teachers. When it comes to the Aims and tasks and Development requirements of this text, one noticeable feature is a much stronger emphasis on analysing the social role of media. Mass-media is positioned as a powerful actor that has a strong effect on the audience. This powerful role is outlined with evaluative statements (Fairclough, 2003). As we have seen earlier, evaluative adjectives and adverbs are important for understanding how the authors of this curriculum position mass media. Throughout the text mass media is referred to as a "prominent field" (2000, p. 775), there is a "rapid expansion of audiovisual telecommunications systems" (2000, p. 775), that influences the "transformation of the public sphere" (2000, p. 775). Moreover, pupils should know about "the strategies through which public opinion can be influenced" (2000, p. 775) or about "mass media's mode of action and its social psychology" (2000, p. 775). Evaluative statements reflect what is desirable or undesirable, and they reflect explicit or assumed values. By positioning mass media as an important actor with a power to influence people, the curricula's authors are also positioning this subject as a relevant one for the education and life of students.

The Aims and tasks and the Development requirements are the same for grade 11 and 12, however the Topics and the Conditions for advancement are different for the two grades. For grade 11 there are four Thematic areas in the Topics: The technical image, Moving image language, Development of the moving image culture and Excerpts of film history. Semantically the titles of these areas are revealing, and they support the claim made earlier of a very strong focus on the moving image. For grade 12 the Thematic areas are: Messages of the media, The TV, Life - in a media environment and Interactive media. Compared to the thematic areas from version $\mathrm{A}$, the titles (and to a certain degree the content) of these areas in version B strike as unusual: the authors use literary devices. This genre mixing (Fairclough, 2003) is somewhat uncommon in policy texts. It is important to mention this interdiscursive hybridity, because it can potentially provide valuable analysis results. The literary devices used in this text are the following: personification ("messages of the media"), the use of em dash as a stylistic device ("life - in a media environment), or antithesis ("The copy is the real thing: the virtual reality of media"). The use of figures of speech, and particularly 
metaphors, is an aspect taken up by Cohran-Smith (2005), who came to the conclusion that when debating education reforms, the relevant actors are "spinning out dramatic metaphors" (p. 182) quite often (see for instance "No Child Left Behind Act"). Similarly, McCandless (2012) observes that the use of figures of speech can be problematic in framing policy questions. It is not clear what the purpose of these stylistic devices was. However, I reckon that since the local school curricula were drafted based on these framework curricula, a clearer or more unambiguous language use would have helped teachers.

The Conditions of advancement for the $11^{\text {th }}$ and the $12^{\text {th }}$ grade are formulated in broad terms. Once again, the authors use the term "pupils" to refer to the actors who need to know specific things in order to advance. As mentioned earlier, by using the term "pupils" for all children attending secondary school, this practice becomes an act of uniformizing. This is quite dangerous because there are very big differences between schools, educators and pupils alike, that have to be taken into consideration.

One of the pillars of media literacy education is media production: students should be able not only to critically understand media, but to create and distribute their own messages. If we take the definition ad literam, than we cannot talk about media literacy education in its fullest sense, based on the Conditions of advancement. The conditions enumerated in this last part are - to a large extent - connected to what pupils should know. The verbs used in these sentences strengthen this finding: pupils "should locate phases of moving image culture’s development” (“legyenek képesek a mozgóképkultúra fejlődésének egyes mozzanatait elhelyezni”), „should know the characteristics” (,ismerjék a jellegzetességeit”), "should recognize the tools of the moving image" ("ismerjék fel a filmnyelv egyes kifejező eszközeit”). The situation is similar for 12th graders as well: "knowledge of basic information” (,alapvető ismeretek elsajátítása”), the pupil "should know and decipher" ("ismerje és értelmezze"). The authors use frequently the verb "to know" and its synonyms, which highlight an approach towards a lexical knowledge rather than a more hands-on approach to media (such as media production). 


\section{Conclusion}

The introduction of the framework curriculum was a major milestone for Hungarian public education. Consequently, this change also influenced the teaching of Culture of the moving image and media education. The aim of this chapter was to present, thus, the changes in media literacy education at the turn of the millennium. When it comes to the macro level, this period was characterized by an urgent review and correction of the 1995 National Core Curriculum. The 1998 election's winning coalition urged the reform of the educational system. The reconfiguring of the political landscape had thus relevant consequences for media literacy education as well. With the introduction of framework curriculum, the Culture of the moving image and media education was transformed into a module subject, that had a smaller number of stipulated hours per academic year (less than 1 hour per week).

The micro semantic analysis of the subject revealed some important features.

Figure 5 below summarizes these findings.

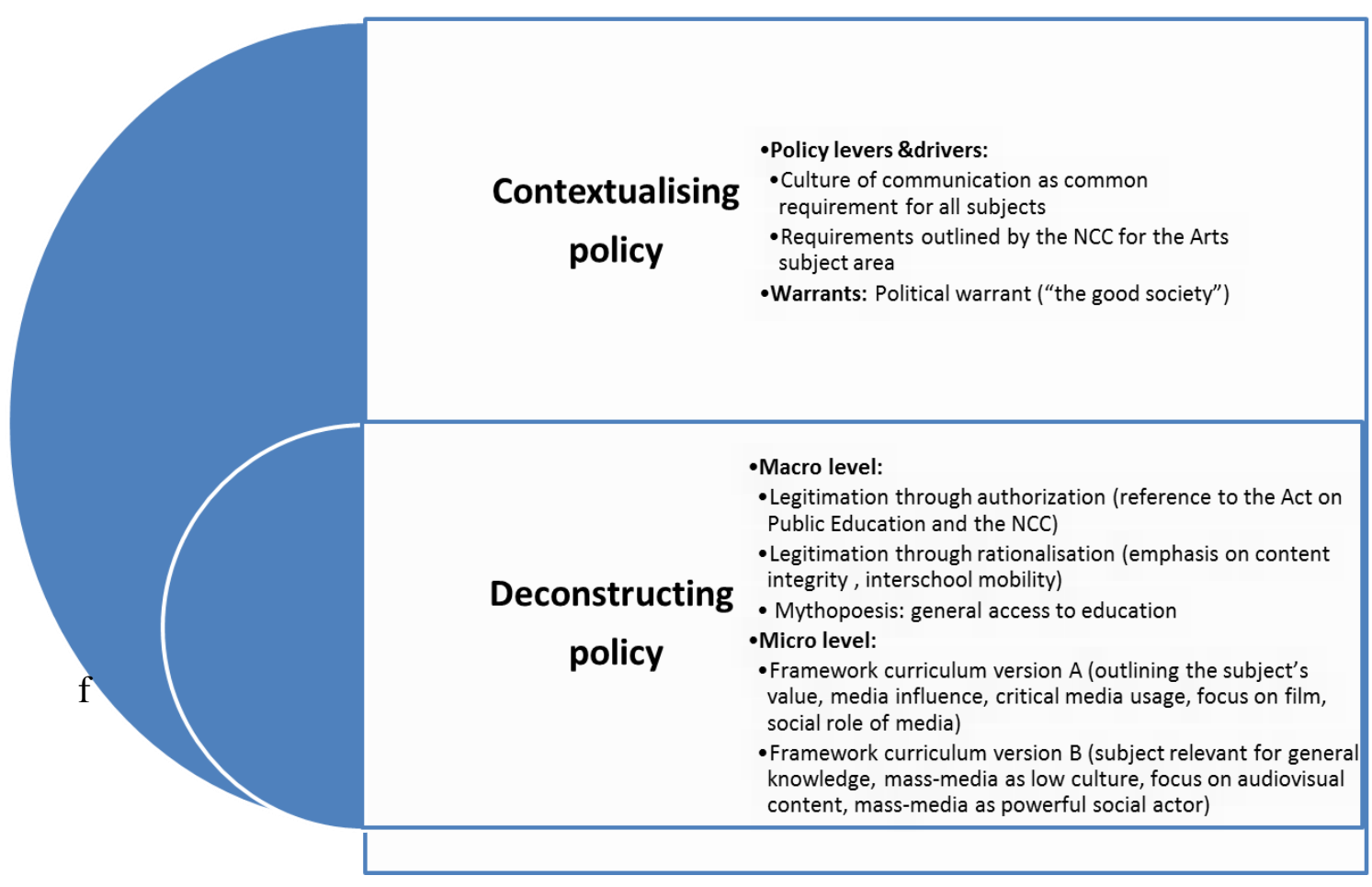

Figure 5: Synthesized results of CDA-analysis framework curricula 2000

Early on in this chapter I presented György Jakab's analysis in which he highlighted the fact that in Hungarian media literacy education both the mass culture 
paradigm and the representation paradigm are prevalent. His observations are in line with the findings of this project with one observation. The first paradigm, in which mass media is presented as a threat to high culture, is also quite present in the curricula. With the help of stylistic devices, the authors stress in many instances the so-called extraordinary impact of the media. By presenting the mass media as an important actor with a power to influence people, the curricula's authors were positioning this subject as an important one for pupils' development.

When it comes to the style of the policy text, a very interesting aspect was discovered: the use of metaphors, enumeration, personalization, etc. in the framework curricula. While this was prevalent in the version B of the framework curricula, stylistic devices were also found in version A, nonetheless. The mixture of a literary writing and educational policy text makes the text somewhat difficult to decipher.

The focus on the moving image was noticeable from the micro analysis, as well as from the interviews I carried out with the main actors of the media literacy movement in Hungary. The print press, the radio, and the internet were mentioned rarely throughout the framework curricula. However, one of the important aims of subject that comes across when analysing the framework curricula was that the authors would have liked pupils to have an active relationship with the media. When analysing the desirable outcomes of the subject, the authors used evaluative adjectives and noun phrases with implicit values, such as ("an independent" and a "critical" attitude and an "open mind"). It is important to highlight that Hungarian media literacy advocates in the beginning of the $21^{\text {st }}$ century were already working for having an education that teaches pupils to use the media in an independent and critical way.

This chapter presented relevant findings that are valuable for understanding how political and social pressure can influence the teaching of a certain subject. The analysis also revealed that the background and interest of the curriculum authors had taken the subject towards moving image, while other areas, such as the print press, did not appear in the curricula.

The next chapter will present the next milestones of media literacy education development in Hungary, and more specifically, it will deal with the NCC modifications that took place in 2003 and 2007. 


\section{Chapter 6: 2003 and 2007 - international influences in education}

\section{Introduction}

This chapter is intended to give an overview of two major revisions of the National Core Curriculum: the first in 2003, and the subsequent in 2007, and to present how international organizations can influence educational policymaking. There are three major reasons why these two are presented in one chapter. The first one is that in both 2002 and 2006, the Hungarian Socialist Party won the elections, and this meant a certain continuity in policy-making. The second reason is that there are only a few differences between the two revised NCC when it comes to content connected to media literacy education. Finally, the frame curricula for the Culture of the Moving Image and Media Education were only slightly modified in this period. Thus, the chapter will present an analysis of the two NCCs with the help of the critical discourse analysis framework. The frame curricula of the Culture of the Moving Image and Media Education subject will be briefly touched upon as well. The chapter will end with a discussion focusing primarily on the role of supranational political institutions (mainly the European Union) and international actors (Organization for Economic Cooperation and Development) in educational policy-making, and subsequently in policies regarding media literacy education.

\subsection{Political landscape}

As it was shown in previous chapters, the parliamentary elections in Hungary had a very important effect on the educational system. The 1998 elections were a major defeat for the left: the right-of center alliance led by the Fidesz outvoted the main force of the left, the Hungarian Socialist Party (MSZP). In 2002 though, the results of the elections came as a surprise. The required 5\% threshold needed to win parliamentary mandates was exceeded by only three parties: the Hungarian Socialist Party (MSZP), the Association of Free Democrats (SZDSZ), and the Fidesz-Civic Party/Hungarian Democratic Forum (MDF). The sharp competition between the two political forces ended in an unforeseen defeat of the Fidesz-led alliance. Therefore, the alliance of the Hungarian Socialist Party and the Alliance of Free Democrats formed a government 
with only a ten-seat lead (Benoit, 2002). The new government had important tasks in front of it: fiscal consolidation, reducing the expenditure cost, and the 2003 referendum on EU membership (Datamonitor, 2005). The most important foreign policy objective of the country was to achieve early European Union (EU) membership. Hungary formally applied for joining in 1994, and the country eventually joined the European Union in 2004.

The 2006 elections brought then a new surprise: for the first time since the elections of 1990, a Hungarian government remained in office for a second time around. Csizmadia (2006, p. 75) argues that this was due to the MSZP's (Hungarian Socialist Party) successful communication that evolved around the prime minister, Ferenc Gyurcsány, and the failure of Fidesz to create a right-wing coalition. Ilonszki and Kurtán (2007) observed that although the performance of the government was not very impressive, the dynamism of Gyurcsány proved to be essential in mobilizing his party. After the elections, however, a major political crisis was on the way that deeply affected the trust of the citizens. In a secret speech that was later leaked to the press, the PM admitted that they lied in order to remain in office with regards of the economic situation of the country, and demanded his party to switch tactics. In the aftermath of this speech, people went on the streets, demonstrating against the ruling PM, and demanded the resignation of the government. Nonetheless, the PM did not resign, and "nine former ministers got a portfolio in the 13-member cabinet" (Ilonszki and Kurtán, 2007, p. 973).

In relation to the economy, from 2002 onwards, Hungary had to confront some difficult times. Because of the higher level of public expenditure (higher pensions and public sector wages), the general government deficit increased to $9 \%$ in 2002 (Datamonitor, 2005). Adding to this, in 2006 the European Commission rejected the Hungarian convergence program, and asked for corrections. By 2006, inflation rose to above $6 \%$, more taxes were introduced and economic growth stalled. All of which impacted the educational sector as well.

In terms of politics and educational policy-making, a curious process started from 1998 onwards, that was further strenghtened during the two left-wing governments: public policy was placed under what Radó describes as “informal political control" (2010). Radó (2010) argues that there were specific tools through which this process was aided, such as assigning policy-making responsabilities to governmental 
agencies. Radó (2010) also noted that the process was continued by later governments as well, and this led to a transparency problem. While initially administrative mechanisms could ensure a minimum of transparency, political interests overturned professional discourses in the sphere of education: "In essence, informal politics overwrote formal educational policy-making" (Radó, 2010). The entangled situation of the public education sector was further complicated by the appearance of supranational organisations in the educational policy arena.

\subsection{International developments and Hungarian educational policy-making}

One of the major political-economic events that influenced education policymaking in this period was Hungary's accession to the European Union. While the EU does not have tools to directly influence education policy-making on national level, its policies have strongly affected public education. Halász (2006) observes that through the Lisbon Strategy ${ }^{14}$ a new educational paradigm was born, one that focuses on lifelong learning. Hungary, by joining the EU in 2004, participated in the Lisbon Strategy's education policy and education development programs. The Lisbon Strategy, focusing on economic development, people's skills and job creation, influenced to a large extent the public education of the EU countries. Another major international reform in higher education was the Bologna Process which introduced a common bachelor-mastersdoctorate system within the EU member states. However, the Lisbon Strategy and the Bologna Process draw fervent criticism from those arguing that "[...] both policy projects contribute to a commercialisation of higher education" (Garben, 2010, p. 209).

A similar important milestone in the 2000s was connected to the Organisation for Economic Co-operation and Development (OECD) and its Programme for International Student Assessment (PISA) ${ }^{15}$. The PISA examinations were introduced in 2000 in Hungary, and it caused a major turmoil in the country. Pupils' poor results were fervently discussed in the media, and they were frequently mentioned in the political campaign leading to the 2002 elections (Halász, 2006).

\footnotetext{
${ }^{14}$ According to the European Commission, the Lisbon Strategy for Growth and Jobs came as a response to globalisation, and it aims to generate growth, more jobs, a greener economy and innovation. More on the Lisbon Strategy for Growth and Jobs can be found here:

http://ec.europa.eu/archives/growthandjobs_2009/objectives/index_en.htm

15 The Programme for International Student Assessment is an international survey that evaluates education systems and the skills and knowledge of 15-year-old students. More on PISA can be found here: http://www.oecd.org/pisa/aboutpisa/
} 
As it was expected, these international institutions had a major (though somewhat indirect) role in shaping educational policies in Hungary. Among one of the major documents drafted in this period by educational experts was the Medium-term Strategy of Public Education (2004). The strategy developed by the National Institute for Public Education outlined the following priorities: "laying down the foundations for lifelong learning by developing key competencies; reducing the inequalities in education; improving the quality of education; supporting the development of teaching profession; promoting the use of ICT tools; improving the physical conditions of education; and improving the cost-effectiveness and management of public education" (National Institute for Public Education, 2004). The new funding opportunities and the international cooperation had an overall modernizing effect on Hungarian public education. For the purpose of this dissertation, it is very important to acknowledge the strong emphasis on ICT and digital skills during this period. These skills were highlighted in the National Core Curriculum, but in various other official documents as well. For instance, in the Knowledge for All! Action Plan introduced in 2006, the government promised the continuation of the reforms in the education system. The Action Plan contained 163 points, and at point number 20, it is highlighted that: "We want to enhance digital literacy skills, and the presence of multimedia educational opportunities that help efficient individual learning" (Ministry of National Resources, 2006, p. 2). The difference or resemblance between digital literacy and media literacy in public education (and specifically in the NCC) will be discussed in detail in the following.

\subsection{Contextualising policy on media literacy}

The development of media literacy education in educational policy cannot be understood without a thorough analysis of the revised National Core Curriculum of 2003 and 2007. Thus this section will present the two key building blocks of policy contextualization: 'policy levers $\&$ drivers' and 'warrants'. As presented earlier, policy levers\& drivers deal with the specific aims and goals of a policy document, while warrants provide the rationalization of a certain policy (Hyatt, 2013). In an effort to understand the NCC it is also important to include in this analysis the amendments to the Act on Public Education (1993) that came into effect in the summer of 2003. These new amendments introduced new educational priorities and tools. Because of their 
significant effect, "[...] in the course of the legislative process, the regulations attracted great professional and public attention" (Radácsi, 2004). Among the most important changes were the prohibition of all forms of discrimination, the extension of pupils' and parent rights and the increase of class time devoted to foreign language and basic competency education (Radácsi, 2004).

In terms of warrants, it is revealing to see the rationalization of the 2003 amendments to the Act on Public Education. In a ministerial document (Indoklás a közoktatásról, 2003), there is an ample text presenting the rationalization for these new amendments. Among the reasons why the Act on Public Education has to be modified, this official document enumerated the following: the level of pupils' literacy is inadequate compared to other countries; public education reproduces social inequalities; pupils are overburdened; graduates cannot use IT tools and do not know how to put their theoretical knowledge into practice (Indoklás a közoktatásról, 2003). By using a mix of different types of warrants, the ministerial document presents the changes in educational policy as undeniably necessary. The evidentiary warrant (justification is based on empirical facts, and thus it is undisputable) comes to fore when the authors state that analyses show that pupils have too much schoolwork. However, it is not specified which reports are being discussed, who performed them and for what reason. The empirical results of these analyses are presented as evident reasons why policy has to be changed. The accountability warrant calls for action in order to improve results. The accountability warrant highlights that the level of pupils' literacy it is not at an acceptable level, and it has to be changed. And finally, the political warrant refers to a justification that brings into discussion the public interest: public education in its current form reproduces social inequalities.

As a direct consequence of the revised Act on Public Education, the National Core Curriculum was comprehensively reviewed as well. Therefore a "[...] less regulated real core curriculum was born with no teaching material specifications" (Radácsi, 2004). In the following, I will focus on analyzing the policy concerning media literacy education from a macro semantic and societal level, and then turn to the micro, lexico-grammatical level. 


\subsection{Deconstructing policy}

\subsubsection{The macro semantic level}

For understanding policies, it is important to analyze how governments justify their actions. Policies are frequently justified by attaching them to dominant norms (Hyatt, 2013). Fairclough (2003) distinguishes four modes to accomplish legitimation discursively: authorization, rationalization, moral evaluation and mythopoesis (legitimation through narratives).

When examining to the NCC, the first paragraph (NCC, 2003) presents the following goals:

The principal function of the National Core Curriculum (NCC) is to define the basic principles and the approach which govern the content of public education. By allowing room for the autonomy of individual schools, it defines the general objectives of public education which should be pursued nationwide, the main domains education must cover, the phases of public education in terms of content, and the development tasks which must be fulfilled in the various phases. The NCC lays down the foundations for the body of knowledge to be acquired in school, and thus creates unity in public education.

The aims outlined in this quote strengthen the above mentioned observation: we can see here that policy-makers want to highlight a less regulated core curriculum. The introduction talks about "basic principles", "general objectives" and school autonomy. In critical discourse analysis it is very important to note the choice of vocabulary. In this case, the vocabulary denotes a certain approach to educational policy-making, decentralization. Out of the four modes of legitimation, policymakers are using here moral evaluation, "an appeal to a value system around what is good or desirable" (Hyatt, 2013, p. 840). What is desirable here is to have an NCC only as a foundation for further educational documents, and for this the autonomy of schools is also outlined. In the second chapter of the NCC (2003), the policy-makers enumerate the common values of education:

The NCC helps schools operate in a way that teaching and learning processes are organised to promote the values of democracy, humanism, respect for the 
individual, freedom of conscience, personality development, progress towards cooperation between fundamental communities (family, nation, community of European nations, mankind), equality between peoples, nations, national minority and ethnic groups and genders, solidarity and tolerance. The NCC seeks to strengthen a school system which advances the achievement of equality of chances.

Similarly to the NCC drafted in 1995, the first value introduced is that of democracy, which is then proceeded by individual and community values. In contrast with the 1995 NCC, the document talks about the "community of European nations" (NCC, 2003, 2007), instead of a more general phrasing that appeared in the 1995 document (European values). This reflects the changes that happened during that period, and Hungary's application to join the EU. The overall message of this fragment can be thus understood as a political warrant: the NCC is an important document because it helps to construct 'the good society'. This warrant is couched in the evocative and positively evaluated terms of 'equality', 'solidarity', 'tolerance', and so on. In addition to this warrant, the 2003 NCC (and consequently the revised one in 2007) introduces a new justification on why the NCC is important, and that is economic development. This new reason did not appear in the previous NCC (1995), and it reflects perfectly the changing times:

The NCC [...] propels school education towards contributing to the economic development of Hungary. [...] It regards the knowledge and behavioural characteristics that are indispensable for the Hungarian economy to reinforce its position in global economic competition and to maintain sustainable growth to be particularly valuable. It cherishes all values that represent highlevel expertise, the sound management of assets, reliability in one's work, the creation of value through work, quality work and an effective participation in the economic arena. It appreciates all efforts directed at the acquisition of knowledge that is the driving force of the modern economy.

For understanding how economic development came to be an important aspect in education policy-making, we need to see how the authority of the state has changed over time. Steer et al. (2007) argue that in the post-Keynesian state governance was interchanged with neoliberal forms of authority, which resulted in the involvement of various actors in policy-making. Hyatt (2013, p. 838) notes that this process "was 
underpinned interdiscursively through the interpenetration of discourses of governance and marketisation." In the above fragment one can spot the penetration of a market discourse through concepts such as 'global economic competition', sustainable growth', or 'sound management of assets'. This indicates a market-oriented policy language (Ball, 2007, Knight and Yorke, 2004), that can now be considered a global phenomenon, in which market terms, such as 'quality', 'efficiency', or 'entrepreneurship' came to dominate educational policies. Policymakers thus use moral evaluation: 'it is desirable to have an education that contributes to economic development' as a form of legitimation. The above analysis presented the most important elements of policy analysis from a macro level in terms of the national core curriculum and the next section looks at it from the micro level.

\subsubsection{The micro, lexico-grammatical level}

As discussed in previous chapters, the micro, policy deconstruction builds on tools and lenses derived from Fairclough's model $(1989,1995)$ for critical discourse analysis, and Hyatt's Critical Literacy Analysis (2005). For revealing the most important aspects of these texts, a particular attention was given to Vocabulary:

- The relational, experimental and expressive values of words used (such as euphemisms, ideologically contested words, formal and informal words, etc.)

- Use of stylistic devices (metaphors, repetition, etc.)

Grammar:

- Passive/active sentences \& agency

- Use of specific terms

- Use of verbs (tenses and modality) and pronouns

- The expressive values of grammatical features

In the $2003 \mathrm{NCC}$, one of the key development tasks was Information and Communication Culture. In 2007, Digital competency appears as one of the key 
competencys in the NCC. Because the 2003 development task and the 2007 competency have many common features in connection with media literacy, I will address these from a micro level. In the second part of the analysis, I will focus on how the standalone subject, Culture of Moving Image and Media Education.

Information and Communication Culture - Key Development Area (2003 NCC). Key development areas work as cross-curricular themes that have to appear in all elements of school education (NCC, 2003). Among the eight key development areas, Information and Communication Culture is the fifth, and it is proceeded by Self-image and Selfknowledge, Homeland and Peoples, European Identity-Universal Culture, Education for Environmental Awareness. Its position has not changed if we compare it to 1995 NCC in which Communication Culture occupied the fourth place out of seven crosscurricular requirements. An important element that has to be noted here is the change of the name itself from Communication Culture to Information and Communication Culture. For policymakers it was seemingly important to talk about information separately, and not as a segment of the larger field of communication. In Chapter 1, I presented the different concepts in connection with media literacy: information literacy and media and information literacy are two of these competing terms. Moreover, media and information literacy is strongly promoted by UNESCO and its partners. While this is not the focus of the analysis, it has to be noted that there are strong opponents of this term in Hungary too. László Hartai, for instance, seemed quite skeptical about this term: "It makes no sense to talk about media and information literacy. What does 'information' mean, after all?" (interview with László Hartai, 19 December 2014). In understanding the reasons why 'information' was added to the title, the description of the key development area might be helpful. In comparison with the 1995 version of the NCC, there is a higher number of times when the term 'information' is used. In the 1995 NCC this term is used only once, while in the 2003 NCC, this term appears three times, and there is an ample explanation how the schools should prepare pupils for using information:

The school should educate pupils to understand the mechanisms of electronic media (highlighted in the original text) and to navigate among a variety of media. The school should also teach pupils to find the needed information, and its selective use, by taking into account the protection of individuals' psychological health. The school should 
cultivate young people who are able to use the possibilities and tools of the information web in their lifelong learning.

In the above fragment the authors use the modal verb of 'should' ('kell') in order to emphasize the obligation of schools. Modal verbs can have a wide variety of communicative functions, but in this situation we can talk about deontic modality. Deontic modality shows a necessity in terms of freedom to do something: it is the schools duty to do as stipulated by the policymakers. Moreover, the use of this type of modality shows the speakers "estimation of the necessity that the proposition expressed" (Nida, 1949, p. 169). For schools it is thus imperative to follow these guidelines. One could argue, however, that these guidelines are phrased in quite general terms. There is no specification on how schools should educate children to "find the requested information" (NCC, 2003), for instance. Similarly, the use of the general term of 'schools' abolishes the differences between schools, and it suggests that all schools can achieve these goals. The use of these general concepts and explanations might be explained by the role of the cross-curricular requirements. According to the NCC (2003), the requirements have to be present in all school subjects, thus a more general phrasing can aid their implementation in the various subjects.

Going further, one cannot overlook the fact that 'electronic media' is emphasized in the text by using a larger and italic font. In the whole text of this requirement there are two elements highlighted in this way: the 'development of cognitive abilities' and 'electronic media'. Halliday (1985) argues that language fulfills three communicative functions: to convey ideas, attitudes and to give coherence. Van Leeuwen (2005) asserts that this is true for typography, as well. In his model of analysis, typography has three functions: it represents ideas (e.g. a metallic font shows durability), it offers attitudes (e.g. a bold font shows a warning), and it gives coherence (e.g. the use of a font throughout a document) (Machin and Niblock, 2008). In the 2003 NCC throughout the key development areas, there are some emphasized concepts that are more visible than the rest of the text. The larger and italic font has the role of outlining the most important elements in a text. The fact that 'electronic media' is emphasized in the 2003 NCC shows a shift in the discourse on media, since in the 1995 NCC's common requirements the focus was still on the 'audiovisual environment'. The last element of interest in this text is the final sentence: the verb used here is very peculiar. The school should 'release' or 'equip' ('kibocsátania') pupils. While one could argue that it is just a figure 
of speech, it strengthens the previously mentioned modality question. Just as the use of modal verbs, the fact that pupils should be 'released' from school shows implicit authority claims and implicit power relations. One of the hidden power relations is between policymakers and 'the school', while the other is between 'the school' and the pupils: 'schools' are obliged to follow the guidelines, and pupils have to do the same.

At the beginning of this section, I speculated that the description of the development area might offer a solution to why the name of this requirement has changed from Communication Culture to Information and Communication Culture. While there was no explanation for this change, the 2003 NCC provides a more detailed account of how schools should prepare students for a critical usage of information gathered through electronic means. The existence of the interconnected terms of information literacy, media literacy and media and information literacy shows that the discussion among proponents of these concepts is hardly over. The 2003 NCC in this sense seems draws upon the discourses associated with information literacy (the importance of careful retrieval, analysis and use of information). As Wallis (2014) observes the discourse on 'information society' surfaced in the second part of the 1990s, and continued with the rise of the internet. This discourse highlights the "emergence of a novel form of society" (Webster, 1995, p. 218) and it is connected to the so-called knowledge economy, that "produces and distributes ideas and information rather than goods and services" (Drucker, 1992, p. 263). Th authors of the 2003 NCC connect the skill of information gathering to the lifelong learning paradigm, as proposed by the OECD and the EU.

Digital competency - Key competency (NCC 2007). A concept closely connected to media literacy occupies an important role in the 2007 NCC: digital competency. The chapter on competencies was added to the revised NCC of 2007. In introducing the new term of competencies, the NCC's authors argue that

In the conceptual network of key competencys all knowledge and abilities were incorporated that will capacitate all citizens of the EU to quickly and efficiently adapt to this ever-changing modern world and to actively participate in influencing the direction and the content of these changes. That is the reason why the system of key competencys has evolved into a standard canon of school education. 
This quote is a revealing example of how the Organization For Economic Cooperation and Development's (OECD) policy discourse has influenced national education policy discourse in Hungary (Ball, 2008, Bieber and Martens, 2011). As outlined in an earlier chapter, the OECD's Programme for International Student Assessment (PISA), has had a major influence on Hungarian educational policymaking. One of the reasons is the media frenzy that surrounds the yearly results of this assessment, highlighting the poor achievement of Hungarian pupils. However, it is important to see that the OECD's concepts of 'key competencies', 'lifelong learning' or 'knowledge economy' have gained more and more recognition over the years in Hungary. These have been consequently adopted by the European Union, and consequently, by the member states (Takayama, 2013). However, many scholars criticize the OECD's and other supranational entities' discourse on education. One of the criticisms highlights the radical change in the way meritocracy appears in modern educational systems. Instead of having a standardized assessment of prescribed knowledge and skills, students have to prove their 'functional potential': "students are to be assessed in terms of their ability to accomplish a given task in a concrete, real-life circumstance" (Takayama, 2013, p. 71). The problem with this assessment is that most of the skills needed in these tasks cannot be taught in formal settings, and the socio-economic background of pupils has a major contribution. Regardless of these criticisms, the new educational discourses are present and well represented in the Hungarian policy documents, in the second part of the 2000s. In terms of policy analysis, it is also important to highlight that the Ministry of Education's Mid-term Strategy of Public Education (2003) also emphasizes the development of basic competencys as top priority.

Among the key competencies, thus, digital competency is clearly important in terms of media literacy education. As presented in the beginning of this thesis, there are a number of interrelated concepts when it comes to defining media literacy. One of the major 'competitors' of media literacy is exactly 'digital literacy' or 'digital competency', because of the very similar and even potentially overlapping areas of interest such as Internet safety, digital production. In the NCC (2007), digital competency is defined as follows:

the confident and critical use of Information Society Technology (IST) for work, communication and leisure purposes. This is based on the following skills and activities: recognizing, retrieving, 
evaluating, storing, creating, presenting and exchanging information as well as communication and cooperation in networks via the Internet.

One can argue that these skills comprise only a small area of media literacy. However, in the description of this competency it highlighted the importance of critical thinking and responsible use of information and media. These are important skills in media literacy education as well. Another interesting aspect is that there are two other key competencies that are very much connected to media literacy: Aesthetic and Artistic Awareness and Expression, and Social and Civic Competencies. In terms of policy development, the presence of Digital competency (and to some extent Aesthetic and Artistic Awareness and Expression and Social and Civic Competency) in the NCC is important because the key development tasks of the National Core Curriculum build upon the key competencies.

Culture of the Moving Image and Media Education in the NCC. The 2003 revised version of the NCC does not contain any detailed teaching content or criteria. Instead, development guidelines and objectives were drafted for each subject. Vass (2008, p. 3) argues that because of these changes the "document is substantially shorter and more transparent, and most importantly, the focus has shifted from content to competencybased learning." As a consequence of these revisions, content regulation was transformed into a three-tier system, "where the central transmitting level provides new documents, alternative curricular solutions and directly adaptable teaching programs" (Radácsi, 2004). The 2007 revised version further developed the 2003 NCC's learning concept, while introducing the key competencies that were presented earlier. In terms of the Culture of the Moving Image and Media Education, its subject description was not modified from 2003 to 2007 NCC.

The Culture of the Moving Image subject is part of the Arts subject area, together with Literature, Music, Dance and Drama, and Visual Culture. However, a close examination of the description of this subject shows a more social sciences approach:

The aim of the Culture of the Moving Image and Media Education subject is the development of film literacy and the exploration of the social role and mode of operation of mass media. This involves learning the basics of audiovisual 
literacy and the development of critical media literacy. Media education is a skill and personality development tool that is necessary for citizens to be able to make informed choices in the age of information explosion and modern market economy. (NCC, 2003, 2007)

In 2003, media literacy appeared for the first time as a term in the Hungarian national core curriculum. The focus is primarily on the moving image, since this is the first aim mentioned ("development of film literacy”, "basics of audiovisual literacy"). However, the role of mass media in society occupies a central role in this description. The social sciences aspect is further strengthened by the presence of such concepts as: "personality development", “citizens", "modern market economy", “democracy”. Media education is presented as a solution for the "modern market economy". It is interesting to note the use of "citizens" in this context: instead of using "pupils" or "children", or the more general term of "people", policymakers stress that media education is beneficial for citizens. This discourse is connected to a more ample discussion on the role of media literacy in society. Wallis (2014) has also found that in the UK one of the leading discursive threads in connection with media literacy involves citizenship and civic engagement. In these discourses media literacy is seen as a tool to further the empowerment of citizens. A similar approach can be discovered in this educational policy. Besides positioning children as citizens, a further emphasis is on the type of choices citizens can make ("informed choices"). The evaluative statement (Fairclough, 2010) shows that it is desirable to make informed choices, in contrast with other type of choices. It is also suggested that without media education, this would not be possible. The civic aspect is further developed in the following part of the subject's description:

Because media strongly influences us on how to think about the goings-on of the world, and its influence rivals the influence of traditional socializing agents - the family and the school-, Culture of the Moving Image and Media Education is the school of democratic education and of values such as the acceptance of diversity, development of critical thinking and conscious choice. (NCC, 2003)

Fairclough (1989, p. 114) argues that "some words are ideologically contested, the focus of ideological struggle:" socialism, democracy, nationalization are all examples of ideologically contested terms. Moreover, Fairclough (1989) adds that the occurrence of ideological frameworks (and their corresponding concepts) will tend to ideologically 
place a text. In this above fragment there are (at least) two contested terms: "democratic education" and "acceptance of diversity". In addition, by categorizing critical thinking and conscious choice as "values", the authors position these skills as something that pupils should strive for. As a further important element that needs to be mentioned here is the powerful media paradigm, that regards mass media as a strong actor able to influence masses. This paradigm is represented here by two statements that are written in expressive modality: "Because media strongly influences us" and "its influence rivals the influence of traditional socializing agents". The verbs are in the simple present tense form. According to Fairclough „This is one terminal point of expressive modality, a categorical commitment of the producer to the truth of the proposition" (1989, p. 129). This is an extremely important point because there could have been alternative modes of presenting these sentences, such as: „,because media might have a strong influence". However, by choosing the present tense form, the authors' ideological interest lies in the authenticity claims. The powerful media paradigm can be found in the Hungarian NCC and framework curricula since 2000, when Culture of the Moving Image and Media Education was first introduced as a module subject. As I argued in the previous chapter, this focus on the powerful media effects might be explained by a conscience choice of policymakers to convince schools and teachers about the importance of this subject.

The development guidelines are arranged into two groups: guidelines for the seventh and eight grades and the guidelines for the ninth and twelfth grades. The guidelines are visually presented in a table, and they "define different areas for the development of students' skills, which designate the desirable key competencys that have to be developed in the different schooling stages" (NCC, 2003). The structure for the Culture of the Moving Image and Media Education development guidelines is made of six areas: Observation; Learning; Communication; Interpretation, analysis, tolerance; Critical thinking, problem sensitivity; Self-knowledge, collaboration, choice, tolerance, interest towards creation. For each of these areas there are a number of examples. For instance in the case of Observation, the following example is given: "Studying the habits of the audience's media consumption based on the given criteria, transcribing the results" (NCC, 2003). The examples are all phrased in sentences that lack verbs. This stylistic choice can be explained by the overall role of the revised NCC to shift the focus from content to competency-based learning. The NCC offers thus only 
general guidelines. This can be and was considered problematic for those who argue for a more centralized core curriculum. In the parliamentary debates of that period, this conflict came to the fore. In one of the official interpellations addressed to the Minister of Education, it is highlighted that "compared to the NCC of 1995, the revised NCC does not have specific curricula, compulsory and common requirements. If no frame curricula will be made with recommendations for lesson-planning - as it was with the 1995 NCC- we can expect disputes involving existential issues that will stir up the emotions of the educational community." (Hogyan lehetne, 2003). As an answer to these concerns, the minister replied "all this helps schools to have diversified curricula and educational programs in order to improve the quality of their work. This is the true professional appreciation of teachers, in contrast with that comprehension that does not consider teachers capable of independent thinking and curriculum development based on the NCC. Education management that is based on such comprehension is obviously better served with mandatory curriculum" (Írásbeli válasz, 2004). As it will be discussed in the conclusion of the thesis, these two antagonistic approaches to education management influenced policymaking to a great extent in the last 20 years. The development guidelines for this subject too, then, offer only general references to what is expected from pupils to know by the end of their eight and twelfth grade, respectively. In terms of microanalysis, what is important to see is the frequent mentioning of the term "moving image" or terms from the same semantic field ("films", "moving image memory", "story-board", "video connection", etc.). The "questions for steering awareness" are interesting elements of the frame curricula. These come right after the development guidelines, and are quite unique in the NCC, since similar questions cannot be found at other subjects. These questions seem to be added to the document as some sort of aid to class discussions: "What is the role of the TV (cinema, radio, newspaper) in my life and in others' life?" or "Does media usage influence my daily schedule (and how)?" It is unusual in terms of style that the majority of these questions are written in first-person (singular and plural). The use of the first-person plural ("we") shows a certain partnership or solidarity between the author and the reader (Fairclough, 1989). In this case, it might also refer to the partnership between teacher and pupils. Moreover, the use of guiding questions shows also a different type of approach towards education. Advocates of media literacy stress that media literacy education "helps youth express their voices, connect with communities and increase their civic engagement by sharing with peers and adults their opinions about socially 
important issues (gun violence, drugs, bullying, etc.) (Friesem, 2014, p. 45). These questions show exactly a type of collaborative learning. In contrast with the development guidelines, the bulk of the questions use terms from the social sciences ("public space", social role of media, "interests", role of ads, role of celebrities, ethics and so on). The questions for grades 9-12 are more sophisticated in terms of the used concepts and the difficulty of the topics. However, the social sciences line is further strengthened with concepts, such as "citizenship", "consumer society", or "fundamental human rights" (NCC, 2003, 2007).

Information technology in the NCC. There is one more subject in the NCC where content connected to media literacy can be found, and that is Information technology. One of the development guidelines in this subject is called Media informatics (Médiainformatika). The description of this guideline highlights that the "savvy usage of the media interwoven by IT tools (web portals, interactive-digital TV, digital photography), presupposes IT knowledge as well. The electronic versions of traditional media open up new possibilities. The possibilities of IT allow the appearance of totally new media (virtual reality, interactive media)" (NCC, 2003, 2007). In this short section the word 'possibilities' ('lehetőségek') appears twice, and there are two instances when 'traditional' is juxtaposed to 'new' or 'electronic'. The text here belongs to those strands of discourse that highlight the importance of technology. One can find these texts in various governmental e-programs, or CSR programs of tech giants. These discourses position "technology's power as a crucial agent of change" that has "a prominent place in the culture of modernity" (Marx and Smith, 1996, p. ix). The different texts promoting the use of new technology are intertextually connected by highlighting the (previously non-existent) possibilities that these technologies can unlock. By situating antagonistically the old/traditional way of working or learning to the new opportunities, the positive features of the latter one are outlined. The critique of these educational initiatives is usually that the "relationship that children can establish with digital media, how these are present in their lives, the competencys required to deal critically and creatively with these means [...] are usually overlooked by policymakers" (Pereira and Pereira, 2015, p. 338). Unfortunately, these critiques stand for this development guideline as well. Moreover, there is no connection made in the text with the Culture of the Moving Image and Media Education subject, which could strengthen the critical analysis aspect. 
Culture of the Moving Image and Media Education - the frame curriculum. As it was mentioned in the introduction of this chapter, the frame curricula for this subject have not changed considerably from the first version of this curricula introduced in 2000 . This is quite surprising, since in the seven years that passed between these versions, there were major changes happening in terms of digital culture, or civic engagement, two very important areas of media literacy education. Another odd feature is that while in the 2000 and 2003 frame curricula there were two versions, A and B, version B completely disappeared from the 2007 document. Just as there was no explanation on why there were two versions in the first place, there was no justification of why the second version disappeared. In an interview one of the experts however mentioned that "the two versions did not really have an impact in teaching, because the textbooks were written based on the first version" (personal communication with György Jakab, December 9 2015). This might be the reason why version B was deleted eventually from the curriculum. In the next part, I will present only the modified segments of the frame curricula, since the initial version was thoroughly analyzed in the previous chapter.

The most significant change in the frame curricula was introduced in the 2007 version. This is when media literacy in English appears as a term. The following fragment is a very important milestone in the policy history of media literacy education in Hungary:

Audiovisual literacy is a component of media literacy [the term appears here in English]. The two other components are written texts literacy and, in today's information society, the increasingly important digital literacy. Development of media literacy is interconnected with learning to be an active and involved citizen, as well as with the development of critical and creative skills. [Media literacy] contributes thus to the following key competencies appearing in the National Core Curriculum: native language communicational skills, digital, social and citizenship competencies, as well as with the development of aesthetic and artistic awareness and expression. (Framework Curriculum, 2008)

The text starts with a 'realis statement', or statement of fact (Fairclough, 2003): audiovisual literacy is one of the components of media literacy. 'Realis statements' are used to communicate a statement about what is or was the case (Fairclough, 2003). 
However, these statements are implicitly evaluative because it is always a matter of choice of what is presented as a fact. In this case the authors aim to stress that audiovisual literacy is important because it is a constitutive element of media literacy. The next sentences are all 'realis statements': media literacy is connected to active citizenship and development of critical and creative skills. And since audiovisual literacy is part of media literacy, the subject is connected to relevant key competencies that appear in the NCC. One could ask why it was important for the authors to add this text to the otherwise slightly modified frame curriculum. One of the reasons might be the positioning of this subject as a relevant one for gaining key competencies. The authors seemingly do not want to let go of the moving image focus, and this is why audiovisual literacy is proposed as a building block of media literacy. In Chapter 1, I presented a lengthy description of how media literacy is defined, and which are its interconnected and competing terms. Digital literacy was one of those. In this case, though, the authors add digital literacy to one of the components of media literacy. This fluidity in how media literacy is used shows once again what Wallis (2014) has also discovered in the UK educational policy: media literacy is sometimes embraced, sometimes rejected, depending on when those who use it can benefit or not from it. The other modifications that are important to mention in the 2007 version are the inclusion of the print press to the typical media texts that have to be addressed in class. In the previous versions of the frame curricula the audiovisual media was the main focus of analysis. In this respect, adding print media can be seen as an important milestone in having a more thorough media text landscape. 


\section{Conclusion}

In this chapter, the aim was to analyze the two revised versions of the national core curriculum, versions of 2003 and 2007. There were multiple reasons why the two versions were presented in the same chapter: the continuity in the political leadership of the country, the relatively few differences between the two NCCs and the frame currricula of Culture of the Moving Image and Media Education. The role of supranational organizations (OSCE, EU) was also discussed because they had a traceable and recognizable effect on educational policies of that time. In Figure 6 below the synthesized results have been outlined.

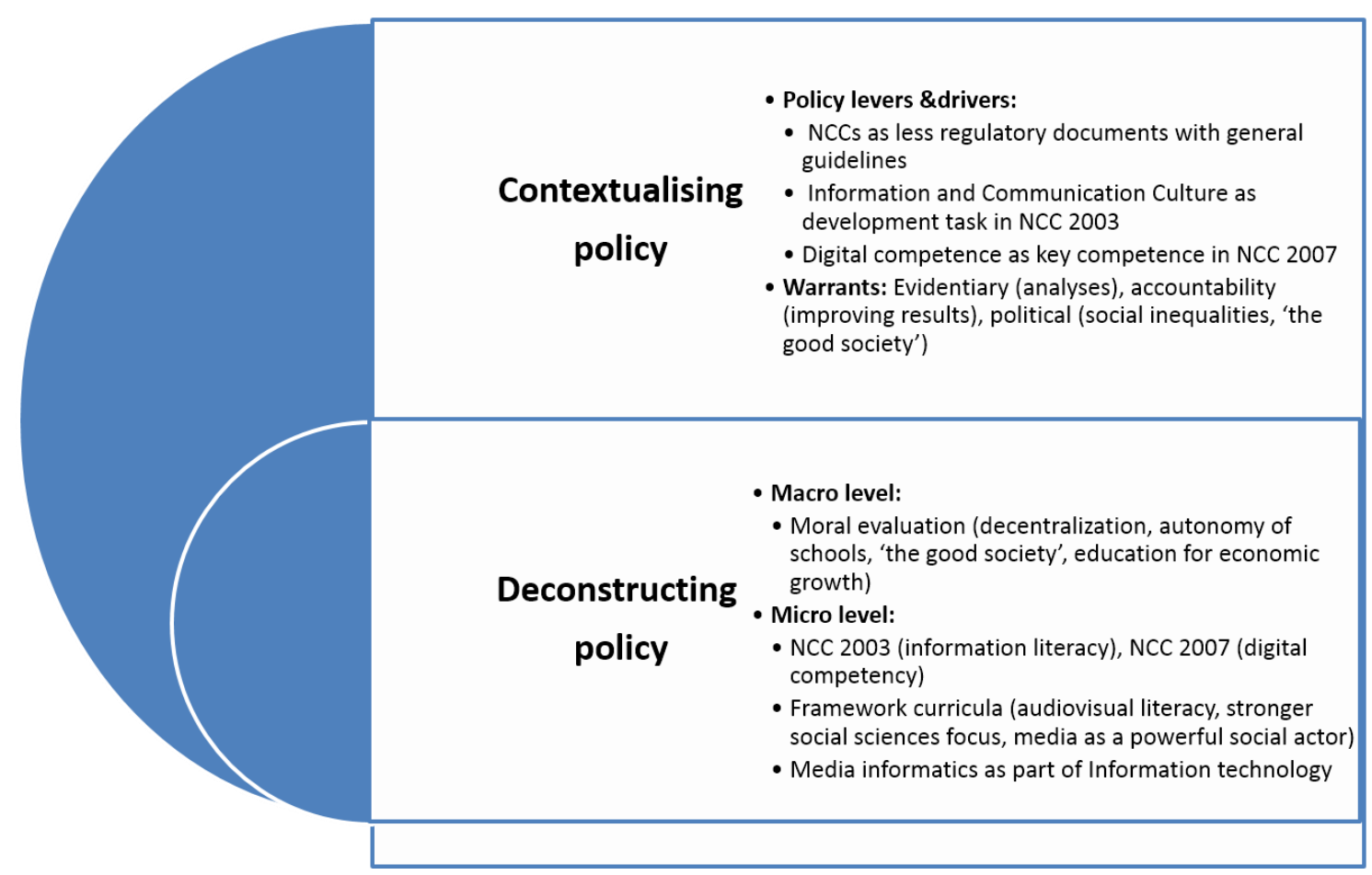

Figure 6: Synthesized results of CDA-analysis NCC and framework curricula, 2003 and 2007

In terms of micro analysis, the two NCCs introduced various elements in connection to media literacy. The 2003 NCC introduced Information and Communication Culture as a development task, while the 2007 version advanced the term of Digital competency. The analysis revealed that the global discussions and dilemmas referring to the different concepts that deal with digital media, can be found in the Hungarian educational policy documents as well. While the NCC 2003 promotes the term information literacy, the 2007 NCC focuses on the concept of digital literacy. An important element is that media 
literacy is mentioned in the framework curricula of Culture of the Moving Image and Media Education. As it was the case with previous documents, in the framework curricula the focus is again in on audiovisual content, but a stronger social sciences focus could be detected, compared to previous educational documents. This social science approach is supported by the introduction of such concepts as "public space", "interests", "ethics" within the Culture of the Moving Image and Media Education frame curricula. A last point to be made is that media literacy content appears in the frame curricula of the Information technology under the label of Media informatics. However, in this case, the text draws on the techno-optimist discourses of possibilities opened up by new technologies. The next chapter will present the changes that were to happen in 2012 with the introduction of the new core curriculum. 


\section{Chapter 7: 2012 - the year of major educational changes}

\section{Introduction}

This chapter focuses on the latest, 2012 National Core Curriculum. Using the critical framework presented in the previous chapters, I will discuss how media literacy education is positioned within this new NCC. For a complex understanding of the changes that were implemented by the 2012 NCC, I will first describe the political context in which this core curriculum was adopted followed by an analysis of how media literacy education appears in the policy documents both as a separate subject and a cross-curricular theme. And finally, by building on existing literature and the expert interviews carried out, an assessment of the strengths and weaknesses of the 2012 NCC's media literacy education content will be presented.

\subsection{Political landscape}

The latest National Core Curriculum and consequently media literacy education cannot be understood without a glance at the political context in which it was created. In general terms the Hungarian political and economic situation can be characterized by a growing role of the state. In 2010 center-right Fidesz (Hungarian Civic Alliance) party won the elections, and for his second period as Hungary’s prime minister, Viktor Orbán led his coalition to a two-thirds majority. The overwhelming majority helped the coalition to pass many laws through Parliament that needed a two-third majority. The changes in the political system were followed by changes in public broadcasting, senior managers and editors of public service broadcasters were replaced (Bajomi-Lázár, 2014). Rearrangements were in place at the National News Agency (MTI) as well. The new director of the National News Agency, Csaba Belénessy declared that "public broadcasting should be loyal to the government and fair to the opposition ("Belénessy Csaba a köz új szolgálatáról”, 2010).

Media legislation saw similar changes: a succession of amended and new laws was put into force through the so-called Hungarian "media law package." The ruling coalition modified the media law without further consultations with opposition parties and professional organizations. Initially the new media law (Act CLXXXV of 2010 on 
Media Services and Mass Media) highlighted that "the exercise of the freedom of the press may not ... violate public morals." There was no further definition or explanation on what freedom of press or public morals are. Numerous international criticisms followed these actions. The European Parliament adopted a resolution in March 2011 in which it warned Hungary that the legislation contravenes international standards. The resolution concluded that "there should be a serious, concerted and urgent effort to free the media, particularly the printed press, from content prescriptions, the imposition of sanctions, pre-emptive restraints via registration procedures, and threats to the integrity and anonymity of sources" (Council of Europe Commissioner for Human Rights, 2011). However, Tibor Navracsics, European Commissioner for Education, Culture, Youth and Sport, declared that the controversial parts of the media law package were discuseed with the Council of Europe and the European Commission. As a result, he said, Hungary amended the law (Fazekas, 2014).

The Fidesz government made radical changes in the field of education as well. The changes influencing the educational system meant first of all centralization: a central governmental agency became the employer of all teachers, and the choice and provision of textbooks became centralized as well. The 2012 new core curriculum came to be an important milestone in this transformation. Then Secretary of State for education, Rózsa Hoffman, considered the NCC "modern and in line with the latest European Union trends," yet in the same time, Hoffman stated that the new NCC will represent "a return to the old traditions and baseline standards of cultural literacy. Around 90 per cent of what high school teachers can teach will be fixed, providing the basis for a unified cultural language throughout Hungary" (Murphy, 2012). Media literacy education, once again, was profoundly influenced by the revision of the national core curriculum. 


\subsection{Contextualizing policy on media literacy}

When it comes to the intended goals of media literacy policy, it is helpful to analyse the exact position of this policy in the text of the 2012 curriculum. Media literacy education is mentioned for the first time in the development areas.

The development areas or educational goals are positioned as important elements in the process of education. According to the 2012 NCC's introduction the development areas reflect "shared values" and "they incorporate traditional values together with the $21^{\text {st }}$ century's new societal needs" (p. 10641). One could presume that this shows a clear interest of the government towards media literacy. Yet when this aspect was pointed out to one of the Hungarian media literacy experts, Lányi dismissed it as "pedagogical haze" (interview with András Lányi, January 16, 2015). He argued that "in the development areas policy-makers tend to write about an ideal world of education. I don't think that this can help the advancement of the subject" (ibid.). It might be an ideal world, and yet among the thirteen development areas media literacy ranks twelfth. Not a significant position, since it is proceeded by areas such as Ethics education, National consciousness and patriotic education, Citizenship education or Development of self-knowledge and social culture. It is interesting to note here that media literacy education and citizenship education are strictly demarcated, yet media literacy scholars stress that "honing in on civic engagement may have real strategic value" (Berger, Hobbs, Mihailidis, 2015, p. 6).

The National Core Curriculum then goes to expand on the goals of media literacy education, as a development area:

The aim [of media literacy education] is for children to become competent participants of the global mediated public: to understand the language of new and old media. Media literacy education prepares [students] for the culture of participatory democracy and a meaningful and value-based everyday life that is being influenced by the media. It does all these by developing a critical and actionoriented attitude. Pupils are introduced to the operation and mechanisms of the media, to the mutual relationship between media and society, to the differentiation between real and virtual, public and confidential and to the importance of these differences' and media characteristics' legal and ethical significance. (2012, p. 10644) 
For understanding these goals thoroughly it is important to see what levers are accessible to the Hungarian government to transpose these aims in everyday teaching. According to Hyatt (2013) levers aid policy-steering, being instruments "the state has at its disposal to direct, manage and shape change in public services... functional mechanisms through which government and its agencies seek to implement policies" (Steer et al., 2007, p. 177). In educational settings these levers can be target-setting, funding, inspection etc. (Hyatt, 2013). When it comes to the National Core Curriculum, there are no specific targets set for the different subjects. The NCC serves "as a key reference for authors and editors of framework curricula and local curricula, as well as for the developers of pedagogical programmes" (International Bureau of Education, 2012). Information on targets, as well as specific details, such as number of hours devoted to each topic, are to be found in the framework curriculum of each subject. According to László Hartai, one of the interviewed experts, teachers do not actually read this document. He thinks that the National Core Curriculum is "not much more then a so-called 'fig leaf', the real regulation is in the frame curricula" (Interview with László Hartai, November 21, 2013). Thus the NCC appears to be a political instrument that sets the general boundaries of public education.

As another important element of contextualization, warrants provide justification for policies. The construction and the debate of policy happen through language and thus they are discursively meditated (Hyatt, 2013). As mentioned previously, CochranSmith and Fries (2001) identify three types of warrants: evidentiary warrants, accountability warrants and political warrants. In this case the political warrant is the most relevant since the new curriculum was one of the major milestones of the new Hungarian government's policy changes. Moreover media literacy education and policy cannot be separated from the warrants of the new National Core Curriculum.

The new curriculum was presented by the Minister for Human Resources as "timeless and modern" at the same time (Orientpress, 2012). The Minister said that a major, multi-year work preceded the publication of this document, and that the patrons of the Curriculum are respectable professionals.

It is relevant to note here that the new policy is being justified not only in terms of the national interest, but a warrant of authority is also used by outlining that a body made of "respectable professionals" offered their patronage and expertise for the policy 
document. The Minister, however, did not specify who these professionals were. Later on, an article appeared on fn24.hu in which a list of these experts was published, at the insistence of journalists.

\subsection{Deconstructing policy}

In the following I will analyse the policy concerning media literacy education from a macro semantic and societal level, and then turn to the micro, lexicogrammatical level. Since the "key aim of critical approach to analysis resides in attempts to uncover the process of naturalization in any discourse" (Hyatt, 2013, p. 840), I will present a number of relevant aspects regarding media literacy that can be discovered by using analytical lenses and tools derived from CDA.

\subsubsection{The macro semantic level}

When it comes to policy analysis it is crucial to shed light on how governments justify their actions. As mentioned earlier, according to Fairclough (2003) there are four modes to accomplish legitimation discursively: authorization, rationalization, moral evaluation and mythopoesis (legitimation through narratives). The Minister of Human Resources used both a moral evaluation and authorization warrant for introducing the new National Core Curriculum. Furthermore, this type of moral evaluation can also be observed by advancing a bit and narrowing our view towards the development areas since media literacy is listed among these.

The development areas expression is being used interchangeably with pedagogical aims in the text. Already in the first sentence, it is outlined that these areas are representing common values. The policymakers are appealing to a value system that is supposed to be shared by all Hungarians. As in the process of 'naturalization' (Fairclough, 1989), these values are presented as if they were of common sense and inevitable.

The curriculum then goes on to point out that these development areas "incorporate traditional values together with the $21^{\text {st }}$ century's new societal needs" (2012, p. 10640). There is no further explanation on what traditional values or new societal needs mean. One can only make assumptions by looking at the thirteen 
development areas. In many instances, texts seek to establish the legitimacy of their claims through reference to other texts. The chapter of the NCC introducing these development areas is a good example of interdiscursivity. Morality, national pride and patriotism are frequent themes in the public communication of the present Hungarian government. From outdoor banners advocating the role of the government in protecting its citizens against the EU, to Viktor Orbán PMs speeches on how Hungarian's are freedom fighters who will not follow the Western European track (Politics.hu, 2014) these texts interdiscursively strengthen the communicational goals of the government.

When it comes to the aims of media literacy education, the policy-makers enumerate the following goals: pupils should become responsible participants of a global mediated public and for this, they need to understand the language of new and traditional media. Policymakers strengthen through these goals the following rationale: by receving media literacy education, pupils will understand the language of media. This is the key to participatory democracy, a value-based life and eventually to participation in the global mediated community. If we only focus on this specific part, we could conclude that media literacy is strongly connected to citizen education or civics. Yet when examined closely, media literacy appears in the framework curriculum in the arts area.

Both in primary and secondary education media literacy appears as a cross-curricular topic in Visual Arts, and in lower secondary education it also appears in Hungarian Language and Literature, History and Ethics. In upper-secondary level (years 9-12) media literacy is a separate subject and schools can opt to teach either drama or media studies in year 9. In years 11 and 12, schools can "once again decide whether to devote two lessons per week to teaching visual culture, drama or media studies as part of their art education" (Pérez-Tornero, 2014, p. 7). Thus in upper-secondary level as well, media literacy classes are among the so-called arts formation subjects. This shows certain indecision in policymaking: is this subject connected to social studies or art studies?

On evaluating concepts and theories of media literacy education, Martens (2010, p. 6) notes that many scholars "view access and understanding of contemporary media as a vital aspect of citizenship in general." Globally there is also a growing interest in 
framing media literacy as an integral concept for citizenship education (for example, the UNESCO and the European Union definitions).

Uusitalo explains that in the Finnish context, for instance, "media literacy has been designated as an essential civic competence and media education is hoped to produce active citizen-subjects who will uphold democracy through their actions" (2010, p. 69). Hungarian policy-makers are obviously trying to follow this trend. Yet in the current state it seems that as a development area, media literacy is defined as a civic competency, while in actual practice it is regarded as an arts subject. In the case of Hungary, the somewhat curious situation can be explained by the initial media literacy activists' and lobbyists' interest and background. László Hartai is a film director and he was leading the team advocating in the '90s for the introduction of this subject. Since they could not lobby for introducing media as a separate education area, it was immersed into arts area. In an interview Hartai admitted that "it is nearly impossible to remove it from that area. There is no political or educational will. It's a difficult situation” (Interview with László Hartai, November 21, 2013).

\subsubsection{The micro, lexico-grammatical level}

Media literacy is both taught as a cross-curricular topic (primary and lower secondary) and a separate media literacy optional subject, which is taught in one lesson per week on upper secondary level. For the lexico-grammatical level analysis, I will focus on both of these. The fine-grained analysis draws largely on Fairclough (1989) and Critical Literacy Analysis (Hyatt, 2003) and the following elements will be taken into consideration the following:

Vocabulary:

- The relational, experimental and expressive values of words used (such as euphemisms, ideologically contested words, formal and informal words, etc.)

- Use of stylistic devices (metaphors, repetition, etc.)

\section{Grammar}

- Passive/active sentences \& agency

- Use of specific terms 
- Use of verbs (tenses and modality) and pronouns

- The expressive values of grammatical features

The framework curricula of all subject follows roughly the same pattern: a description of the subject is followed by a table. The table is split into two major parts: the upper part lists the following elements: Theme unit/Developmental goal, Number of hours, Preliminary knowledge, Educational-developmental goals of unit. Below this part there are three columns: Knowledge, Development requirements, and Links to other subjects. In some of the frame curricula there are further details or guidance given for activities, mostly in parenthesis.

For a more thorough microanalysis of this content, I will first focus on the separate subject, Culture of the Moving Image and Media Education. The separate subject is presented in both the National Core Curriculum and in the frame curricula. Therefore, I will analyze the two policy texts. I will then turn to media literacy, as a cross-curricular topic, as found in the frame curricula.

\section{Media literacy in the National Core Curriculum}

The dilemma of how media literacy should be positioned in the NCC, comes up when analyzing the detailed description of the subject. Even at a lexico-grammatical level it is revealing to analyze the actual name of the subject: Culture of the Moving Image and Media Education. The first part of the subject name definitely suggests a strong emphasis on film education.

As mentioned earlier, the interest towards civic competencies and societal problems in present-day can be also explained by the influence of European Union regulations and an overall interest in child protection issues. This assumption is strenghtened lexically in the text of the NCC by the introduction of these areas: "Developing critical media literacy - in line with child protection, value-based pedagogy and European Union recommendations for developing media literacy through the following elements" (2012, p. 10807).

The European Union discourse on responsible citizenship is echoed intertextually when it is stated in the NCC that "Those responsible citizens who are part of media democracy should (also) be media literate.” (2012, p. 10807) 
There are several elements listed as being important in developing media literacy: differentiation of the real and the virtual world; knowledge and protection of European and Hungarian audiovisual heritage; development of critical thinking; development of a conscious consumer attitude; conscious and creative participation in online communication; knowledge of data security, addiction and avoiding other dangers, and learning ethical rules in creating content on social media. In terms of evaluation the majority of these elements evolve around the question of protection: protecting the child from not knowing what is real and what is virtual, protecting the national audiovisual heritage and so on. Consciousness also appears several times in the list, while being media literate is simultaneously connected to being a good citizen (knowledge of ethical norms) and an informed consumer (developing a conscious consumer attitude).

The NCC also introduces specific developmental aims through four components: reading and analysis; learning, communication and critical thinking. These components are constructed according to age groups and define in broad terms what pupils should know. What follows in the text is a very detailed list of what is expected from students to know upon completing this subject. It starts with development of vocabulary and reading skills through media texts in first grade and it ends with -among others debating editorials about media for 9-12 graders. These aims are formulated in sentences that lack verbs which makes the style very much impersonal. There are a number of questions that should be asked in connection with these aims: the responsability of reaching these aims rests only on the teachers, what is the role of the pupils (or parents, for that matter) in this endeavour, or what is the appropriate level of knowledge. By using sentences without verbs and pronouns, the curriculum leaves room for freedom of interpretation.

\section{Media literacy in the Frame Curricula}

At upper secondary level (usually covering grades 9-12, pupils aged 14-18) the Culture of the Moving Image and Media Education subject is an optional one. In year 9 schools can opt between drama or media literacy. Then in year 11 and 12 schools can choose between devoting two lessons per week to teaching visual culture, drama or media literacy. 


\section{Media literacy as a separate subject in secondary education - Culture of the Moving}

Image and Media Education. The frame curriculum for the separate subject is a thorough document describing how media literacy education should be carried out in schools. The introduction is a two-page long text discussing the aim and tasks of this specific subject. The authors of the curriculum highlight that the subject's aims are "primarily to develop the understanding of media texts and the clarification of the audiovisual media's societal role and operating mode" (Framework Curriculum, 2013). The use of specific terms is of uttermost importance in CDA analysis. Therefore it is interesting to note throughout the framework curricula that when it comes to the societal role of media, what is being mentioned is firstly the audiovisual media and the internet. In the theme units, this focus is even stronger, since one of the educationaldevelopmental goals is: "The clarification of the societal role of media, and especially, the role of audiovisual media and the internet [...]" (Framework Curriculum, 2013). The sequence of terms suggests again a stronger focus towards the moving image, then a focus on the internet. There is a complete lack of mention of print media. In CDA analysis what is not discussed in a text carries an equal weight (Faiclough, 1989).

The curriculum then goes on to offer reasoning on why the above two aims were selected for this subject. In these sentences it is relevant to observe that the authors first present the (presumed) effects of television, and then they turn to the internet. According to the Framework Curriculum (2013), TV "makes a daily program for the crowds" ("tömegek napirendjét osztja be"), "it starts dietary, shopping trends" (2013) ("étkezési, vásárlási divatokat indít"), "it produces héroes, ideals and life goals" ("hősöket, eszményeket, életcélokat teremt"). Both the tense, the voice and the verbs used are revealing. In the overall text the passive voice is more common. However, in this part the active tense presents explicitly a subject (TV) that has a strong role. Furthermore, the verbs used in present tense (starts, produces, makes, etc.) reveal a strong actor that is capable of influencing people. Similarly, the internet "functions as a second home for young people, where they spend more time than in any other place (2013). The "second home" expression points towards a common fear among teachers and parents alike, and as a metaphor its aim is to highlight the pervasive power of the internet. The authors of the Framework Curriculum (2013) use the stylistic device of enumeration to highlight the many things media can do: "transform: language, value system, sense of rhythm, taste, desires, heroes, taboos, arts [...]”. And since it can 
transform all these, "media education is the main tool of personality development" (Framework Curriculum, 2013) With the careful selection of verbs, tenses and stylistic devices, the authors are trying to argue about the importance of this subject. This finding can be explained by the fact that the separate subject is optional on upper secondary level, and schools have to opt for it in order to be taught. In a way, this serves as a sort of advertising for the subject: making the subject as important and interesting as possible so that the school managements will choose it (schools can opt to teach either this subject or drama in year 9, or visual culture, drama in years 11 and 12).

\section{Media literacy as a cross-curricular topic}

Due to the changes in the 2012 NCC, media literacy appears also as a cross-curricular topic in primary (first four years of education) and secondary low (years 5-8) education in Visual Arts, Mother Tongue, and History. I will first analyze the media literacy content for primary education than I will continue with lower secondary education (typically grades 5-8).

Media literacy in primary education. Visual Culture. The bulk of media literacy content at primary level appears in the subject titled Visual Culture. The mass media emerge as a new focus point in this subject. In the second sentence of the Framework Curricula for Visual Culture (2013), the authors highlight that "the subject does not deal only with the fields of fine arts and applied arts, but it adds to its topics the examination of visual phenomena in everyday communicational forms, such as the visual appearance of mass-media, the newest phenomena related to electronic media and the created environment." Lexically it is interesting to note the phrasing used for introducing the new content ("tartalmai közé emeli"). An exact translation is difficult to provide ("introduces in its content"), but the key message that comes across is that from now on besides fine arts and applied arts, media literacy will be on the spotlight for this subject. The importance of the new media literacy content is further emphasized by the several sentences long explanations given on the role of media content in the framework curricula. However, media literacy here is used somewhat for accentuating the relevance of the Visual Arts subject: "The high number of the information channels brings along not only the importance of text reception, but the importance of the conscious inclusion of visual information. Nowadays it is a common phenomenon to interpret jointly text and image [...]. All this emphasizes the importance of this subject." 
(Framework Curriculum, 2013, p. 2) The lexical examination brings us to an interesting finding: media literacy is a good tool to use for strengthening the role of a different subject. As I presented it in the chapter on definitions, because of its interdisciplinary nature and relative novelty, media literacy has been used for achieving many different goals. When asked, the media literacy expert who wrote this part of the framework curriculum, Krisztina Nagy, added: "At the Hungarian Institute for Educational Research and Development (OFI) the aim was to give Visual Arts a new boost, to renew it. So that the subject will be enhanced. But I was happy that at least media literacy educational content can finally be found on primary level." (ibid.)

The media literacy content in the framework curriculum revolves around a number of key terms that are frequently used and repeated all through the text: "media experience" (médiaélmény), "processing media experience" (médiaélmény feldolgozása), "media texts" (médiaszövegek), “activity centered" (tevékenységközpontú). One of the major aims of critical discourse analysis, based on Foucault's discourse theory, is to identify what becomes valid knowledge in a specific place and time for specific group of people. (Jager \& Maier, 2009). In this case it is important to stress the usage of the above mentioned terms because they reflect a certain mode of education. According to Nagy: "What I tried to convey here is a new approach in education. It was a German concept (Medienpädagogik) which highlights that we need to start media literacy education from the children's own media experiences. And we need to process those media experiences." (ibid.). One of the major issues at stake here is that this content is quite different from all other media literacy contents in the NCC. The choice of terms and the aims show a distinct approach to teaching media literacy. While this specific framework curriculum is important for the agenda of media literacy, some questions need to be answered. Why is there no continuation of this approach in higher grades? Alternatively, to put it the other way around: Why is this specific curriculum not written in the same way as the other ones? A coordinated approach that would continue from primary to secondary education would probably be more effective in educating media literate children.

Media literacy in primary education - Other subjects. While media education is mostly included in Visual Arts, it is also mentioned in several other compulsory subjects at primary level including Hungarian language and literature, Mathematics, Ethics, Music, 
and Sports. There are some references to media literacy in elective subjects as well: Dance and Internet and Computer Technology.

For compulsory subjects, media literacy is mentioned through linking the theme units with visual arts. For instance in the case of Hungarian language and literature, for the Verbal skills development unit, the authors of the curriculum suggest observing works of art, discussing the differences between media texts through children's own media experiences. It is interesting to note here the intertextuality aspects of the curriculum. Fairclough (1992) highlights that all texts draw on other texts and these texts can assimilate, contradict, ironically echo, etc. each other. By using the intertextual perspective, we can explore how texts move from one context to other, and how these other texts shape interpretation. When examining the compulsory subjects, it becomes clear that by adding links to the theme units that connect the main subject to other subjects, the goal is to guide teachers towards an interdisciplinary approach. Since media literacy became a cross-curricular theme in the 2012 NCC, teachers are aided to add this type of content into other disciplines. Much of the language pattern and word choices of the other disciplines are similar to the Visual Arts' curriculum word choices such as "media experiences" and "media texts".

However, one of the most interesting intertextual features appears in Mathematics. The authors of the Framework Curriculum for Mathematics write, "Deciphering data, tables and graphs can greatly help in our daily routine, moreover in really understanding press releases." (2013, p. 2) One of the aims of media literacy is indeed to critically evaluate media content. Yet media literacy is mentioned here just as with Visual Arts, as a reason why a certain subject might be important. Similarly for Music: "Music can effectively contribute to the following development areas: [...] media literacy education (elegance, selection ability that draws from a developed taste, motivation to receive valuable media content)". When analyzed from a micro perspective, it is interesting to note how this text appropriates and shapes media literacy content to reflect its own aims (e.g. by outlining the aesthetics aspect of media literacy).

Media literacy in lower secondary education The general introduction presents the expected evolution of the NCC development areas for 5 to 8 graders. Media literacy 
education is one of the development areas, and thus there is an enumeration of goals or knowledge expected from students. By doing a CDA microanalysis, one can spot a number of intriguing aspects. The expected goals are introduced using the present tense such as "The pupil can do effective searches on the internet, using key words". The vagueness of this text leaves room for various interpretations: When, how and through which means will the pupil know all these? Similarly, the subject, "pupil," is also very general. This type of formulation does not take into consideration the vast differences among children's capabilities or the resources of different schools. The responsibility of having this knowledge rests on the pupil, since there is no mention of what the teachers' role is in this process.

The goals show an overall child protection approach: pupils should know what the "appropriate" usage of video games is, or that the pupils should "possess a communications' strategy for preventing verbal aggression on social media" (Introduction..., 2013). There is no explanation of what "appropriate" usage or "communications' strategy" is. While most of the goals listed are valid and important for pupils to become media literate, what is missing here is the connection to specific subjects. For instance it would be important to see how these goals are being reflected in the subjects' framework curricula.

Media literacy in lower secondary education -Visual Culture The introduction of Visual Culture follows the main lines of the one I already analyzed for primary education. Yet in contrast with the word choice used in the case of primary low education, in this framework curriculum we cannot find any reference to the „media experience"-centered approach found in the previous Visual Culture curriculum. While in the former one (for primary education) there was a detailed description on the importance of children's media experience and knowledge, there is no mention of this in the latter. As mentioned earlier the lack of continuity in the approach towards media literacy (and even more when it comes to the same subject), is an issue educational experts need to address.

When presenting how this subject strengthens the NCC development areas in $5^{\text {th }}$ and $6^{\text {th }}$ grade, the authors explain that „Developing media literacy is a priority. For 
instance by analysing the advertising industry's mechanism a road is opened towards critical, interpretative thinking and a foundation of active citizenship." (Framework Curriculum..., 2013) The sentences lack subjects: it is not clear for whom this is (or should be) a priority, or who will open the door towards critical thinking. There is no further information on what "critical thinking" or "active citizenship" means. It is important to mention that the subject's connection to the other development areas (such as digital competence) is similarly vague.

Media literacy education appears in a number of theme units further on for $7^{\text {th }}$ and $8^{\text {th }}$ graders, but even on a strictly quantitative aspect, its relevance is much diminished compared to the first four years of this same subject. Media literacy appears in three theme units ( 7 hours of teaching for the two years). The three theme units focus mainly on the moving image. The titles of the units are revealing: Reproduction and portrayal - the dual nature of the moving image, Main tools of accentuation in the case of the moving image, the print and online press, and The scope and basic forms of montage in moving image representation. The required developments of these three units build on terms borrowed from the cinematic arts, such as "light/colour", "camera movements", "montage", and "rhythm". For instance in explaining the difference between documentary and fiction, the authors recommend Bunuel or Tarr movies. Media appears in one of the theme units. The authors highlight elements that teachers should discuss, such as letter size, the effect of colours or photos and so on. The theme units have the same goals: development of age-appropriate moving image comprehension ability, independent and critical attitude, film literacy skills, and a basic awareness of visual language. It is interesting to note that the authors use parenthesis to explain what they mean by moving images: movies, television, videos, computer games and web. The order of these media platforms shows once again the focus on the cinematic art I mentioned earlier.

Media literacy in lower secondary education - Other subjects On lower secondary education media literacy content is present in Hungarian language and literature, History, Societal and Citizenship Education, and Ethics. The framework curriculum of Hungarian language and literature highlights that it is important for children to "develop a media literate behaviour, the recognition of manipulation, and protection against 
manipulation." (Framework Curriculum..., 2013). In this case media literacy is understood as protection against manipulation. Further on the curriculum presents many other aspects of media literacy. In the Media expression tools theme unit, the focus is on aesthetics and moving image culture; then in the Social role of media unit the authors use a social sciences approach: from understanding the role of media in society or the role of stereotypes in media to becoming a critical, active citizen of the world. This specific curriculum is the best example for presenting media literacy as a multifaceted concept and that has multiple layers. Depending on the goals of each theme unit, the terms and topics "borrow" from different fields: cinematic arts, citizenship studies, media studies and so on. This intertextuality shapes to a large extent the media literacy content found it the Hungarian language and literature framework curriculum.

In the case of the History curriculum, media literacy is positioned as a potential tool for aiding the understanding of the subject: "Media knowledge can be added, to different historical, societal, citizenship and economic themes, according to needs, in a way that it helps to better understand the topic, and the developmental aims of media literacy education." (Framework Curriculum..., 2013) In most of the other curricula what should be taught is strongly outlined. In this case, a different subject position is being offered to teachers: they are free to decide which media education content to use for their purposes. Furthermore, for $7^{\text {th }}$ and $8^{\text {th }}$ graders, it is highlighted that " $20^{\text {th }}$ century history, societal, citizenship and economic themes offer exciting opportunities for adding the media module to their content" (Framework Curriculum..., 2013). The style used in this sentence is closer to the style used in commercials ("exciting opportunities"). This is quite uncommon in the curricula and it shows an intention to promote the media module. The choice of style is understandable in the light of the new core curriculum's changes: the former standalone media literacy subject was excluded from lower secondary level, and its content was split among different subjects. This meant in practice that teachers who in the previous years taught history, had to comply and add the media literacy content to their classes. The style used in presenting this new content is revealing; it aims to make media literacy content appealing to History teachers. It might be hoped that by using this approach, educators will be more willing to teach media literacy. 
And finally in the Ethics curriculum media literacy appears as a remedy against the influence of media. In three theme units pupils are to learn about the influences of technical developments, the role of advertisements, and the connection between media and reality. In the case of $7^{\text {th }}$ and $8^{\text {th }}$ graders' ethics classes, media literacy education should occupy "an eminent place, highlighting that it is an important part of citizenship and democratic education, and the development of aesthetical-arts literacy and expressivity." (Framework Curriculum..., 2013). The Ethics curriculum uses a personal, conversational style by using questions to exemplify possible topics: "Why are there so many commercials in the TV and on the internet? What are the tools used by commercials to influence us? Why and how TV series influence us?" (Framework Curriculum..., 2013). Additionally, by using the "us" pronoun, it aims to build a common platform with teachers (and consequently with pupils).

With less focus, but media literacy is also mentioned in Science (the questions of body image), Biology (media addiction) and Geography (search for facts, photos and touristic offers).

And lastly media literacy is taken up in ICT classes during both primary and secondary education. Topics usually connected to media literacy (such as a critical knowledge of traditional media and online media; or responsible behaviour in the online world), appear in ICT education under the media informatics section. The policymakers here, as elsewhere around the globe, have difficulties in clearly demarcating the line between media literacy and ICT knowledge. This is just another evidence in the rather complex discussion on what media literacy actually incorporates (see for instance RobbGrieco, 2014). 


\section{Conclusion}

In this chapter a detailed analysis on the 2012 NCC's and frame curricula's media literacy content was presented. Figure 7 below synthesizes the main findings.

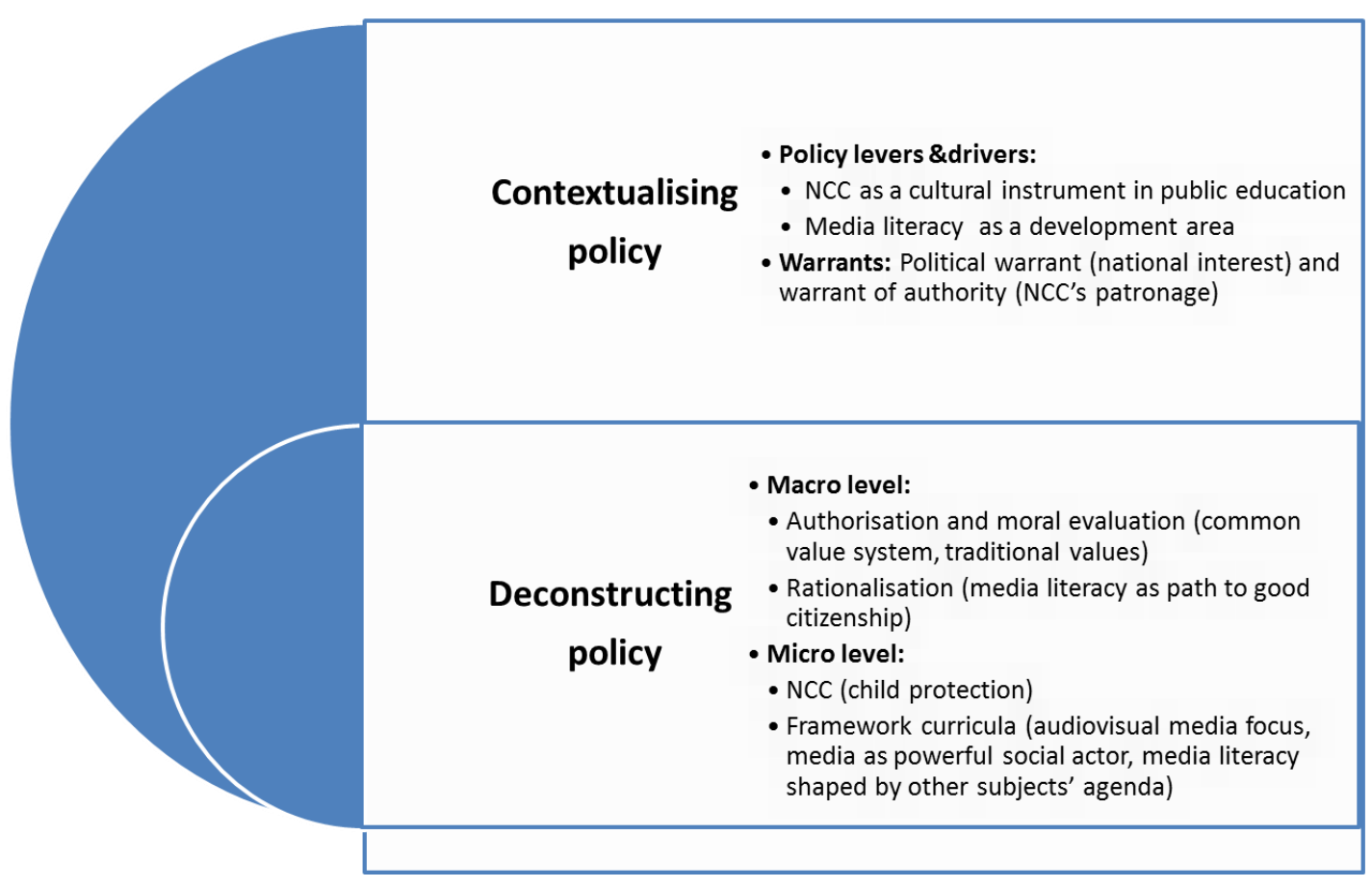

Figure 7. Synthesized results of CDA-analysis NCC and framework curricula

Media literacy education is mentioned for the first time in the NCC in the development areas. By analyzing the goals listed in the 2012 NCC I conclude that media literacy education is presented as a tool for pupils to understand the language of media, which is the key to participatory democracy, a value-based life and eventually the ability to participate in the global community. While I highlighted that it is certainly a positive sign that media literacy education is posititioned as one the 13 development areas, there are some incongruences when it comes to its definition. As a development area, media literacy is defined as a civic competency, while Culture of the Moving Image and Media education is defined as an arts subject. Through the expert interviews it became clear that this situation can be explained by the initial media literacy activists' and lobbyists' interest and background in cinematic arts. From the 2012 NCC I turned to do a detailed analysis on the framework curricula. The microanalysis draws largely on Fairclough (1989). For understanding how media literacy education is exactly positioned as a 
separate and a cross-curricular topic I examined such elements as the relational and expressive values of words used; passive/active sentences \& agency; use of specific terms; use of verbs (tenses and modality) and pronouns, and the use of stylistic devices.

The focus of media literacy as a separate subject at the upper secondary level is on the moving image and on cinematic art. Nonetheless, there are some specific units that deal with the role of media in society. When analysing the introduction of the framework curriculum through CDA lenses, it is interesting to note how the authors position television and the internet as extraordinarily powerful. In this specific text, the authors use the active tense, which further strengthens this message. The curriculum contains a lot of topics that have to be taught in class, and it requires serious knowledge on the part of the teachers. The teachers need to be equipped with specific information on the cinematic arts, media theory, or media production. It would be an interesting future research project to see how media educators can cope with these challenges.

Media literacy as a cross-curricular topic appears mostly in Visual Culture at the primary level (with some references in ICT education), and at the lower secondary level in Visual Culture, Hungarian Language and Literature and History (with some references in Science, ICT, Biology and Geography). The most clear-cut result of analyzing the cross-curricular theme is that media literacy is understood and defined in a number of ways, and that different subjects appropriate and shape these meanings in order to strengthen their own agendas. In primary education, media literacy content is a compact material with clear structure and a very specific media experience approach. Unfortunately, this approach is not continued on lower secondary level. In the latter, the goals of education rely on terms borrowed from cinematic arts, the focus being on a more aesthetic approach.

As a conclusion, the changes in the 2012 Core Curriculum have strongly affected media literacy education in Hungary. The cross-curricular approach is well grounded in Visual Arts at primary level, but this approach is not continued in the next stage of education. On the one hand, for the other subjects (Mother tongue, History, etc.) media literacy seems to appear as a tool for aiding the understanding of those specific subjects. On the other hand, the separate subject on upper secondary level has a strong moving image focus, with some reference to the internet, but with very few new 
media content. It seems that because of the 2012 transformations, the authors tried to cram in as much media literacy content as possible.

Media literacy education is presented both as a cross-curricular topic and a standalone subject. In all the interviews I carried out with media education experts, they feared that the educators will not be prepared to handle media literacy as a crosscurricular topic, and the teachers will focus solely on their own subject. When asked about this, the former Secretary of State for Education, Rózsa Hoffman, said that the solution lies in introducing media literacy education in the university courses of future teachers. But since she "ran out of time" (interview with Rózsa Hoffman, April 1, 2015), she did not know whether this has been implemented since then in higher education.

\footnotetext{
${ }^{16}$ Rózsa Hoffman was removed from office in 2014.
} 


\section{Conclusion}

"John Dewey was asked whether he was an optimist or a pessimist, and replied that he was a tremendous optimist about things in general, but a terrible pessimist about everything in particular." (Ryan, 2013, p. 277)

\section{The research project and its aims}

The rationale of this research project was to understand the position of media literacy in education policy, the interesting historical path of media literacy education in Hungary, and the roles of various actors in the development of media literacy education. Besides filling in a knowledge gap in research on Hungarian media literacy education, the more general goal of the dissertation was to present contemporary discourses on the relationship between mass media and education. This general aim is inspired from a deeper consideration: disputes over what has to be taught in schools always reflect broader political and social concerns (Parry, 1999).

There is a wide public interest lately in topics such as Internet safety, online bullying, or the skills future citizens need to thrive in a digital world. Through initial immersion in the literature of media literacy education, it seemed that Hungary is in a very fortunate situation: it is one of the few countries in which media literacy appears in the educational system as a stand-alone optional subject. Moreover, the subject was first introduced over twenty years ago, which seemingly meant that it had developed a prestige and recognition among educators and pupils alike. However, the interviews with media literacy experts and educational policy-makers painted a very different picture. In comparison with their initial enthusiasm in the 1990s, these experts predicted the total demise of media literacy education in the coming years. Their pessimism was in stark contrast to what the educational policies were showing.

In trying to find the key to this dilemma and understand the position of media literacy in the Hungarian educational system, three major research questions were formulated: How and why did media literacy education in Hungary make its way into the public education system during the 1990s? In what ways did this area of study evolve over time? What is the position of media literacy education in contemporary 
Hungary? For contextualizing these research questions, the first two chapters were devoted to presenting current issues in the field of media literacy. In Chapter 1 I presented a complex answer to a seemingly easy question: What is media literacy? This involved the presentation of several terms and discourses that evolve around the new type of literacies needed in today's world. In the second part of the chapter, I presented the history of media literacy education in Hungary in order to understand recent policy developments. For a comprehensive understanding of media literacy education, however, it was necessary to understand the scholarly roots of this field. Jean-Jacque Rousseau's and John Stuart Mill's work was used to put into context the aims of media literacy education (Chapter 2). Research results from Hungarian and international literature were then used to present contemporary concerns within the field of media literacy research.

The empirical study was guided by Hyatt's analytical framework designed for educational policy analysis (Hyatt, 2013). The framework borrows its constitutive elements from critical discourse analysis and critical literacy analysis. By applying Hyatt's framework, this work can be associated with a novel strand in policy studies: interpretive policy analysis. The analysis involved a detailed assessment of national core curricula, framework curricula and other policy documents from 1995 to 2012. The textual analysis was augmented by expert interviews carried out between 2013 and 2015 with the most important actors involved in the process of policy-making and advancement of media literacy education in Hungary. The historical account of this policy process was presented in the second part of the thesis. Chapters 4, 5, 6 and 7 described the major milestones in the history of media literacy education in Hungary. The textual analysis and the expert interviews helped in finding answers to the three main research questions. Policy-oriented qualitative research can be a tool for engaging both the researched and the researcher in evaluating the current situation (Finch, 1984). In the last section of the dissertation, based on the results of the project, I will reflect thus on the status of media literacy education in Hungary. In the following, I will present the main findings of the dissertation, structured around the three main research questions. 
How and why did media literacy education in Hungary make its way into the public education system during the 1990s?

Media literacy education in Hungary has its roots in aesthetics education. As a means for educational innovation, in the 1960s literature teachers were assigned to teach four hours of film aesthetics per year in secondary education (Szíjártó, 2007). This is not the least surprising, since as Martens observes: "historically, media literacy education has often been synonym for learning to appreciate the aesthetic qualities of mass media, especially the cinematic arts" (2010, p. 8). Moreover, the concept of literacy itself initially meant to be knowledgable about works of aesthetic quality. The lack of teachers' professional training in film aesthetics, however, eventually led to the "disappearance" of these classes from the daily practice of teachers. The popularity of the Eastern European New Wave in filmmaking together with a gradual opening of the Communist regime, gave rise to extra-curricular classes and film clubs around Hungary. These film passionate teachers eventually formed a working group. They lobbied for the introduction of the Culture of the Moving Image and Media Education subject at the beginning of the 1990s. The introduction of media literacy in Hungarian public education was possible through an opening of a "policy window" (Kingdon, 2003). "Policy windows" open when "a problem is recognized, a solution is available, the political climate makes the time right for change, and the constraints do not prohibit action" (Kingdon, 2003, p. 88). The "window" opened for media literacy education with the 1995 National Core Curriculum. The introduction of the 1995 NCC was proceeded by fierce political and media debates, since it aimed to introduce a more decentralized approach to education, and to present modern elements. The Culture of the Moving Image and Media Education subject offered a solution: it presented contemporary and innovative content that could further strengthen the modern image of the new NCC (Szíjártó, 2007). Much of the inital story of media literacy education can be summarized bluntly with what Kingdon calls "messiness, accident, fortuitous coupling and dumb luck" (2003, p. 206).

In terms of the educational content, media literacy as such did not appear in the core curriculum. However, a cross-curricular requirement called Culture of Communication presented many similar traits to what we call media literacy today. The critical discourse analysis revealed a protectionist discourse with regards of harmful media effects. This protectionist discourse can be observed all through the analyzed period, but I will touch upon this finding when discussing the second research question. 
In terms of how media literacy education appeared in educational policies, the Culture of the Moving Image and Media Education subject's strong film focus has to be acknowledged. Many concepts, theories and examples were found that pertain to the field of aesthetics and film education.

In Chapter 5 a further policy development was analyzed, that strongly influenced the history of media literacy education in the late 1990s. With the change of government, new provisions were introduced in public education. The introduction of the framework curricula resulted in transforming Culture of the Moving Image and Media Education into a module subject with a smaller number of stipulated hours per academic year (this was the case with other "modern" subjects as well, such as Dance and drama or Social studies). The module subjects were in a very peculiar situation. On one hand, schools and teachers had to struggle with an ever-growing educational content (in the case of traditional subjects), while there was no opportunity for having even more compulsory subjects in an overloaded educational system (Jakab, 2003). On the other hand, it became obvious that these new subjects were needed, and had to be somehow crammed into the curriculum. Media literacy education could have striven and develop, but in practice this was hardly possible. This ambivalent situation could be recognized in the textual analysis as well. In the framework curricula of the Culture of the Moving Image and Media Education subject, the authors relied heavily on the discourse of powerful media. By using stylistic devices, the authors stressed the socalled extraordinary impact of the media on youth. By presenting the mass media as an important actor with a power to influence people, the curricula's authors were positioning this subject as an important one for pupils' development. The analysis also showed an interesting attitude towards mass media products: as a threat to high culture. As it was presented in detail in Chapter 5, this can be explained by the professional background of those who worked on the content of the curricula (e.g., film directors, philosophers). As a continuation of the $1995 \mathrm{NCC}$, in the frame curricula the film focus was clearly discernible, while the print press, the radio or the internet were seldom mentioned. However, an important finding was that policymakers would have liked pupils to have an active relationship with the media. When analyzing the desirable outcomes of the subject, the authors used evaluative adjectives and noun phrases with implicit values, such as "an independent" and a "critical" attitude and an "open mind". Thus Hungarian media literacy advocates at the end of the 1990s-beginning of 2000s 
were already striving for an education content that was going to equip pupils with skills to use the media in an independent and critical way.

In what ways did media literacy evolve over time?

As it was mentioned earlier, media literacy education began with a strong moving image focus and this has not changed throughout these last twenty years. The textual analysis revealed that in the description of the subject many concepts pertained to film culture and film studies. Moreover, in these documents the first aim of the subject had always been the development of "audiovisual" or "film literacy". However, from the beginning of the new millennium, one could observe a shift towards a social sciences discourse. The social sciences aspect was highlighted by the presence in the framework curriculum of such concepts as: "personality development", "citizens", "civic engagement", and so on. The role of mass media in society occupies a central position in the latest, 2012, curriculum as well. As it was argued in Chapter 1, media literacy has a somewhat ambiguous meaning, and there are many interrelated concepts in connection with it. The CDA-analysis revealed that there are a number of subjects that are "interested" in embracing media literacy education. One of these subjects was from the very beginning, Information Technology (IT). As early as 1995, the main areas of teaching for the Information Technology subject were: computer skills, information literacy, technical aspects of information management, and mass media. There is a constant struggle between advocates of media literacy, media and information literacy, and information literacy. The appropriation of media literacy by IT can be traced through all major policy documents. Topics usually connected to media literacy (such as a critical knowledge of traditional media and online media; or responsible behaviour in the online world), appear in IT education under the media informatics section. The policymakers here, as elsewhere around the globe, have had difficulties in clearly demarcating the line between media literacy and IT knowledge since in many ways they overlap. As presented earlier, the lack of agreement among media literacy scholars leads to an appropriation of this field by other areas. The range of discourses reflects different interests and shifting priorities within public education.

Finally, an interesting evolution that could be traced in the last twenty years was the changes in cross-curricular requirements. These cross-curricular requirements had different names in different educational policies, yet their main purpose was the same: to present themes that had to appear throughout the educational system. Although media literacy education was introduced as a development area only in 2012, contents that can 
be connected to this field can be found as early as 1995. In the 1995 NCC, Communication Culture was one of these requirements. In the description of Communication Culture, the perceived power of mass media to potentially influence people's lifestyle and thinking was highlighted. Then in the 2003 NCC, Information and Communication Culture was introduced. The 2003 NCC provided a detailed account of how schools should prepare students for a critical usage of information gathered through electronic means. The change of name shows a discourse that is associated with information literacy. The 2007 NCC then introduced another concept: Digital competency, as one of the key competencies (this later appeared in the 2012 NCC as well). As presented in Chapter 6, the introduction of "competencies" was a revealing example of how the Organization for Economic Cooperation and Development (OECD) has influenced national education policy discourse (Ball, 2008; Bieber and Martens, 2011). When analysing the description of this competency using the analytical framework, it became clear that the skills needed to become "digitally competent" constitute only a smaller part of what media literacy stands for. However, the description of this competency also highlights the importance of critical thinking and responsible use of information and media, which is an integral part of media literacy education. In addition to Digital competency, two other competencies are also relatively close to media literacy: Aesthetic and Artistic Awareness and Expression, and Social and Civic Competencies. The last NCC in 2012 introduced Media literacy as a development area. The aims of this development area can be summarised in the following way: through media literacy education pupils will understand the language of media, which is the key to participatory democracy, a value-based life and eventually participation in the global mediated community.

It has to be highlighted that there is no straightforward answer to the second research question. Throughout the years media literacy (or, more accurately, what the contemporary understanding of media literacy is) appeared in different discourses. The analysis showed that shifting governmental priorities, supranational political organizations and other subjects' advocates have all borrowed the term for their own rhetorical aims.

What is the position of media literacy education in contemporary Hungary?

For answering the third research question, I focused on the latest National Core Curriculum, of 2012, and the frame curricula adopted in 2013. The analytical tool used 
for examining these policy documents was useful in uncovering the different discourses that shape contemporary media literacy education in Hungary. There are a number of novelties in the $2012 \mathrm{NCC}$ that can be considered positive in terms of media literacy education development. First of all, media literacy appears for the first time as a development area. The development area's aim is to "permeate the whole educational process" (NCC, 2012). This is a very important policy lever, since it highlights that media literacy should appear throughout public education. The CDA-analysis showed that, as a development area, media literacy is defined as a civic competency: media literacy is positioned as a key aspect of participatory democracy and a tool for global communication. However, the subject that is directly connected to media literacy, Culture of the Moving Image and Media Education is positioned among Art subjects. The ambiguities of the subject were also obvious from the CDA-analysis. The focus of Culture of the Moving Image and Media Education is on the moving image and on cinematic art. Nonetheless, as shown above, over the years the number of units that deal with the role of media in society kept on growing. Another change that occurred in the 2012 NCC was that media literacy education did not only appear in the stand-alone subject, but also as a cross-curricular theme. Media literacy as a cross-curricular topic appeared in Visual Culture on primary level (with some references in ICT education), and on lower secondary level in Visual Culture, Hungarian Language and Literature and History (with some references in Science, ICT, Biology and Geography, as well). The CDA-analysis revealed that media literacy was understood and defined in a number of ways by the different actors writing these educational documents. Different subjects appropriated and shaped media literacy in order to strengthen their own agendas. The CDA-analysis also revealed that in primary education, for the Visual Culture subject the media literacy content has a clear structure and a very specific media experience approach based on the German concept of Medienpädagogik. Unfortunately, this approach is not continued on lower and upper secondary level. While media literacy education seemed to be in a very good position when it came to educational policies, the expert interviewees presented a very grim situation. For this reason exactly, it was necessary to complement the findings of the CDA-analysis. It is important to mention though, that there is no "truth" out there that these experts can formulate. From a constructivist ontological position, the task of the researcher is to search for meanings that actors use to make sense of their world (Sarantakos, 2005), and not truths. For instance media literacy expert Krisztina Nagy, who worked on the frame curriculum for 
Visual Culture, expressed satisfaction that at least media literacy now appears on primary level as well. It seems though, that those who were very active during the initial phase of media literacy education development (László Hartai, György Jakab, András Lányi), see recent developments in a gloomy light. Some of their arguments are wellrounded: teachers who did not receive an education on how to teach media literacy will probably not add this topic to their daily practice (irrespective of the fact that it appears in the NCC and the frame curricula). This is true for subjects where media literacy was added as a cross-curricular topic (History, Visual Culture, Hungarian Language and Literature). Moreover, they argue that by making media literacy a cross-curricular topic, it will slowly but surely disappear from the education system. And lastly, they contend, since Culture of the Moving Image and Media Education is only offered as an optional subject on upper secondary level, there is no proper class time for children to be able to understand media literacy.

These findings are somewhat ambivalent. On the one hand, it is clear that in comparison with other countries, Hungary is in the special position of having media literacy education clearly stipulated in the national core curriculum and the framework curricula. On the other hand, it seems that there is no clear strategy of how media literacy should be taught in public schools. In the following, I will provide a number of possible recommendations based on the findings of the research project.

\section{Further Research Directions and Recommendations}

My aim with this $\mathrm{PhD}$ dissertation was to present the development of media literacy education in Hungary in light of educational policy-making from 1995 to the latest national core curriculum in 2012. Nevertheless, the goal was not only to describe these changes, but also to provide a critical insight to how current concerns regarding the mass media appear in educational policy-making. As I was nearing the end of this quest, the draft versions of the dissertation were circulated among scholars representing different disciplines such as pedagogical studies, media studies, political science. I started my research from the assumption that media literacy is obviously an educational necessity in our media-permeated world. However, as different scholars commented the draft, it became clear that this initial assumption is not self-evident at all. This epiphany led to questions that can indicate future research directions. It would be interesting to see how, for instance, teachers themselves, see the role of media literacy education in 
Hungary: do they advocate teaching media literacy in school or would they see it rather as an extra-curricular activity? Furthermore, policies on teacher education and local curricula could further be analyzed to see if and how media literacy appears in these documents.

One of the most important future research directions is to see how the policies analyzed in this project are delivered in schools. Or, to put it more directly: how does media literacy education happen in schools? Such an endeavor would enrich greatly our understanding to what happens during media literacy classes, what kind of teaching resources (textbooks, lesson plans, digital tools) are available for teachers, and what are the major difficulties in teaching media literacy. Moreover, by doing classroom research, best practices could also be gathered, then later shared among media literacy educators. Because of their shared historical paths and cultural proximity, this line of research could also be extended to other Central and Eastern European countries. As a first step, it would be interesting to see a comparative policy analysis on media literacy education between neighboring countries. Then this comparative approach could be extended to classroom research in the CEE region. This would add important resources to the body of knowledge in media literacy research.

It was not in this project's scope to address the role of media industry or nongovernmental organizations (NGOs) in media literacy education. Nevertheless, these two actors are of major interest in Hungary as well. Lately, there has been a growing interest in topics such as internet safety and cyber bullying on part of the mass media and various NGOs (most probably because of increased public interest and EU-funded projects in this area). While these are just two of the many areas of media literacy, it would be a compelling project to see how these actors see their role in promoting media literacy.

In this final part of the dissertation, I will present some recommendations based on the findings of the research project. As stated in the introductory chapter, the goal of the thesis was not only to trace the development of media literacy education, but also to find answers which will further media literacy in Hungarian educational policy-making. For this reason in Chapter 2, I introduced the main aims of media literacy education and tried to position these goals in a larger academic context with the use of J.J. Rousseau's and J.S. Mill's work. A further step in trying to advance media literacy education is to outline the major inconsistencies found in these educational policies with the help of the analytical framework. One of the first questions that need to be addressed 
by policymakers is where to position Culture of the Moving Image and Media Education. As it was mentioned several times throughout the dissertation, the initial focus of the Culture of the Moving Image and Media Education was film culture, and therefore it was positioned among Arts subjects. However, throughout the years, this focus has diminished and the social aspects of mass media became more prevalent. In order to be in line with contemporary strands within media literacy, it would be important to position Culture of the Moving Image and Media Education among Social Science subjects. This in turn, would be an important step for clarifying the role of the subject in public education. On a more general level, it was mentioned several times in this dissertation that content related to media literacy appears in a number of crosscurricular requirements, development areas and subjects over the years. However, it seems that these are not purposefully interconnected, and they present several discourses. This seems to be the case in other countries as well: Wallis (2013), for instance, discovered seven discourses associated with media literacy in the UK. In Hungarian educational policies I could find the following discourses: media education (as teaching and learning about media), technology-enhanced learning (mostly in the case of IT studies), up-skilling of the workforce (mostly when discussing digital competency), and citizenship engagement (media literacy as development area). A coordinated approach towards media literacy would probably help in advancing the goals of this field of study. For having a coordinated approach, however, policymakers should agree on what they mean by media literacy and should be consistent throughout all educational policies. Consistency is one of the key recommendations when it comes to a more specific level in the frame curricula. Media literacy content in primary education differs greatly to what can be found on upper levels. The educational approach, the wording, and the style are all dissimilar on primary and secondary level. The reasoning behind this difference is, according to the interviewees, is that two distinct teams worked on the frame curricula. While for one of the teams (primary education), the focus was on children's media experience, the other team continued the tradition of film culture (secondary education). An initiative to standardize the content could further strengthen the development of media literacy education.

The above-mentioned recommendations should be regarded as constructive criticisms, and not finger pointing. The empirical study involved a close scrutiny of policy levers, drivers, warrants, and policy deconstruction from a macro and micro, 
lexico-semantical level. The findings of this research project rely thus on a large amount of empirical data, that was analysed with the utmost attention. The outlined recommendations should be understood as an engaged researcher's advices. It is hoped that these proposals can be of help since it seems that a revision of the 2012 national core curriculum is on the way, according to the Secretary of State for Public Education (InfoRádió, 2016).

I started the dissertation with a pessimistic quote from of one of most well known Hungarian media literacy activists. He argued that media literacy education in Hungary is on the verge of disappearance. The Dewey-quote I chose for this concluding chapter reflects my own opinion on the situation of media literacy education: I am a tremendous optimist when it comes to how media literacy appears in educational policy documents in Hungary, but a terrible pessimist about the particularities of how these policies are transposed in regular school settings on a day to day basis. The media literacy activist mentioned above had a very descriptive Hungarian expression to characterize the situation: "under the frog's bottom". If I were to continue this allegory, I would resort to the Russian variant of the Frog Princess fairy tale. In the fairy tale, the prince shoots an arrow which lands in the mouth of a frog. The frog then turns into Vasilisa the Wise, a beautiful, intelligent, friendly girl. By having more research projects, NGO and media campaigns I hope that media literacy will not disappear from the Hungarian public education system. And even more importantly, if teachers themselves will get education on media literacy during their studies, it will be an insurance that media literacy education has reached full maturity: the frog has turned into a wise princess. 


\section{APPENDIX A: CORPUS OF MATERIAL FOR ANALYSIS}

1993. évi LXXIX. Törvény a közoktatásról

130/1995. (X. 26.) Kormány rendelet a Nemzeti alaptanterv kiadásáról.

1999. évi LXVIII. törvény a közoktatásról szóló 1993. évi LXXIX. törvény módosításáról.

28/2000. (IX. 21) Oktatási Miniszter rendelete a kerettantervek kiadásáról, bevezetéséről és alkalmazásáról.

243/2003. (XII. 17.) Kormány rendelet a Nemzeti alaptanterv kiadásáról, bevezetéséről és alkalmazásáról.

10/2003. (IV. 28) Oktatási Miniszter rendelete a kerettantervek kiadásáról, bevezetéséröl és alkalmazásáról szóló 28/2000. (IX. 21.) OM rendelet módosításáról.

243/2003. (XII. 17.) Kormány rendelet a Nemzeti alaptanterv kiadásáról, bevezetéséről és alkalmazásáról a 202/2007. (VII. 31.) Kormányrendelettel módosított, egységes szerkezetbe foglalt szöveg

110/2012 (VI. 4) Kormány Rendelet A Nemzeti alaptanterv kiadásáról, bevezetéséről és alkalmazásáról.

51/2012 (XII. 21) Emberi Erőforrások Minisztériuma rendelet a kerettantervek kiadásának és jóváhagyásának rendjéröl 


\section{APPENDIX B: SAMPLE INTERVIEW QUESTIONS}

How would you define media literacy?

Can you, please, present the historical path of media literacy education in Hungary?

Who, in your opinion, were the major actors of this story?

How would you define your role in the development of media literacy education?

What was your task in the development of the National Core Curriculum and/or frame curricula?

Did any other countries' or pedagogical tradition influence your work? If so, which one(s)?

What were the major difficulties in the development of media literacy education?

How do you envisage the future of this educational field? 


\section{APPENDIX C: LIST OF INTERVIEWEES}

Name

Bajomi-Lázár, Péter

Hartai, László

Hartmann, Ibolya

Hoffman, Rózsa

Horváth, Ádám Márton

Jakab, György

Lányi, András

Muhi, Klára

Nagy, Krisztina

\section{Position}

Head of Institute, Budapest Business School

President Hungarian Moving Image and Media Education Association, textbook writer

Media literacy expert, Romania

Media literacy educator

Former Secretary of State for Education (2010-2013)

Media literacy educator

Senior Research Fellow, Hungarian Institute for Educational Research and Development Docent, Eötvös Loránd University, former cultural policy advisor for Fidesz (19901992)

Textbook writer, media literacy educator

President Televele Media Education Association 


\section{LIST OF REFERENCES}

168 Óra Online. 2010. Belénessy Csaba a köz új szolgálatáról. Available from <http://www.168ora.hu/itthon/belenessy-csaba-a-koz-uj-szolgalatarol-66304.html> [Accessed 19 Oct. 2014].

Act CLXXXV of 2010 on Media Services and Mass Media.[online] Available at: <http://net.jogtar.hu/jr/gen/hjegy_doc.cgi?docid=A1000185.TV\#lbj1param>.

Alan, R., 2011. J. S. Mill on education. Oxford Review of Education, 37(5), pp.653-667.

Alverman, D.E. and Hagood, M.C., 2000. Critical medical literacy: Research, theory, and practice in 'new times.' The Journal of Educational Research, 93(3), pp.193-205.

American Library Association, n.d. Instruction Section: How It All Began. [online] American Library Association. Available at: $<$ http://www.ala.org/acrl/aboutacrl/directoryofleadership/sections/is/iswebsite/about/ho wallbegan> [Accessed 22 Aug. 2015].

American Library Association, n.d. Introduction to Information Literacy. [online] American Library Association. Available at: <http://www.ala.org/acrl/issues/infolit/overview/intro> [Accessed 22 Aug. 2015].

Van Audenhove, L., 2007. Expert Interviews and Interview Techniques for Policy Analysis. [PPT presentation] Available at:

<http://www.ies.be/files/060313\%20Interviews_VanAudenhove.pdf> [Accessed 12 Oct. 2014].

Aufderheide, P., 1992. Aspen Media Literacy Conference Report. [online] Queenstown: The Aspen Institute Wye Center. Available at: <http://www.medialit.org/reading-room/aspen-media-literacy-conference-report-part-ii > [Accessed 15 Aug. 2014].

Avgerinou, M. and Ericson, J., 1997. A Review of the Concept of Visual Literacy. British Journal of Educational Technology, 28(4), pp.280-291.

A. Y. L. Lee and C. Y. K. So, 2014. Media Literacy and Information Literacy: Similarities and Differences. Alfabetización mediática y alfabetización informacional: similitudes y diferencias., 21(42), pp.137-145. 
Bacchi, C., 2010. Policy as Discourse: What does it mean? Where does it get us? Discourse: Studies in the Cultural Politics of Education, 21(1), pp.45-57.

Bajomi-Lázár, P., 2014. Party Colonisation of the Media in Central and Eastern Europe. Budapest: CEU Press.

Bakos, E., 2013. A kiskorúak védelme a lineáris és a lekérhetö audiovizuális médiaszolgáltatással szemben az Európai Unió és hazánk szabályozása tükrében. [online] Szegedi Tudományegyetem. Available at: <http://www.ajtkdi.hu/pdfs/Bakos_Eszter_Ertekezes_mhv.pdf> [Accessed 5 Nov. 2014].

Ball, S., 2007. Education Plc: Understanding private sector participation in public sector. New York: Routledge.

Ball, S.J., 1993. What is policy? Texts, Trajectories and Toolboxes. Discourse: Studies in the Cultural Politics of Education, 13(2), pp.10-17.

Ball, S.J. and Bowe, R., 1992. Subject departments and the 'implementation' of National Curriculum policy: an overview of issues. Journal of Curriculum Studies, 24(2), pp.97-115.

Balogh, E.S., 2013. The New Ethics Textbook for Hungarian Fifth Graders. Hungarian Spektrum. Available at: <http://hungarianspectrum.wordpress.com/2013/09/13/the-new-ethics-textbook-forhungarian-fifth-graders/> [Accessed 22 Aug. 2015].

Báthory, Z., 2001. A maratoni reform. A magyar közoktatás reformjának története, 1972-2000. Soros Oktatási Könyvek. Budapest: Ökonet.

Bawden, D., 2001. Information and digital literacies; a review of concepts. Journal of Documentation. [online] Available at: <http://arizona.openrepository.com/arizona/bitstream/10150/105803/1/bawden.pdf> [Accessed 22 Aug. 2015].

Beck, A.W., 1981. Review. British Journal of Educational Studies, 29(2).

Belgin Tanriverdi and Özlem Apak, 2010. Analysis of Primary School Curriculum of Turkey, Finland, and Ireland in Terms of Media Literacy Education. Educational Sciences: Theory \& Practice, 10(2), pp.1187-1213.

Benoit, K., 2002. Like Déjà Vu All Over Again: The Hungarian Parliamentary Elections of 2002. Journal of Communist Studies and Transition Politics, 18(4), pp.119-133. 
Bezzeg Anya (blog), 2012. Elfogadhatatlan az új Nemzeti alaptanterv a magyartanárok szerint. Available at: <http://bezzeganya.postr.hu/elfogadhatatlan-az-ujnemzeti-alaptanterv-a-magyartanarok-szerin> [Accessed 14 Febr. 2015].

Bieber, T. and Martens, K., 2011. The OECD PISA study as a soft power in education? European Journal of Education, 46(1), pp.101-116.

Bodó, M., 2012. Az új Nemzeti Alaptanterv értékei, összevetése a korábbi NATokkal. Tanitás-Tanulás Szakfolyóirat, (October), pp.28-29.

Bolter, J.D., 1998. Hypertext and the Question of Visual Literacy. In: D. Reinking and C.M. McKenna, eds., Handbook of literacy and technology: Transformations in a post-typographical world. Mahwah: Lawrence Erlbaum Associates, pp.3-13.

Böröcz, J. and Kovács, M. eds., 2001. Empire's New Clothes. [online] UK: Central Europe Review Ltd. Available at: <aei.pitt.edu/archive/00000144/01/Empire.pdf> [Accessed 11 Dec. 2015].

Breivik Senn, P., Hancock, V. and Senn, J.A., 1998. A Progress Report on Information Literacy: An Update on the American Library Association Presidential Committee on Information Literacy: Final Report. [online] National Forum on Information Literacy. Available at: <http://www.ala.org/acrl/publications/whitepapers/progressreport> [Accessed 22 Aug. 2015].

Brown, J.A., 1998. Media Literacy Perspectives. The Journal of Communication, 48(1), pp.44-57.

Buckingham, D., 1990. Watching Media Learning: Making Sense of Media Education. United Kingdom: Falmer Press.

Buckingham, D., 2003. Media Education: Literacy, Learning and Contemporary Culture. Polity.

Buckingham, D., 2009. The future of media literacy in the digital age: some challenges for policy and practice. Euromeduc. Media literacy in Europe. Controversies, Challenges and Perspectives. [online] Bruxelles. Available at: <http://www.euromeduc.eu/IMG/pdf/Euromeduc_ENG.pdf> [Accessed 18 Oct. 2014].

Buckingham, D., 2010. Do We Really Need Media Education 2.0? Teaching Media in the Age of Participatory Culture. In: Digital Content Creation. [online] Peter Lang. Available at:

<https://www.academia.edu/20475674/Do_We_Really_Need_Media_Education_2.0_T eaching_Media_in_the_Age_of_Participatory_Culture> [Accessed 19 Jan. 2016]. 
Buckingham, D., 2011. Agenda for Media Literacy. Policy Recommendations for European Cities to support Children and Young People. Stuttgart: Coordination Office Cities for Children.

Buckingham, D. and Sefton-Grane, J. eds., 1994. Cultural studies goes to school: Reading and teaching popular media. London: Taylor \& Francis.

Bulger, M. and Livingstone S., 2013. Media Literacy Research and Policy in Europe. A review of recent, current and planned activities. [online] Brussels: The European Cooperation in Science and Technology. Available at: <http://www.lse.ac.uk/media@1se/documents/mpp/cost-media-literacy-research-andpolicy-in-europe-final.pdf> [Accessed 19 Apr. 2014].

Bundy, A., n.d. One essential direction: information literacy, information technology fluency. Journal of Literacy, 1(1), pp.7-22.

Capello, G., Felini, D. and Hobbs, R., 2011. Reflections on Global Developments in Media Literacy Education: Bridging Theory and Practice. Journal of Media Literacy Education, 3(2), pp.66-73.

Carbone, P.F., 1983. John Stuart Mill on Freedom, Education, and Social Reform. The Journal of Educational Thought, 17(1), pp.3-12.

Carter, S., Kelly, F. and Brailsford, I., 2012. Structuring your research thesis. China: Palgrave Macmillam.

Center for Media and Communication Studies, 2012. Hungarian Media Laws in Europe: An Assessment of the Consistency of Hungary's Media Laws with European Practices and Norms. [online] Budapest: Central European University. Available at: <http://cmds.ceu.hu/node/274> [Accessed 19 Oct. 2014].

Chauvin, B.A., 2003. Visual or media literacy? Journal of Visual Literacy, 23(2), pp.119-128.

Cochran-Smith, M., 2005. The politics of teacher education and curse complexity. Journal of Teacher Education, 36(3), pp.181-185.

Cochran-Smith, M. and Fries, M.K., 2001. Sticks, Stones, and Ideology: The Discourse of Reform in Teacher Education. Education \& Educational Research, 30(8), pp.3-15.

Codd, J.A., 1988. The construction and deconstruction of educational policy documents. Journal of Education Policy, 3(3), pp.235-247. 
Cohen, D. and Crabtree, B., 2006. The Interpretivist Paradigm. [online] Qualitative Research Guidelines Project. Available at:

<http://www.qualres.org/HomeInte-3516.html> [Accessed 5 Dec. 2015].

Collins, H., 2010. Creative Research: The Theory and Practice of Research for the Creative Industries. Lausanne: AVA Publishing SA.

Council of Europe Commissioner for Human Rights, 2011. Opinion of the Commissioner for Human Rights on Hungary's media legislation in light of Council of Europe standards on freedom of the media. [online] Available at: <https://wcd.coe.int/wcd/ViewDoc.jsp?id=1751289> [Accessed 19 Oct. 2014].

Csizmadia, E., 2006. Star search Hungary - The 2006 Parliamentary Election. OSTEUROPA, 56(5), pp.75-92.

Csordás, I., Attila Főző, Katalin Lévainé Müller, Szilvia Tóth-Mózer and Valéria Viniczai, 2013. Country Report on ICT in Education. [online] European Schoolnet. Available at: <http://www.eun.org/c/document_library/get_file?uuid=f8ff53ba-37a841fe-b6c3-adb59f4760c8\&groupId=43887> [Accessed 20 Feb. 2014].

Culver, S.H. and Kerr, P. eds., 2014. Global citizenship in a digital world. Göteborg: NORDICOM.

Davis, J., 1989. Five Important Ideas to Teach Your Kids About TV. Media \& Values, [online] (52-53). Available at: <http://www.medialit.org/reading-room/fiveimportant-ideas-teach-your-kids-about-tv> [Accessed 20 Feb. 2015].

Denzin, N.K. and Lincoln, Y.S., 2005. The SAGE Handbook of Qualitative Research. 3rd ed. Thousand Oaks: Sage.

Diem, S., Young, M.D., Welton, A.D., Mansfield Cummings, K. and Lee, P.-L., 2014. The intellectual landscape of critical policy analysis. International Journal of Qualitative Studies in Education, 27(9), pp.1068-1090.

Van Dijk, T., 1998. Ideology: A Multidisciplinary Approach. London: Sage.

Dubrovszki, D., 2015. Istencsászár megengedte - Dancsó Péter és a magyar tinik. HVG online. [online] Available at: <http://hvg.hu/itthon/20150706_Istencsaszar_megengedte_Kit_imadnak_a_m> [Accessed 22 Feb. 2016].

Duffelmeyer, B.B., 2004. Visualizing respect: Visual media literacy and students' understanding of globalization and technology issues. Journal of Visual Literacy, 24(2), pp.165-184. 
Dull, S., 2011. Az udvarlásra és a családalapításra is taníttatná a diákokat a kormány. Origo.hu. [online] 25 Oct. Available at:

<http://www.origo.hu/itthon/20111024-a-csaladi-eletre-neveles-a-parvalasztas-es-azudvarlas-is.html> [Accessed 26 Oct. 2014].

European Association for Viewers' Interests, 2009. Study on Assessment Criteria for Media Literacy Levels. A comprehensive view of the concept of media literacy and an understanding of how media literacy levels in Europe should be assessed. Brussels: EAVI - European Association for Viewers' Interests.

European Association for Viewers Interest, 2014. 2014 Policy Recommendations on Media Literacy. [online] eavi.eu. Available at: <http://www.eavi.eu/joomla/eavi-iiroma/47-media-literacy> [Accessed 19 Oct. 2014].

European Commission, n/d. Media Literacy. [online] European Commission. Available at: <http://ec.europa.eu/culture/policy/audiovisual-policies/literacy_en.htm> [Accessed 19 Oct. 2014].

European Commission, Directorate-General for the Information Society and Media, European Schoolnet and University of Liege, 2013. Survey of schools ICT in education: benchmarking access, use and attitudes to technology in Europe's schools. [online] Luxembourg: Publications Office. Available at: <http://ec.europa.eu/digitalagenda/sites/digital-agenda/files/KK-31-13-401-EN-N.pdf> [Accessed 19 Feb. 2014].

Fairclough, N., 1989. Language and Power. London: Longman.

Fairclough, N., 1992. Intertextuality in Critical Discourse Analysis. Linguistics and Education, 4, pp.269-293.

Fairclough, N., 1995. Critical Discourse Analysis. The Critical Study of Language. Edinburgh Gate: Pearson Education Limited.

Fairclough, N., 2010. Analysing discourse: textual analysis for social research. reprinted ed. London: Routledge.

Fazekas, P., 2014. Három órán át faggatták Navracsics Tibort az Európai Parlamentben. Origo.hu. [online] 1 Oct. Available at http://www.origo.hu/itthon/20141001-navracsics-meghallgatas-biztos.html [Accessed 18 July 2016]

Fedorov, A., 2013. Media Education Literacy in the World: Trends. European Researcher, 67(1-2), pp.176-187.

Finch, J., 1984. Research and Policy: the uses of qualitative methods in social and educational research. London: Falmer Press. 
Flick, U., 2007. Designing Qualitative Research. London: Sage Publications.

Foster, S., 1993. Information literacy: some misgivings. American Libraries, 24 (344).

Fn24, 2012. Megtudtuk, kik a NAT védnökei. fn24.hu. [online] 6 Jun. Available at: http://fn.hir24.hu/itthon/2012/06/06/megtudtuk-kik-a-nat-vednokei/ [Accessed 9 May 2015].

Frau-Meigs, D., 2014. Divina Frau Meigs on the Paris Forum: Media Literacy's motto should be 'No Coding Without Decoding!'. [Gabinete Comunicacion y Educacion website] 23 May. Available at:

$<$ http://www.gabinetecomunicacionyeducacion.com/news/divina-frau-meigs-parisforum-media-literacy $\% 25 \mathrm{E} 2 \% 2580 \% 2599$ s-motto-should-be-\%25E2\%2580\%259Cnocoding-without-decoding\%25E2\%2580\%259D> [Accessed 15 Oct. 2015].

Freedom House, 2014. Freedom of the Press 2014. [online] Washington: Freedom House. Available at:

<http://www.freedomhouse.org/sites/default/files/FOTP_2014.pdf> [Accessed 24 Apr. 2015].

Friesem, E., 2014. A Story of Conflict and Collaboration: Media Literacy, Video Production and Disadvantaged Youth. Journal of Media Literacy Education, [online] 6(1). Available at: <http://digitalcommons.uri.edu/jmle/vol6/iss1/4/> [Accessed 20 May 2015].

Fulcher, G., 1989. Disabling Policies? A comparative approach to education policy and disability. London: The Falmer Press.

Gábor, L., Levendel, Á. and Stumpf, I., 1994. Parlamenti választások 1994. Budapest: Osiris-Századvég.

Gabinete de Comunicación y Educación, 2014. Research on Existing Media Education Policies. Country Overview - Hungary. [online] Barcelona: Gabinete de Comunicación y Educación. Available at:

<http://www.eumedus.com/images/Hungary.pdf> [Accessed 21 Apr. 2015].

Garcia, A., Seglem, R. and Share, J., 2013. Transforming Teaching and Learning Through Critical Media Literacy Pedagogy. Learning Landscapes, 6(2), pp.109-122.

Gilster, P., 1998. Digital literacy. New York; Chichester: Wiley Computer.

Gritsenko, V. and Dovgiallo, A., 1997. Planning our societies for the multimedia environment: Ukranian experience and the need for international co-operation in digital literacy. International Information and Library Review, 29(3-4), pp. 341-345. 
Hagood, M., 2011. Media Literacy Education: On the Move. Journal of Media Literacy Education, 3(1), pp.11-13.

Halász, G., 1988. Oktatáspolitika és neveléstudomány a hetvenes években: a hatos föirány története. Tájékoztató a közoktatási kutatásokról, 9, pp.5-49.

Halász, G. ed., 1998. Secondary Education in Hungary. Germany: Council of Europe Press.

Halász, G., 2001. A magyar közoktatás az ezredfordulón. Budapest: Okker.

Halász, G., 2011. Az oktatáspolitika két évtizede Magyarországon: 1990-2010. Available at: <http://halaszg.ofi.hu/download/Policy_kotet.pdf> [Accessed 24 Sept. 2015].

Halász, G. and Lannert, J., 2006. Jelentés a magyar közoktatásról 2006. [online] Országos Közoktatási Intézet. Available at: <http://ofi.hu/tudastar/jelentesmagyar/jelentes-magyar-090617-4> [Accessed 24 Sept. 2015].

Hart, A. and Suss, D., 2002. Media Education in 12 European Countries. A Comparative Study of Teaching Media in Mother Tongue Education in Secondary Schools. [online] Euromedia Project, p.3. Available at: <http://ecollection.library.ethz.ch/eserv/eth:25953/eth-25953-01.pdf> [Accessed 15 Jun. 2014].

Herczog, C., 2012. Studying media literacy of students in the 14-18 age group. [online] University of Szeged. Available at: <http://www.edu.uszeged.hu/phd/downloads/Herzog_angol_tezis.pdf> [Accessed 12 Febr. 2014].

Herczog, C. and Racskó, R., 2012. „Mindenevők-e” a tizenévesek? A 14-18 éves tanulók médiaműveltség vizsgálata a kritikus médiahasználat vonatkozásában. $U_{j} j$ kutatások a neveléstudományokban, 4, pp. 33-63.

Hoffmann, R., 2013. Médiatudatosságra nevelés. In: E. Pálfi, ed., Médiatudatosság az oktatásban. [online] Budapest: Oktatáskutató és Fejlesztő Intézet. Available at:

<http://www.oktatas.hu/pub_bin/ikt/kepek/2014/februar/mediatudatossag_az_oktatasba n.pdf> [Accessed 11 Dec. 2013].

Hogyan lehetne több a Nemzeti Alaptanterv egy kapkodó szakmai próbálkozásnál? IV.[online] Available at: http://www.parlament.hu/irom37/5434/5434.pdf [Accessed 15 Febr. 2016]. 
Human Rights Watch, 2012. Memorandum to the European Union on Media Freedom in Hungary. Available at: <http://www.hrw.org/node/105200> [Accessed 9 Jun. 2014].

Hyatt, D., 2013a. A Critical Literacy Frame for UK secondary education contexts. English in Education, 39(1), pp.43-59.

Hyatt, D., 2013b. The critical policy discourse analysis frame: helping doctoral students engage with the educational policy analysis. Teaching in Higher Education, 18(8), pp.833-845.

Ilonszki, G. and Kurtán, S., 2007. Hungary. European Journal of Political Research, 46(7/8), pp.966-973.

Index, 2014. A mindennapos testnevelés egy unikum. Index.hu. [online] 17 Sep. Available at:

<http://index.hu/belfold/2014/09/17/hungarikum_a_mindennapos_testneveles/> [Accessed 10 Jun. 2014].

InfoRádió, 2016. "Van szándék a Nemzeti Alaptanterv felülvizsgálatára" - a nap hírösszefoglalója. InfoRádió. [online] 3 Dec. Available at:

$<$ http://inforadio.hu/hir/belfold/van-szandek-a-nemzeti-alaptanterv-felulvizsgalatara-anap-hirosszefoglaloja-805285> [Accessed 15 Mar. 2016].

International Bureau of Education, 2012. World Data on Education. [online] UNESCO. Available at:

<http://www.ibe.unesco.org/fileadmin/user_upload/Publications/WDE/2010/pdfversions/Hungary.pdf> [Accessed 22 Febr. 2014].

Írásbeli válasz interpellációra/kérdésre 'Hova vágtázik, Miniszter úr? '. [online] Available at: <http://www.parlament.hu/irom37/7734/07734-0001.pdf> [Accessed 15 Febr. 2016].

Izsák, L., 2010. Három választás - három kormány. Historia. [online] Available at: <http://www.historia.hu/userfiles/files/2010-05/Izsak.pdf> [Accessed 26 Nov. 2015].

Jacques, J., Fastrez, P. and De Smedt, T., 2013. Organising Media as Social Objects: an exploratory assessment of a core media literacy competence. Media Education Research Journal, 4(1), pp.42-58.

Jakab, G., 2002. Modultárgyak és általános tanulmányok I. Új Pedagógiai Szemle.

Jakab, G., 2003. A csökött kistestvérek panaszai - A modultárgyak helyzetéröl. Helyzetkép, [online] (2). Available at: <http://folyoiratok.ofi.hu/uj-pedagogiai-szemle/acsokott-kistestverek-panaszai-a-modultargyak-helyzeterol> [Accessed 28 Apr. 2015]. 
Kalmus, V., Pruulmann-Vengerfeldt, P., Runnel, P. and Siibak, A., 2009. Mapping the terrain of 'Generation C': Places and practices of online content creation Estonian teenagers. Journal of Computer-Mediated Communication, 14(4), pp.12571282.

Karttunen, L., 1971. Implicative Verbs. Language, [online] 47(2). Available at: <http://web.stanford.edu/ laurik/publications/archive/implicative.pdf> [Accessed 11 Jun. 2015].

Kellner, D., 1998. Multiple Literacies and Critical Pedagogy in a Multicultural Society. Educational Theory, 48(1), pp.103-122.

Kellner, D. and Share, J., 2007a. Critical media literacy, democracy, and the reconstruction of education. In Macedo, D. and Steinberg, S. R. eds. 2007. Media literacy: A reader. New York: Peter Lang Publishing, pp.3-23. Available at: <http://sudikoff.gseis.ucla.edu/archive/pdfs/philosophy/Summary_Kellner_CritLitDemo cracy.pdf> [Accessed 11 May 2015].

Kellner, D. and Share, J., 2007b. Critical media literacy is not an option. Learning Inquiry, 1(1), pp.59-69.

Kelly, K. and Donohew, L., 1999. Media and primary socialization theory. Substance Use and Misuse, 34(9), pp.1033-45.

Kennisnet, 2013. Media Education in Four EU Countries. How do Finland, Sweden and the UK Tackle Media Education? And How Does That Compare to the Netherlands? Common Problems and Possible Solutions. [online] Stichting Mijn Kind Online, Kennisnet. Available at: $<$ http://www.kennisnet.nl/fileadmin/contentelementen/kennisnet/Dossier_mediawijshei d/Publicaties/rapport_media_onderwijs_EU.pdf> [Accessed 10 Jun. 2014].

Kerber, Z., 2000. A kerettanterv hatása a NAT-ra és a helyi tantervre. $U^{\prime} j$ Pedagógiai Szemle, [online] (Április). Available at: <http://epa.oszk.hu/00000/00035/00037/2000-04-np-Kerber-Kerettanterv.html> [Accessed 1 March. 2015].

Keszler, B., 2009. Az írásjelek, a szimbólumok és az egyéb jelek, valamint formai sajátosságaik. Anyanyelv-pedagógia, [online] (2). Available at: <http://www.anyanyelvpedagogia.hu/index.php?issue=6> [Accessed 1 March 2015] .

Kingdon, J.W., 2003. Agendas, alternatives and public policies (2nd edition). New York: Longman. 
Knight, P. and Yorke, M., 2004. Learning, curriculum and employability in higher education. London: Routledge Farmer.

Kocsis, K., 2011. Parlamenti választások. In: K. Kocsis and F. Schweitzer, eds., Magyarország térképekben. [online] Budapest. Available at:

<http://www.mtafki.hu/konyvtar/Magyarorszag/Magyarorszag_terkepekben_Parlamenti _valasztasok.pdf> [Accessed 26 Nov. 2015].

Koltay, T., 2009. Médiamüveltség, média-írástudás, digitális írástudás.

Médiakutató, [online] (Winter). Available at:

<http://www.mediakutato.hu/cikk/2009_04_tel/08_mediamuveltseg_digitalis_irastudas/ $>$ [Accessed 12 Nov. 2015].

Koltay, T., 2011. The media and the literacies: media literacy, information literacy, digital literacy. Media, Culture \& Society, 33(2), pp.211-221.

Körösényi, A. and Renwick, A., 1999. Government and politics in Hungary. Budapest: CEU Press.

Kósa, É. and Miklós, L., 2010. New Trends and Old Habits: Status Report on the Relationship of 12 to 17 Year Olds and the Media. [online] Available at:

<http://insafecommunity.saferinternet.org/c/document_library/get_file?p_l_id=10527\&f olderId=94131\&name=DLFE-2702.pdf\&version=1.4> [Accessed 15 Feb. 2014] .

Lange, A. 2015. Media Literacy and Child Development in the First 10 Years, ECREA Forum. [online] 19 Jan. 2015. Available at: <ecrea.eu.> [Accessed 20 Jan. 2015].

Lannert, J. and Halász, G., 1996. Jelentés a magyar közoktatásról 1995. Országos Közoktatási Intézet.

Lannert, J. and Halász, G., 1998. Jelentés a magyar közoktatásról 1997. [online] Budapest: Oktatáskutató és Fejlesztő Intézet. Available at: http://ofi.hu/kiadvany/jelentes-magyar-kozoktatasrol-1997 [Accessed 22 Oct. 2015].

Levinson, B., Sutton, M. and Winstead, T., 2009. Education Policy as a Practice of Power Theoretical Tools, Ethnographic Methods, Democratic Options. Education \& Educational Research, 23(6), pp.767-795.

Lingard, B. and Sellar, S., 2013. Globalization, edu-business and network governance: the policy sociology of Stephen J. Ball and rethinking education policy analysis. London Review of Education, 11(3). 
Littig, B., 2009. Interviewing the Elite - Interviewing Experts: Is there a difference? In: A. Bogner, W. Menz and B. Littig, eds., Interviewing Experts, Research Methods Series. Palgrave Macmillan UK.

Livingstone, S., 2004. Media literacy and the challenge of new information and communication technologies. The Communication Review, 7(1), pp.3-14.

Livingstone, S., Wijnen, C. W., Papaioannou, T., Costa, C. and del Mar Grandío, M., 2013. Situating media literacy in the changing media environment: critical insights from European research on audiences. In: N. Carpentier, K. Schrøder, and L. Hallett, (eds.) Audience Transformations: Shifting Audience Positions in Late Modernity. London: Routledge. ISBN 9780415827362

Loboda, Z., Kocsis, M. and Vágó, I., 2012. Education in Hungary 2010. [online] Budapest: Hungarian Institute for Educational Research and Development. Available at: <http://www.ofi.hu/sites/default/files/WEBRA/2012/11/angol_jelentes.pdf > [Accessed 21 Oct. 2013].

Machin, D. and Niblock, S., 2008. Branding newspapers. Journalism Studies, 9(2), pp.244-259.

Manovich, L., 2007. Information as an Aesthetic Event. Lecture, London: Tate Modern. Available at: http://manovich.net/content/04-projects/056-information-as-anaesthetic-event/53_article_2007.pdf [Accessed 18 July 2016]

Martens, H., 2010. Evaluating Media Literacy Education: Concepts, Theories and Future Directions. Journal of Media Literacy Education, 2(1), pp.1-22.

Martin, J.R. and Wodak, R. eds., 2003. Re/reading the past Critical and functional perspectives on time and value. Amsterdam: John Benjamins Publishing Company.

Martin, L.E.M. ed., 1997. The Challenge of Internet Literacy: the Instruction-Web Convergence. New York: Haworth Press.

Marx, L. and Smith, M., 1996. Introduction. In: Does technology drive history? The dilemma of technological determinism. Cambridge, MA: Massachusetts Institute of Technology.

Masterman, L., 1989. Media Awareness Education: Eighteen Basic Principles. [online] Center for Media Literacy. Available at: <http://www.medialit.org/readingroom/media-awareness-education-eighteen-basic-principles> [Accessed 21 Nov. 2013].

McCandless, B., 2012. The Use and Misuse of Metaphor in Education and Education Reform. Education, 132(3), pp.538-547. 
McClure, C., 1994. Network literacy: a role for libraries. Information Technology and Libraries, 13, pp.115-125.

MedeaNet, 2014. Charting Media and Learning in Europe. [online] MedeaNet. Available at: <http://www.medeanet.eu/report> [Accessed 11 Oct. 2015].

Mérték Médiaelemző Mühely, 2013. A médiaoktatás médiapolitikai szerepe. Available at: <http://mertek.hvg.hu/2013/12/10/a-mediaoktatas-mediapolitikaiszerepe/> [Accessed 11 Oct. 2015].

Mihailidis, P., 2009. The First Step is the Hardest: Finding Connections in Media Literacy Education. Journal of Media Literacy Education, 1, pp.53-67.

Mill, J.S. 1861. Utilitarianism. London: Everyman (this edition 1993).

Módositó javaslat a T/997. számú törvényjavaslathoz.[online] Available at: <http://www.parlament.hu/irom36/0997/0997-008.htm> [Accessed 11 Feb. 2016].

MTI, 2012. Balog: nem oktatási szaklobbi állította össze a NAT-ot. $H V G$. [online] 17 May. Available at: <http://hvg.hu/itthon/20120517_balog_zoltan_nat/> [Accessed 11 Jun. 2015].

Murphy, P. 2012. Hungary's New Curriculum: Writing Wrongs? The Vienna Review. Available at: < http://www.viennareview.net/news/central-europe/hungarysnew-curriculum-writing-wrongs>[Accessed 5 Aug. 2015].

Nagel, S., 1984. Contemporary Public Policy Analysis. Birmingham, AL: The University of Alabama Press.

National Institute for Public Education, 2004. Quality education for all young people: challenges, trends and priorities - The Development of Education. [online] Budapest: National Institute for Public Education. Available at: <http://regi.ofi.hu/quality-education-for> [Accessed 9 July. 2014].

Neag, A., 2014. From Schools to Start-ups? A Report on Media Literacy Education in Hungary. In: Global Citizenship in a Digital World, Milid Yearbook 2014. Göteborg: NORDICOM.

Nemzeti Erőforrás Minisztérium, 2006. TUDÁST MINDENKINEK! Cselekvési terv 2006-2010 163 pont. Available at: <http://www.nefmi.gov.hu/tudast-mindenkinek090803> [Accessed 9 Oct. 2015].

Neumann, E., 2011b. Negotiating Power: interviews with the policy elite - stories from Hungary lost between genres. European Educational Research Journal, 10(2), pp.225-232. 
Nida, E., 1949. Morphology: The descriptive analysis of words. Ann Arbor, MI: University of Michigan.

Norris, P., Kern, M. and Just, M.R., 2003. Framing terrorism: the news media, the government, and the public. New York: Routledge.

Ofcom, n.d. Media Literacy. [online] Ofcom. Available at: <http://stakeholders.ofcom.org.uk/market-data-research/other/media-literacy/> [Accessed 1 Febr. 2014].

Olson, S.R. and Pollard, T., n.d. The muse Pixeliope: Digitalization and media literacy education. American Behavioral Scientist, 48(2), pp.248-255.

Organisation for Economic Cooperation \& Development, 2007. OECD Economic Surveys: Hungary. pp.8-9.

Orientpress, 2012. Balog: időtálló és korszerü az új Nemzeti alaptanterv. Orientpress.hu [online] Available at: <http://www.orientpress.hu/99155> [Accessed 11 Febr. 2015].

Origo, 2012. Jönnek az öntudatos hazafiak. Origo.hu. [online] 6 Feb. Available at: <http://www.origo.hu/itthon/20120206-megjelent-az-uj-nemzeti-alaptantervvitaanyaga.html> [Accessed 11 Febr. 2015].

Országos Doktori Tanács, 2016. [online] Available at: < doktori.hu> [Accessed 11 Febr. 2016].

Országos Széchényi Könyvtár, 2016. [online] Available at: <http://nektar2.oszk.hu/LVbin/LibriVision/lv_view_records.html> [Accessed 11 Febr. 2016].

Oughton, H., 2007. Constructing the ideal learner: a critical discourse analysis of the adult numeracy core curriculum. Research in Post-Compulsory Education, 12(2), pp.259-275.

Parola, A. and Ranieri, M., 2011. The Practice of Media Education: International Research on Six European Countries. The Journal of Media Literacy Education, [online] 3(2). Available at: <http://digitalcommons.uri.edu/jmle/vol3/iss2/4/> [Accessed 9 March 2014].

Parry, G., 1999. Constructive and Reconstructive Political Education. Oxford Review of Education, 25(1\&2), pp.23-38.

Pereira, S. and Pereira, L., 2015. Digital Media in Primary Schools: Literacy or Technology? Analyzing Government and Media Discourses. Educational Policy, 29(2), pp.316-341. 
Plester, B. and Wood, C., n.d. Exploring relationships between traditional and new media literacies: British preteen texters at school. Journal of Computer-Mediated Communication, 14(4), pp.1108-1129.

Politics.hu, 2014. Orbán describes Hungarians as freedom fighters. [online] politics.hu. Available at: <http://www.politics.hu/20140820/orban-describeshungarians-as-freedom-fighters/> [Accessed 5 Aug. 2015].

Prot, S., Anderson, C.A., Gentile, D.A., Warburn, W. and Hastings, P., 2015. Media as agents of socialization. In: J. Grusec, ed., Handbook of socialization: Theory and research (2nd ed.). New York: Guilford Press, pp.276-300.

Radó, P., 2010. Politika és oktatáspolitika átrendeződő kapcsolatáról. OktPolCafé. Available at: <http://oktpolcafe.hu/politika-es-oktataspolitika-atrendezodokapcsolatarol-849/> [Accessed 7 Jan. 2016].

Redmond, T., 2012. The Pedagogy of Critical Enjoyment: Teaching and Reaching the Hearts and Minds of Adolescent Learners Through Media Literacy Education. Journal of Media Literacy Education, 4(2), pp.106-120.

Rousseau, J.-J., 1762. Émile. London: Everyman (this edition 1993).

Ryan, A., 2013. J.S. Mill on education. In: Ideas of Education: Philosophy and politics from Plato to Dewey. London: Routledge.

Sarantakos, S., 2005. Social Research. Basingstoke: Palgrave Macmillan.

Scheibe, C.L., n.d. A Deeper Sense of Literacy Curriculum-Driven Approaches to Media Literacy in the K-12 Classroom. Available at: <http://www.ithaca.edu/looksharp/PDF_Files/Deeper_Sense_of_Literacy.pdf > [Accessed 9 Aug. 2015].

Scheibe, C. and Rogow, F., 2008. 12 Basic Ways to Integrate Media Literacy and Critical Thinking into Any Curriculum. [online] Ithaca College. Available at: <http://www.projectlooksharp.org/12BasicWays.pdf> [Accessed 5 Sept. 2014].

Schilder, E.A.M.S., 2013. Theoretical Underpinnings of Media Literacy from Communication and Learning Theory. VASA Journal on Images and Culture, [online]. Available at: <http://vjic.org/vjic2/?page_id=1321> [Accessed 15 Oct. 2014].

Schleicher, N. and Rétfalvi, G., 2014. Media and Information Literacy Policies in Hungary. Media and Information Literacy Policies in Europe. [online] University of Applied Sciences. Available at: <http://ppemi.enscachan.fr/data/media/colloque140528/rapports/HUNGARY_2014.pdf> [Accessed 15 Oct. 2015]. 
Schüttler, T., 1998. „Nem kell elölről kezdeni mindent!” - Interjú Környei László közoktatási helyettes államtitkárral1 -. Új Pedagógiai Szemle. [online] Available at: <http://epa.oszk.hu/00000/00035/00019/1998-09-np-Schuttler-Nem.html> [Accessed 27 Nov. 2015].

Selwyn, N., 2013. Researching the once-powerful in education: the value of retrospective elite interviewing in education policy research. Journal of Education Policy, 28(3), pp.339-352.

State Secretariat for Parliamentary and Strategic Affairs of the Ministry for National Economy, n.d. Budapest Runway 2.0.2.0 The Start-up Credo. Available at: <http://www.nih.gov.hu/strategy/publications/budapest-2-0-2-0-runway> [Accessed 14 Feb. 2014].

Steer, R., Spours, K., Hodgson, A., Finlay, I., Coffield, F., Edward, S. and Gregson, M., 2007. 'Modernisation' and the role of policy levers in the learning and skills sector. Journal of Vocational Education \& Training, 59(2), pp.175-192.

Stephen, B., 2008. The Education Debate. Bristol: Policy Press.

Stewart, P., Bravo, O. and Culver, S.H., 2013. Media and Information Literacy and Intercultural Dialogue at the University of the West Indies. In: U. Carlsson, ed., Media and Information Literacy and Intercultural Dialogue. [online] Göteborg: The International Clearinghouse on Children, Youth and Media Nordicom, pp.25-37. Available at: <http://milunesco.unaoc.org/wpcontent/uploads/2013/04/Media_and_Information_Literacy_and_Intercultural_Dialogue .pdf> [Accessed 15 March. 2014].

Strauss, S.G. and Feiz, P., 2014. Discourse analysis: putting our worlds into words. New York: Routledge/Taylor \& Francis Group.

Szíjártó, I., 2001. A média tantárgy a magyar közoktatásban. Médiakutató, [online] (Winter). Available at: <http://www.mediakutato.hu/cikk/2001_04_tel/08_media_tantargy_a_magyar_kozoktat asban> [Accessed 10 Nov. 2013].

Szíjártó, I., 2007. A filmesztétikától a médiaismeretig. Filmkultúra. [online] Available at: <http://www.filmkultura.hu/regi/2007/articles/essays/filmesztetikatol_mediaismeretig.p df> [Accessed 10 Nov. 2013]. 
Szíjártó, I., 2009. Tanártovábbképzés a mozgóképkultúra és médiaismeret oktatásához: egy rendszer kiépülése. Új Pedagógiai Szemle, [online] 6. Available at: <http://www.ofi.hu/tudastar/tanartovabbkepzes> [Accessed 10 Nov. 2013].

Szocioreflex, 1999. A Nemzeti alaptanterv bevezetése, az iskolák helyi tanterve 1998 öszén. [online] Szocioreflex. Available at: <http://ofi.hu/nemzeti-alaptantervbevezetese-az-iskolak-helyi-tanterve-1998-oszen-szemelvenyek-egy-kutatasi> [Accessed 12 Nov. 2015].

Szőts, I., 1945. Röpirat a magyar filmmüvészet ügyében. Available at: <http://www.filmkultura.hu/regi/articles/essays/ropirat.hu.html\#xi> [Accessed 10 Dec. 2015].

Takayama, K., 2013. OECD, 'Key competencies' and the new challenges of educational inequality. Journal of Curriculum Studies, 45(1).

Tarrant, I. and Tarrant, J., 2004. Satisfied Fools: Using J. S. Mill's Notion of Utility to Analyse the Impact of Vocationalism in Education within a Democratic Society. Journal of Philosophy of Education, 38(1), pp.107-120.

Taylor, S., 1997. Critical Policy Analysis: exploring contexts, texts and consequences. Discourse: Studies in the Cultural Politics of Education, 18(1), pp.2335 .

Theorieënoverzicht TCW, 2010. Hypodermic Needle Theory. [online] University of Twente. Available at:

<https://www.utwente.nl/cw/theorieenoverzicht/Theory\%20Clusters/Mass\%20Media/H ypodermic_Needle_Theory/> [Accessed 11 Nov. 2014].

Thomas, S., Joseph, C., Lacetti, J. and Mason, B., 2007. Transliteracy: Crossing Divides. First Monday, [online] 12(12). Available at: <http://firstmonday.org/ojs/index.php/fm/article/view/2060/1908> [Accessed 19 Nov. 2015].

Thompson, A., Frisch, M. and Hamilton, P., 1994. The memory and history debates: Some international perspectives. Oral History, 22(2), pp.33-43.

Thompson, D., 1970. The Democratic Citizen. Cambridge: Cambridge University Press.

Török, B., 2016. On the 1995 National Core Curriculum. [email]. Sent 6 January 2016. [Accessed 7 Jan. 2016].

UNESCO, 2013. Global Media and Information Literacy Assessment Framework: Country Readiness and Competencies. Available at: 
<http://unesdoc.unesco.org/images/0022/002246/224655e.pdf> [Accessed 17 Jan. 2015].

UNESCO, 2014. Paris Declaration on Media and Information Literacy in the Digital Era. Available at:

<http://www.unesco.org/new/fileadmin/MULTIMEDIA/HQ/CI/CI/pdf/news/paris_mil_ declaration.pdf> [Accessed 22 Jan. 2015].

UNESCO, n.d. About Media and Education Literacy. [online] Media\&

Information Literacy. Available at: <http://milunesco.unaoc.org/about-media-andeducation-literacy/> [Accessed 22 Jan. 2015].

Ütőné Visi, J., 2004. NAT-tól NAT-ig a kerettanterveken át. Iskolakultúra, [online] 11. Available at:

<http://epa.oszk.hu/00000/00011/00087/pdf/iskolakultura_EPA00011_2004_11_098109.pdf> [Accessed 11 Jun. 2015].

Vágó, I. and Vass, V., 2009. The Content of Education. [online] ofi.hu. Available at: <http://www.ofi.hu/education-in-hungary-090617-7/chapter-5-the-content-of090617> [Accessed 11 Jun. 2015].

Vass, V., 2008. A nemzeti alaptanterv implementációja. [online] Budapest: Nemzeti Erőforrás Minisztérium. Available at:

<http://www.nefmi.gov.hu/letolt/kozokt/nat_implement_090702.pdf> [Accessed 2 Dec. 2015].

VideóMánia. n.d. Available at: 〈https://www.youtube.com/user/VideomaniaFCS〉 [Accessed 12 Jan. 2016].

Wallis, R. and Buckingham, D., 2013. Arming the citizen-consumer: The invention of 'media literacy' within UK communications policy. European Journal of Communication, 28(5), pp.527-540.

Wallis, R.P.B., 2014. Media literacy as cultural and educational policy under New Labour (1997-2010). PhD Dissertation. Loughborough University.

Warschauer, M., 2001. Millenialism and media: language, literacy, and technology in the 21 st century. In: D. Graddol, ed., Applied linguistics for the 21 st century. International Association of Applied Linguistic.

West, E.G., 1965. Liberty and Education: John Stuart Mill's Dilemma. Philosophy, 40(152), pp.129-142.

Widowsson, H., 1998. The theory and practice of critical discourse analysis. Applied Linguistics, 19, pp.136-151. 
Yates, B.L., 1998. Media Literacy and the Policymaking Process: A Framework for Understanding Influences on Potential Educational Policy Outputs. In: National Media Literacy and Media Citizenship Conference II. Birmingham, USA, 27 June, 1998. Available at: <http://eric.ed.gov/?id=ED424602> [Accessed 18 Dec. 2015].

Zell, H., 1998. Contextual Media Aesthetics as the Basis for Media Literacy. Journal of Communication, 48(1), pp. 81-95.

Zgrabljic Rotar, N. ed., 2006. Media literacy and civil society. Sarajevo: Mediacentar.

Zurkowski, P., 1974. The information service environment: Relationships and Priorities. Related paper no.5. National Commission on Libraries and Information Science. 


\section{THE AUTHOR'S PUBLICATIONS}

Neag, A. 2016. The Unlikely Advocates of Media Literacy Education: Jean-Jacques

Rousseau and John Stuart Mill. Central European Journal of Communication, 9(16), 103-112.

Neag, A. 2015. Media Literacy and the Hungarian National Core Curriculum - A

Curate's Egg. Journal of Media Literacy Education, 7(1), 35-45.

Neag, A. 2014. From Schools to Start-ups? A Report on Media Literacy in Hungary. In S.H. Culver; P. Kerr (Eds.), Global Citizenship in a Digital World. Milid Yearbook - A Collaboration between UNITWIN and the International Clearinghouse on Children, Youth and Media at NORDICOM. 